UNIVERSIDADE DE SÃO PAULO

FACULDADE DE ECONOMIA, ADMINISTRAÇÃO E CONTABILIDADE DEPARTAMENTO DE CONTABILIDADE E ATUÁRIA

PROGRAMA DE PÓS-GRADUAÇÃO EM CONTROLADORIA E CONTABILIDADE

O USO DO LUCRO ECONÔMICO NA FORMULAÇÃO DE CONTRATOS DE INCENTIVO CONTINGENTES AO DESEMPENHO E O PROBLEMA DO HORIZONTE - UMA ANÁLISE EXPERIMENTAL

Luis Paulo Guimarães dos Santos

Orientador: Prof. Dr. Edgard B. Cornacchione Jr.

SÃO PAULO

2012 
Prof. Dr. João Grandino Rodas

Reitor da Universidade de São Paulo

Prof. Dr. Reinaldo Guerreiro

Diretor da Faculdade de Economia, Administração e Contabilidade

Prof. Dr. Edgard Bruno Cornacchione Jr

Chefe do Departamento de Contabilidade e Atuária

Profa. Dra. Silvia Pereira de Castro Casa Nova

Coordenadora do Programa de Pós-Graduação em Controladoria e Contabilidade 


\title{
O USO DO LUCRO ECONÔMICO NA FORMULAÇÃO DE CONTRATOS DE INCENTIVO CONTINGENTES AO DESEMPENHO E O PROBLEMA DO HORIZONTE - UMA ANÁLISE EXPERIMENTAL
}

\author{
Tese apresentada ao Departamento de \\ Contabilidade e Atuária da Faculdade de \\ Economia, Administração e Contabilidade da \\ Universidade de São Paulo como requisito \\ para obtenção do título de Doutor em Ciências \\ Contábeis.
}

Orientador: Prof. Dr. Edgard B. Cornacchione Jr.

\author{
Versão Corrigida \\ (versão original disponível na Unidade que aloja o Programa) \\ SÃO PAULO \\ 2012
}




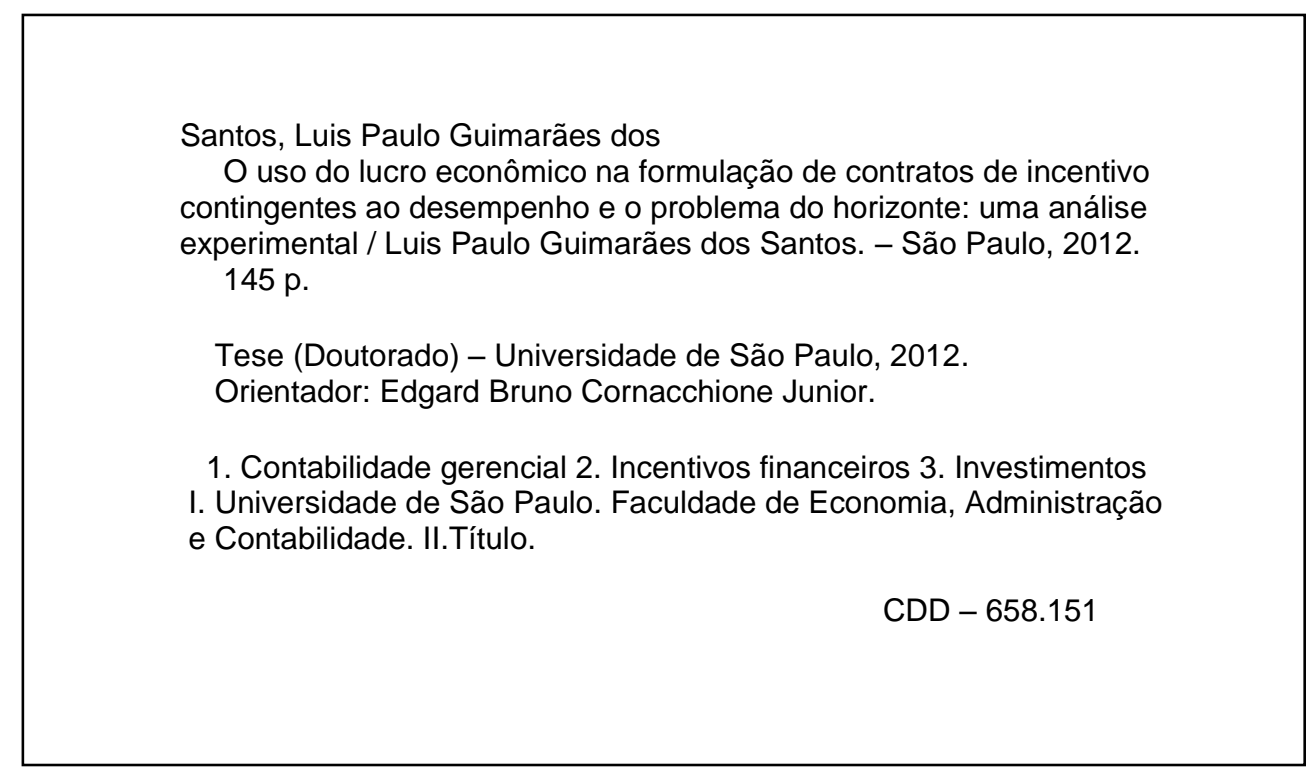


Esta tese é dedicada aos meus familiares pela torcida e pelo sentido que dão a minha vida. À Sheizi, minha esposa, companheira, meu grande amor e a principal razão disso tudo. Sem dúvida, sem o seu apoio essa jornada teria sido mais difícil. 
Gostaria de agradecer ao professor Edgard Cornacchione pelo apoio e privilégio da orientação. Ao Departamento de Ciências Contábeis da Universidade Federal da Bahia pelo suporte institucional, fundamental para que eu pudesse avançar em mais essa etapa da minha formação acadêmica. À Fundação de Apoio à Pesquisa do Estado da Bahia (FAPESB) e à Fundação Instituto de Pesquisas Contábeis, Atuariais e Financeiras (FIPECAFI) pelos auxílios financeiros ao longo do doutorado, importantíssimos para que eu tivesse condição de concluir este trabalho com tranquilidade.

Deixo também registrado meu agradecimento aos amigos (novos e antigos) que de várias formas contribuíram para que eu chegasse ao fim dessa jornada: Arlindino Nogueira Silva Neto, César Valentim de Oliveira Carvalho Júnior, Elton Silva (o grande responsável pelo software do experimento), José Maria Dias Filho, Joséilton Silveira da Rocha e Josué Pires Braga. A convivência e a troca de experiências com vocês tornou a realização desta pesquisa mais interessante, possibilitando valiosos momentos de reflexão.

Ao Programa de Pós-Graduação em Controladoria e Contabilidade (PPGCC) da FEA/USP, por nos possibilitar um curso de doutorado comprometido com a excelência e o desenvolvimento acadêmico e científico. A todos os colegas e professores pelo prazer do convívio, troca de experiências e aprendizado. Aos funcionários da FEA/USP pela maneira profissional e gentil que sempre nos tratam. Finalmente, a todos que de alguma forma contribuíram para o desenvolvimento deste trabalho. 


\section{RESUMO}

O presente estudo investigou se o uso do lucro econômico em contratos de incentivo contingentes ao desempenho motiva os indivíduos a agir de forma mais consistente com os objetivos de longo prazo da empresa quando existe o problema do horizonte. Para tanto, foi utilizado um experimento de fator único entre sujeitos, pré-pós tratamento com grupo de controle, cuja única tarefa dos participantes era investir recursos em ações de longo prazo visando maximizar o fluxo de caixa futuro de uma loja de prestação de serviço. O estudo envolveu a participação de 76 estudantes de graduação, divididos em três grupos, e documentou que, em comparação ao grupo de controle (recompensado com base numa remuneração fixa) e a um segundo grupo de tratamento (recompensado com base numa remuneração variável vinculada ao lucro contábil contemporâneo), os participantes submetidos ao contrato que recompensava com base no lucro econômico agiram de forma mais congruente em relação ao objetivo estabelecido, dedicando mais esforço na realização da tarefa e melhorando o desempenho nas suas decisões de investimentos. Consistente com as predições da teoria da agência, o principal resultado dessa investigação sugere que o lucro econômico ajuda a mitigar o problema de miopia gerencial, indicando que incorporá-lo aos contratos motiva os agentes a agir de forma mais consistente com os objetivos de longo prazo da empresa, mesmo na presença do problema do horizonte. Além disso, a pesquisa documentou novas evidências da inadequação da formulação de contratos de incentivo baseados em medidas de desempenho distorcidas, tal como o lucro contábil. 


\begin{abstract}
The present study investigated whether the use of economic profit in performance-contingent incentive contracts motivates individuals to act more consistently with the long-term goals of the firm when the horizon problem is present. An experimental design was conducted. The experiment used a single factor between-subjects and pre-post treatment with a control group. The experimental task was to invest resources in long-term actions with the goal of maximizing the future cash flow of a photocopy store. The study involved the participation of 76 undergraduate students, divided into three groups, and documented that participants rewarded by contracts based on economic profit acted more congruently with the goal set by devoting more effort to accomplish the task and improving performance in their investment decisions when compared to the control group (rewarded on the basis of a fixed wage) and to the second treatment group (rewarded on the basis of a contingent contemporaneous accounting profit incentive contract). The present study's key findings are consistent with the predictions of the agency theory and suggest that the economic profit helps to mitigate the problem of managerial myopia. These study findings also indicate that the economic profit in incentive contracts motivates agents to act more consistently with the firm's long-term goals even in the presence of the horizon problem. In addition, the present research documented new evidences of the inadequacy of incentive contracts based on distorted performance measures such as accounting profit.
\end{abstract}




\section{SUMÁRIO}

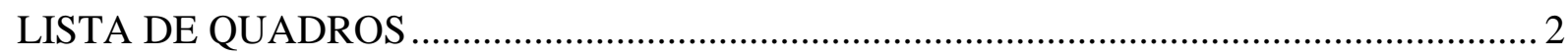

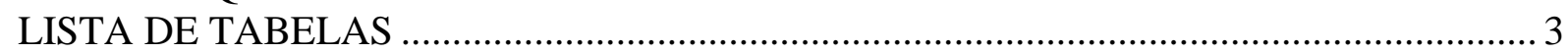

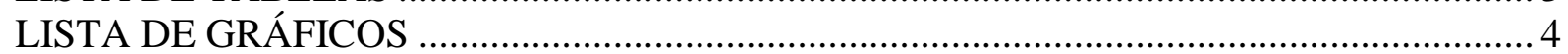

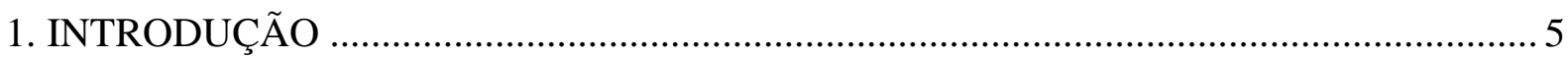

1.1. Contextualização e Problema de Pesquisa.................................................................... 5

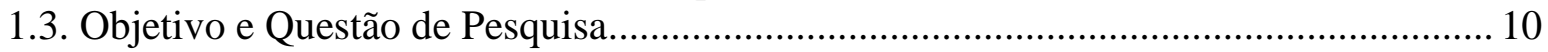

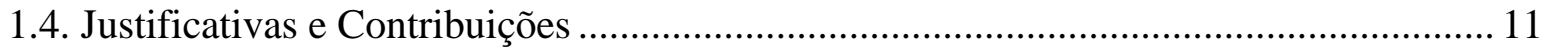

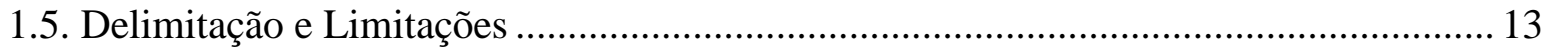

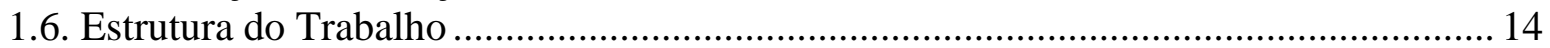

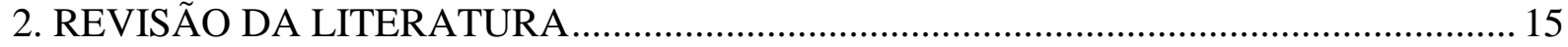

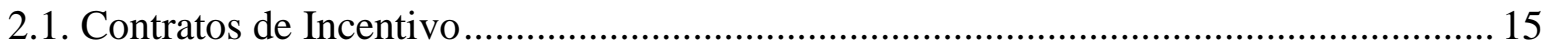

2.2. Orientação Gerencial de Curto prazo e o Problema do Horizonte ................................. 19

2.3. Teoria da Agência, Mensuração de Desempenho e Congruência ................................... 25

2.4. Contratos de Incentivo e Mensurações Forward-Looking .......................................... 32

2.5. O Lucro Econômico Visto como uma Mensuração Forward-Looking ........................... 36

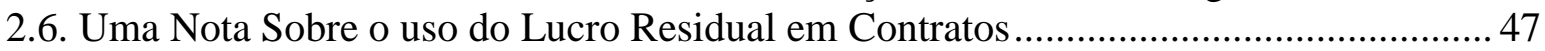

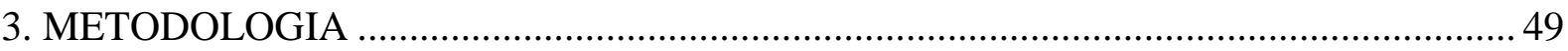

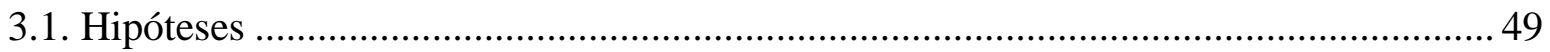

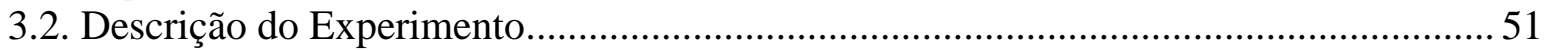

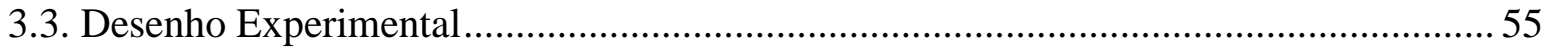

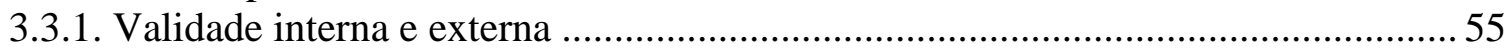

3.3.2 Poder estatístico, Tamanho do Efeito e Tamanho da Amostra ..................................58

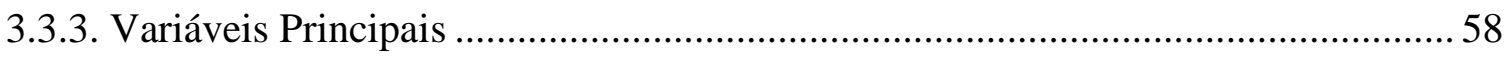

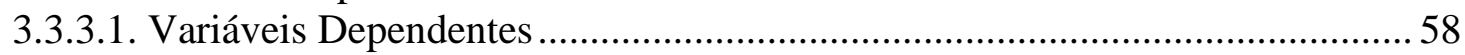

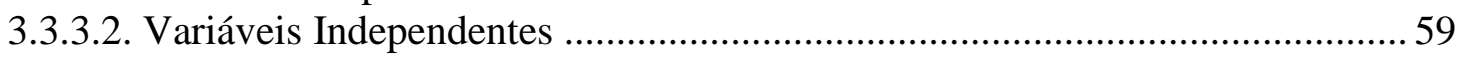

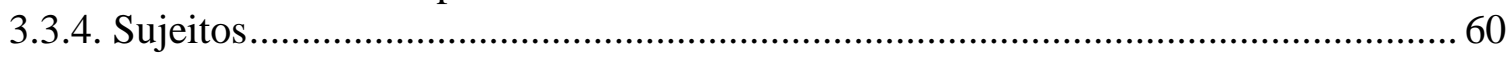

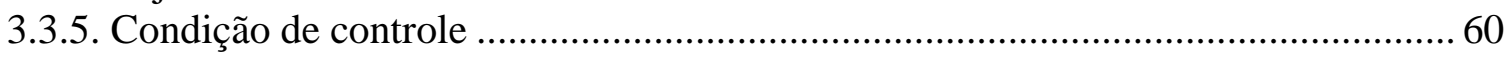

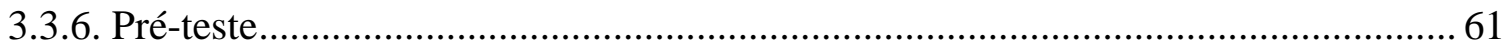

3.3.7. Procedimentos para realização das Sessões Experimentais ..................................... 61

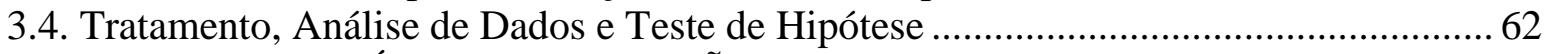

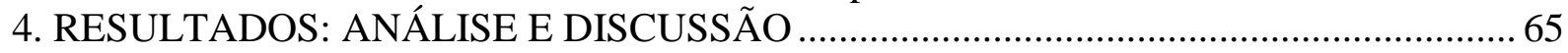

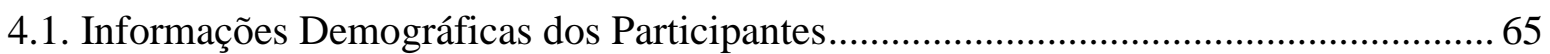

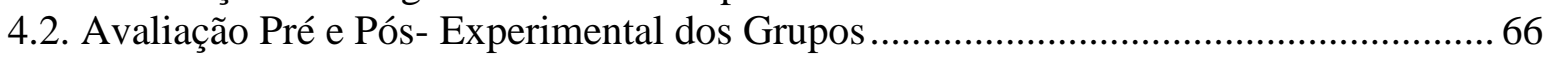

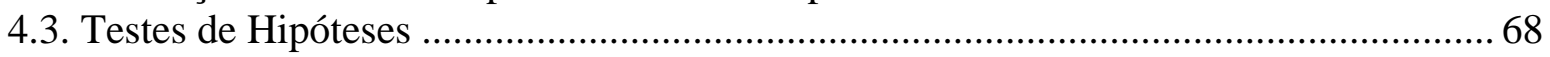

4.3.1. Estatísticas Descritivas das Variáveis Dependentes ............................................69 69

4.3.2. O Efeito do Lucro Econômico sobre o Esforço: Hipóteses H1(a), H1(b) e H1(c) 74

4.3.3. O Efeito do Lucro Econômico sobre o Desempenho: Hipótese H2 ...................... 79

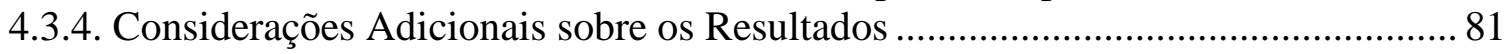

4.4. Teste Não paramétrico das Hipóteses H1(a), H1(b), H1(c) e H2(a) ............................. 86

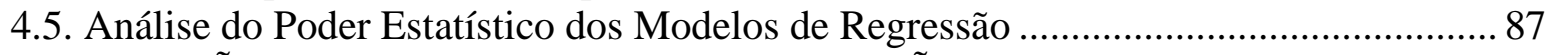

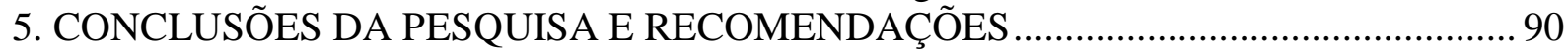

5.1 Recomendações para Futuros Trabalhos ...................................................................... 94

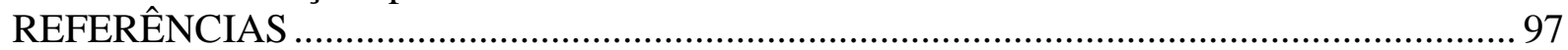

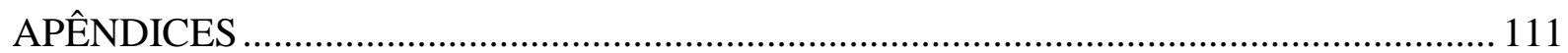




\section{LISTA DE QUADROS}

Quadro 1 - Derivação do Lucro Econômico pelo Método de Fluxo de Caixa Descontados -

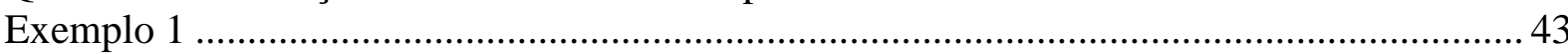

Quadro 2 - Derivação do Lucro Econômico pelo Método de Fluxo de Caixa Descontados -

Exemplo 2 45

Quadro 3 - Derivação do Lucro Econômico pelo Método de Fluxo de Caixa Descontado -

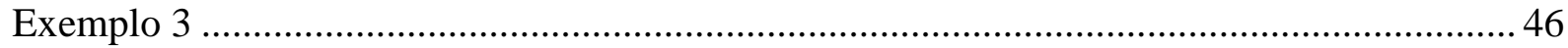

Quadro 4 - Instruções sobre o uso do software do experimento ............................................ 53 


\section{LISTA DE TABELAS}

Tabela 1 - Informações Demográficas dos Participantes 66

Tabela 2 - Estatística Descritiva das Questões Pós-experimento para Todos os Participantes da

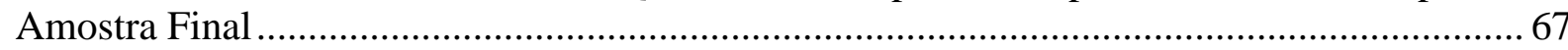

Tabela 3 - Estatística Descritiva das Questões Pós-experimento Por Grupo ............................... 67

Tabela 4 - Resultados da ANOVA de um Fator para as Questões Pós-experimental.............. 67

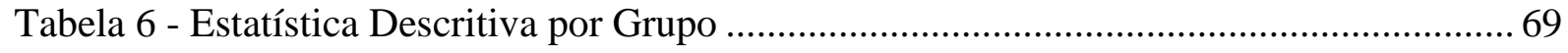

Tabela 7 - Resumo das Médias das Variáveis Dependentes por Período/Loja ......................... 70

Tabela 8 - Resultado do Teste de Contraste Dentro dos Grupos ............................................ 72

Tabela 9 - Resultados do Teste Não Paramétrico Wilcoxon para as Variáveis Dependentes . 73 Tabela 10 - Modelo 1: Resultados da Regressão em Dados em Painel para a Variável Temp

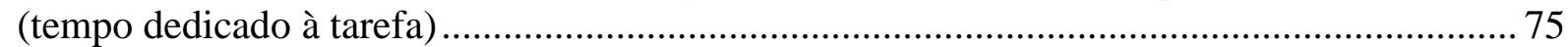

Tabela 11 - Modelo 2: Resultados da Regressão em Dados em Painel para a Variável Simula

Tabela 12 - Modelo 3: Resultados da Regressão em Dados em Painel para a Variável Invest (Valor dos investimentos nas atividades)..... .78

Tabela 13 - Modelo 4: Resultados da Regressão em dados em Painel para a Variável Esforc (Mensuração do Esforço) 79

Tabela 14 - Modelo 5: Resultados da Regressão em Dados em Painel para a Variável Desv (Desvio absoluto da decisão ótima de investimento) 80

Tabela 15 - Modelo 6: Resultados da Regressão em Dados em Painel para a Variável Simula/Temp (número de simulações por minuto).

Tabela 16 - Número de Vezes que o Valor do Investimento Ótimo foi Identificado Antes e Depois do Tratamento

Tabela 17 - Resultado do Teste Mann-Whitney para Amostras Independentes - Grupo de Controle x Grupo de Tratamento

Tabela 18 - Resultado do Teste Wilcoxon para Amostras Dependentes - Dentro dos Grupos84 Tabela 19 - Teste-t: Duas Amostras Independentes Presumindo Variâncias Diferentes - Entre Grupos 84

Tabela 19 - Estatísticas do Teste Mann-Whitney para diferença de Médias - Grupo de Controle x Grupo de Tratamento 1 (lucro contábil)

Tabela 20 - Estatísticas do Teste Mann-Whitney para diferença de Médias - Grupo de Controle x Grupo de Tratamento 2 (lucro econômico)

Tabela 21 - Poder Estatístico e Tamanho do Feito dos Modelos de Regressão 


\section{LISTA DE GRÁFICOS}

Gráfico 1 - Desvio do Fluxo de Caixa Ótimo - Antes e Depois do Tratamento ........................ 70

Gráfico 2 - Número de Simulações - Antes e Depois do Tratamento ....................................... 70

Gráfico 3 - Valor do investimento - Antes e Depois do Tratamento ........................................ 71

Gráfico 4 - Tempo Dedicado à tarefa - Antes e Depois do Tratamento...................................... 71 


\section{INTRODUÇÃO}

\subsection{Contextualização e Problema de Pesquisa}

Já é bem documentado que a criação de riqueza, através das ações que promovam maximização do valor presente líquido (VPL) dos futuros fluxos de caixa, é um dos principais objetivos da empresa. Entretanto, o foco excessivo dos gestores no resultado de curto prazo, conhecido como miopia gerencial, tem sido visto como um entrave para a consecução desse propósito. Existe um extenso registro de evidências sugerindo que a principal consequência desse comportamento disfuncional é a tomada de decisões subótimas de investimentos. Por conta disso, a miopia dos gestores se torna uma questão importante porque pode levar à distorção nos investimentos, reduzindo o valor de longo prazo das empresas.

A literatura tem apontado o problema do horizonte ${ }^{1}$ como uma das razões para o foco excessivo no resultado de curto prazo. Esse problema diz respeito à situação na qual o gestor considera que o tempo que ficará no cargo é inferior ao horizonte de investimento ótimo da empresa (BABER et. al., 1998) e ele antecipa que os resultados de suas decisões atuais não poderão lhe ser atribuídos, pois com alguma probabilidade não estará na sua posição atual (REICHELSTEIN, 2000). O curto horizonte de tempo no emprego gera naturalmente incentivos para o abandono de projetos com VPL positivo porque o gestor não espera estar na empresa para usufruir completamente dos benefícios que esses investimentos de longo prazo poderão trazer (CAZIER, 2009).

Determinadas ocorrências típicas da vida organizacional podem motivar o aparecimento do problema do horizonte. Por exemplo, alguns estudos indicam que os gestores costumam alocar mais esforço nas ações de curto prazo, abandonando projetos com VPL positivo, quando estão próximos da aposentadoria (DECHOW e SLOAN, 1991), têm contrato de trabalho de curto prazo (XU, 2009) ou idade elevada (WUNSCH, 1992; BARKER e MUELLER 2002; CHOWDHURY, 2012). O problema do horizonte além de induzir a decisão de investimento subótima pode levar à prática de gerenciamento de resultados e

\footnotetext{
${ }^{1}$ À luz da teoria econômica, o problema do horizonte é um típico problema de agência, pois leva ao conflito de interesses entre os proprietários e os gestores (LAMBERT, 2001).
} 
fraudes contábeis (KALYTA, 2009), daí a importância das empresas se preocuparem em desenvolver mecanismos corporativos apropriados para lidar com essa questão.

Um dos instrumentos usualmente adotados pelas empresas para alinhar interesses e mitigar os problemas decorrentes do comportamento disfuncional dos gestores é o contrato de incentivo contingente ao desempenho (MILGROM \& ROBERTS, 1992; BRICKLEY et al, 2007; MAHER et al, 2008). Entretanto, existe uma grande discussão em torno dos problemas que são gerados quando a ênfase desses contratos recai sobre mensurações de desempenho baseadas em métricas consideradas distorcidas. Por exemplo, se o lucro contábil contemporâneo for o principal critério de mensuração de desempenho este poderá funcionar como combustível para a miopia gerencial, que será agravada na presença do problema do horizonte (TEHRANIAN e WAEGELEIN, 1985; NARAYANAN, 1985; GIBBONS e MURPHY, 1992; ROGERSON, 1997; FARRELL et all. 2008).

O lucro contábil contemporâneo está fortemente associado ao comportamento míope dos gestores. Um levantamento feito por Graham et al (2005) com 400 executivos mostrou que a maioria enxerga o lucro contábil, especialmente o lucro por ação, como a principal métrica a ser divulgada para o público externo e que $59 \%$ deles evitariam iniciar um projeto com valor presente líquido (VPL) positivo se isso significasse não atingir o consenso dos analistas sobre o lucro contábil trimestral corrente. Segundo os autores, os gestores descreveram um tradeoff entre a necessidade de curto prazo para atingir as expectativas de lucro contábil e o objetivo de tomar decisões de investimento que maximizam o valor da empresa. A pesquisa revelou ainda que os executivos acreditam que superar o consenso dos analistas sobre o lucro contábil de curto prazo constrói credibilidade com o mercado e ajuda a manter ou aumentar o preço das ações da sua empresa.

Isso, provavelmente, serve para explicar porque alguns estudos têm documentado que quando o lucro contábil, ou qualquer outra métrica que dele derive é a base do sistema de recompensa, o contrato estabelecido pode incentivar o comportamento oportunista dos gestores (DECHOW e SLOAN, 1991; FELTHAM e XIE, 1994; ITTNER e LARCKER, 1998; DIKOLLI, 2001; FARRELL et al, 2008; HUANG, 2006). Com efeito, existe um amplo registro de evidências empíricas sugerindo a existência de associação negativa entre investimentos em ações de longo prazo que criam valor para a empresa e sistemas de 
incentivos quando a recompensa está atrelada às métricas contábeis (DECHOW e SLOAN, 1991; WUNSCH, 1992; HOSKISSON et al,1993; TYLER, 1995; CHENG, 2001; XU, 2009).

Desse modo, na presença do problema do horizonte, se o desempenho for recompensado com base em métricas contemporâneas, haverá um problema de incongruência que levará a inadequação na alocação de esforço e nas decisões de investimento. Nesse caso, o agente atuará de forma oportunista, priorizando as ações que aumentem sua compensação no curto prazo, em detrimento do desempenho de longo prazo da firma, uma vez que ele não espera que irá usufruir dos resultados futuros de suas ações atuais. No entanto, se a mensuração de desempenho for congruente no sentido de alinhar os interesses do gestor com os objetivos da empresa, o mesmo terá motivação para escolher o nível de esforço e as decisões de investimento que maximizem o desempenho de longo prazo, desde que esta ação também maximize sua compensação atual.

Por isso, os contratos de incentivo contingentes ao desempenho precisam ser ancorados em critérios de mensuração de desempenho que revelem, de forma consistente temporalmente, o processo de criação de valor da empresa, evitando que os gestores enfrentem tradeoffs intertemporais nas suas decisões de alocação de esforço em ações de longo prazo (WALLACE, 1997; DUTTA e REICHELSTEIN, 2005). Também, Baker et al (1994) chamam a atenção para o fato de que a mensuração de desempenho apropriada deve refletir a contribuição do empregado para o aumento da riqueza da empresa, incluindo os efeitos das ações contemporâneas na criação de valor a longo prazo.

Sendo assim, a mensuração de desempenho deve ser congruente e motivar os gestores a agir de modo que suas decisões promovam a maximização do valor da empresa. Todavia, quando existe o problema do horizonte, a questão de como incentivá-los para investir em projetos cujos resultados são de longo prazo é uma situação de difícil solução. No entanto, uma forma de abordar esse problema é utilizar métricas de desempenho de natureza forward-looking ${ }^{2}$. Muitos trabalhos arguem que esse tipo de mensuração cumpre um papel importante na formulação de contratos de incentivo porque estabelece uma forte vinculação entre as decisões atuais dos gestores e o desempenho econômico futuro, aumentando a congruência

\footnotetext{
2 Em consonância com Dikolli (1998), nesse trabalho, mensuração forward-looking é qualquer métrica contemporânea que reflete um direcionador do desempenho futuro da empresa. Segundo Attmore (2010), informações forward-looking são projeções, e não previsões, baseadas em fatos atuais, considerando certas premissas.
} 
entre a mensuração de desempenho e os objetivos de longo prazo da empresa (DIKOLLI, 2001; SEDATOLE, 2003; LAMBERT, 2007; FARRELL et al, 2008; BERGER, 2009).

Existem estudos mostrando que colocar mais peso nesse tipo de mensuração de desempenho nos contratos de incentivo reduz a miopia gerencial (DIKOLLI 2001; DIKOLLI e VAYSMAN 2006; KELLY, 2007 e 2009; FARRELL et all., 2008; BERGER, 2009) e pode atenuar conflitos de agência relacionados ao problema do horizonte (SEDATOLE et al, 2003; FARRELL et al, 2008). Além disso, as evidências sugerem que a incorporação de métricas dessa natureza pode exercer os papéis de influenciar e facilitar a tomada de decisão, melhorando o desempenho gerencial, porque clarifica para os gestores a maneira mais apropriada de alocar esforços em ambiente de múltiplos períodos e múltiplas atividades, e simplificando o processo cognitivo de tomada de decisão (FARRELL et al, 2008; BERGER, 2009).

Lamber (2007) explica que há várias maneiras de calcular mensurações de desempenho forward-looking, tais como estimar e reconhecer os benefícios futuros dos projetos de investimentos, complementar as medidas financeiras com medidas não financeiras, ou utilizar o preço das ações. No entanto, existem problemas nessas formas de incorporação de informações forward-looking em contratos. Por exemplo, de acordo com Abernethy et al (2009), estudos anteriores documentam que, assim como o lucro contábil, medidas não financeiras podem encorajar o gestor a tomar decisões no curto prazo em detrimento dos interesses de longo prazo da empresa, pois elas podem apresentar o problema de falta de congruência $^{3}$ e não refletir imediatamente o efeito das decisões intertemporais.

Por outro lado, o uso do preço das ações em contratos é problemático porque seu comportamento é afetado por muitos fatores que estão fora do controle dos gestores, tornando-o inevitavelmente em uma medida bastante ruidosa do desempenho gerencial (KIM, 2009) e da contribuição de empregados de níveis hierárquicos mais baixos (BAKER et. al., 1994), além de não ser possível utilizá-lo para avaliar o desempenho de áreas de responsabilidade dentro da organização (UBELHART, 1982; RAPPAPORT, 1983; RAPPAPORT 2001). Além disso, amarrar a recompensa a essa métrica também pode levar ao problema de miopia gerencial (NARAYANAN, 1985; STEIN, 1989; SHLEIFER e VISHNY,

\footnotetext{
${ }^{3}$ Esse problema surge quando se considera na análise principal-agente a situação na qual o esforço do agente deve ser direcionado para várias tarefas ou ações (ambiente multitarefa ou multiação).
} 
1990; BEBCHUK e STOLE, 1993; NOLAN, 2002; HARVEY e RAJGOPAL, 2005; RAPPAPORT, 2005; MATEJKA et al, 2009).

Uma alternativa para lidar com esse problema, que tem sido pouco abordada pela literatura existente, é a utilização do lucro econômico, pois sendo definido como a mudança no VPL dos fluxos de caixa futuros esperados, tem natureza forward-looking (JIA et al, 2010). O lucro econômico é consistente com a metodologia do fluxo de caixa descontado e seu uso em contratos faz com que o gestor passe a usufruir contemporaneamente dos benefícios futuros gerados por suas ações atuais. Sendo assim, ele terá incentivos para tomar decisões de investimentos que maximizem o VPL dos fluxos de caixa futuros, pois quanto maior for o VPL, maior será sua compensação, independentemente do seu horizonte de tempo. Essa propriedade do lucro econômico o torna uma mensuração de desempenho fortemente congruente e estabelece explicitamente uma vinculação entre as ações atuais do agente e o desempenho econômico futuro, sinalizando de forma direta qual o nível de ótimo de esforço que ele deve alocar para maximizar os objetivos de longo prazo da empresa.

Por isso, na presença do problema de horizonte, o lucro econômico pode ser uma maneira efetiva de fornecer incentivos para que os gestores pensem como os proprietários e tenham motivação para tomar decisões intertemporais mais consistentes com os objetivos de longo prazo da empresa, evitando decisões de investimentos incongruentes e subótimas. Além do mais, o lucro econômico apresenta outras importantes propriedades que justificam sua incorporação em contratos. Por exemplo, para contornar os problemas relacionados ao uso pontual de medidas contábeis ou não financeiras na formulação de contratos de incentivo, a literatura profissional tem sugerido o uso de sistemas de mensuração de desempenho que balanceiam concomitantemente múltiplas medidas (financeiras e não financeiras) de desempenho.

Contudo, alguns críticos consideram que esse balanceamento atrapalha os gestores porque não fornece uma única mensuração global de desempenho na qual possam direcionar seus esforços para melhorá-la, com o consequente efeito negativo no desempenho (ITTNER e LARCKER,1998). Além disso, geralmente é muito complicado mensurar todas as dimensões relevantes do desempenho com igual precisão, pois o resultado da ações em certas tarefas é mais difícil de ser capturado ou verificado, tornando o conjunto de medidas de desempenho incompleto ou inapropriado para formulação de contratos de incentivo (SPRINKLE e 
WILLIAMSON, 2007). Adicione-se a isso o fato de que a utilização de um conjunto de multiplas medidas de desempenho também pode causar dispersão dos eforços dos gestores, reduzindo a eficácia do sistema de mensuração de desempenho, além de levar à tomada de decisões não ótimas (HOLMSTRÖM e MILGROM, 1991; ITTNER e LARCKER, 1998).

Por isso, de acordo com Banker e Datar (1989), existe uma demanda por agregação na avaliação de desempenho gerencial porque reportar todas as transações básicas e outras informações não financeiras sobre o desempenho é custoso e inviável. Nesse contexto, o lucro econômico tem vantagens porque é uma medida financeira agregada, por isso reflete as várias dimensões do desempenho em uma única mensuração e não está sujeito aos problemas relacionados com o uso de múltiplas medidas de desempenho, nem com as limitações do uso isolado de mensurações de desempenho forward-looking não financeiras, podendo ser útil no auxílio às decisões de alocação de esforço em ambientes de múltiplas tarefas.

Pelo o exposto, portanto, o problema desta pesquisa diz respeito à incorporação de informação forward-looking em contratos de incentivo contingentes ao desempenho através do lucro econômico e a avaliação do seu efeito no comportamento dos indivíduos quando existe o problema do horizonte de tempo no emprego.

Muitos estudos têm documentado que o incentivo monetário contingente ao desempenho influencia o comportamento dos indivíduos e promove o aumento do esforço na realização das tarefas, porém a definição adequada da mensuração de desempenho tem papel chave em motivar os empregados a agir de forma mais consistente com os interesses de longo prazo da firma. Em função da sua natureza forward-looking, o lucro econômico pode ser um instrumento útil em fornecer o incentivo necessário para que os gestores tomem decisões de investimentos consistentes com a maximização do VPL dos futuros fluxos de caixa da empresa e, consequentemente, com a criação de valor para os proprietários.

\subsection{Objetivo e Questão de Pesquisa}

O objetivo dessa tese é ampliar a discussão sobre o uso de mensurações de desempenho forward-looking em contratos e avaliar empiricamente se as mesmas provêm incentivos para que os gestores atuem de acordo com os interesses da empresa. Mais especificamente, essa pesquisa investiga se o incentivo com base no lucro econômico, em comparação ao lucro 
contábil contemporâneo, motiva os indivíduos a agir de forma mais consistente com objetivos de longo prazo, quando existe o problema do horizonte. Desse modo, a principal questão de pesquisa tratada nesta tese é: o contrato de incentivo baseado no lucro econômico promove a congruência de objetivos, motivando o gestor a agir de forma mais consistentes com os interesses de longo prazo da empresa, quando existe o problema do horizonte?

Para responder essa questão, foi desenvolvido um experimento no qual a única tarefa dos participantes era alocar recursos em ações de longo prazo visando maximizar o fluxo de caixa futuro de uma empresa, conforme descrito no capítulo 3 desse trabalho. Através do experimento, foi possível reunir evidências que apontam para a relevância do uso do lucro econômico, em contraste ao lucro contábil contemporâneo, na formulação de contratos de incentivo contingentes ao desempenho quando existe o problema do horizonte de tempo no emprego. A pesquisa documentou que, em comparação ao grupo de controle recompensado com base numa remuneração fixa e a um grupo de tratamento recompensado com base numa remuneração variável vinculada ao lucro contábil, os indivíduos quando submetidos a um contrato que recompensava com base no lucro econômico agiam de forma mais congruente com o objetivo de longo prazo estabelecido, dedicando mais esforço na realização da tarefa e melhorando o desempenho nas decisões de investimentos.

Além disso, o experimento também identificou que o incentivo monetário baseado no lucro contábil contemporâneo motivou o comportamento míope dos participantes que passaram a agir com mais interesse nas ações de curto prazo, abrindo mão de trabalhar em favor do objetivo de longo prazo estabelecido, documentando evidências sobre as consequências negativas da formulação de contratos de incentivo baseados em mensurações de desempenho distorcidas. Os resultados encontrados são consistentes com as predições da teoria da agência.

\subsection{Justificativas e Contribuições}

Conforme apontam Farrell et al (2008) e Matejka et al (2009), mesmo existindo um grande número de trabalhos teóricos que abordam o problema de como motivar os agentes com horizonte de curto prazo no emprego para as ações de longo prazo, há poucas evidências empíricas que dê suporte aos benefícios de se utilizar mensuração de desempenho forwardlooking em contratos de incentivo para esse fim. Logo, o presente estudo acrescenta 
conhecimento à literatura existente e amplia o entedimento sobre as propriededas das mensurações de natureza forward-looking, pois fornece um teste empírico da teoria existente.

Outra justificativa para o estudo realizado diz respeito ao fato de que no campo da contabilidade gerencial faltam estudos empíricos que examinem o uso de medidas financeiras forward-looking, tal como o lucro econômico ex ante, em contratos de incentivo. Por isso, esse trabalho se torna relevante, pois, ao mostrar que o lucro econômico ajuda a mitigar o problema do horizonte, amplia a literatura existente e traz novos insights sobre o tema.

O trabalho oferece ainda outras contribuições, dentre as quais se destacam:

- Acrescenta informação à literatura sobre miopia gerencial ao fornecer evidências adicionais sobre as circunstâncias em que os contratos de incentivo contingentes ao desempenho podem ajudar a mitigá-la.

- Amplia as evidências sobre o efeito do incentivo monetário e o seu papel em motivar o aumento do esforço e a malhoria do desempenho nas tarefas.

- Ao discutir o papel do uso do lucro econômico em mitigar o problema do horizonte e apresentar evidências empíricas da inadequação do uso do lucro contábil contemporâneo nesse contexto, contribui para ampliar o conhecimento sobre sistemas de incentivos e mensuração de desempenho gerencial, que são temas de grande interesse na agenda de pesquisa internacional em contabilidade gerencial e ainda pouco explorados no Brasil.

- Ao analisar em que circunstâncias o lucro econômico promove incentivos, a pesquisa oferece ideias que podem ajudar na tarefa dos profissionais que têm a responsabilidade de estruturar sistemas de mensuração de desempenho e recompensa nas empresas.

- Os contratos de incentivo contingentes ao lucro econômico podem funcionar como um mecanismo de sinalização ao mercado que a empresa utiliza meios internos de controle gerencial que desincentivam o abandono de projetos com VPL positivo e incentivam o compromisso com as ações que ajudam na criação de valor no longo prazo, por isso os resultados dessa pesquisa também podem servir ao interesse dos participantes do mercado financeiro.

- Por fim, se não for o primeiro, está entre os primeiros a tratar formal e experimentalmente o uso do lucro econômico em contratos de incentivo, abrindo 
espaço para novas pesquisas empíricas que avaliem outras consequências da adoção de sistemas de informações gerencias pautados nessa mensuração de desempenho.

\subsection{Delimitação e Limitações}

Em função das opções metodológicas e do tema abordado, a delimitação dessa pesquisa é importante, pois ela apresenta uma série de limitações que precisam ser levadas em conta na avaliação dos resultados encontrados. Por exemplo, o trabalho não tem como objetivo discutir o processo de mensuração do lucro econômico em si, mas avaliar o efeito da sua natureza forward-looking na formulação de contratos de incentivo. O conceito de lucro econômico utilizado no procedimento experimental é o lucro econômico ex-ante. Todavia, sua definição ex-post tem outras implicações na formulação de contratos, especialmente quando existe o problema do compartilhamento de risco, que é um tema central na teoria da agência e não foi abordado nesse trabalho.

Utilizou-se exclusivamente a teoria da agência para analisar as circunstâncias sob as quais as medidas de desempenho importam para formulação de contratos de incentivo, e derivar as hipóteses sobre o seu efeito nos problemas de agência relacionados à falta de congruência entre os objetivos dos agentes com horizonte de curto prazo no emprego e os interesses de longo prazo da empresa. Por isso, o foco da pesquisa foi avaliar o comportamanto econômico do agente no que se refere às suas decisões de alocação de esforço na realização de tarefas na presença de incentivo monetário.

No entanto, muitos estudos têm sugerido que a relação entre o incentivo monetário e o comportamento dos indivíduos pode ser mediada ou moderada por vários fatores não econômicos. Muitas evidências empíricas têm indicado que os incentivos falham em seus objetivos e frequentemente não produzem os efeitos esperados, de modo que seria importante examinar outras variáveis não econômicas que podem influenciar o comportamento dos indivíduos e se elas afetam a eficácia dos contratos contingentes ao lucro econômico. A observância dessas variáveis pode fornecer explicações alternativas ou complementares aos resultados encontrados.

Os sujeitos da pesquisa foram estudantes de graduação, de modo que seus resultados não podem ser confrontados com estudos que abordaram o mesmo tema ou problema, mas que 
tenham sido realizados com indivíduos com outras formações ou experiências. Além disso, a amostra utilizada foi não probabilística, o que inviabiliza a generalização dos resultados. Outro aspecto que merece ser observado é o fato da pesquisa tratar apenas da miopia gerencial causada pelo problema do horizonte. Os resultados desta pesquisa não podem ser generalizados para situações relacionadas a outras fontes de miopia gerencial, nem a problemas que envolvam a formulação de contratos de incentivo quando os agentes têm horizonte de longo prazo no emprego.

Como estratégia metodológica, foi utilizado o método experimental para produzir os dados necessários à análise empírica do problema formulado. $\mathrm{O}$ experimento foi uma versão simplificada de um processo de tomada de decisão baseado numa única tarefa, tanto antes quanto depois da manipulação experimental (tratamento), e realizado numa única sessão experiemnatal. Entretanto, no mundo real, o natural é que os gestores sejam submetidos a situações em que sejam responsáveis por várias tarefas desempenhadas de forma concomitante e que duram e se repetem ao longo de muito tempo. Em função disso, seus resultados não poderão ser analisados à luz daquelas situações que envolvam ambientes de múltiplas tarefas em um horizonte de tempo indefinido.

Outra limitação do trabalho é o fato dos resultados serem sensíveis à estrutura de incentivo criada. A literatura e a prática indicam diversos tipos de arranjos contratuais possíveis com capacidade de influenciar o comportamento dos indivíduos de várias formas. Portanto, os achados dessa pesquisa não podem ser comparados diretamente com estudos que utilizam outros arranjos contratuais, tais como pagamento por peça/tarefa ou torneio.

\subsection{Estrutura do Trabalho}

Além deste capítulo introdutório, que apresenta o problema e a questão de pesquisa, delimita seu escopo e justifica a importância do trabalho, esta tese é constituída de mais quatro capítulos. O capítulo 2 sumariza a teoria e alguns estudos que deram suporte às hipóteses desenvolvidas. O capítulo 3 apresenta, além das hipóteses, a descrição da metodologia, bem como o desenho experimental e os procedimentos estatísticos utilizados para testar as hipóteses. O capítulo 4 sumariza os resultados da pesquisa, juntamente com uma discussão sobre os mesmos. Finalmente, o capítulo 5 apresenta as conclusões do trabalho, seguida de uma lista de sugestões para futuras pesquisas. 


\section{REVISÃO DA LITERATURA}

A fim de desenvolver uma base conceitual para o estudo e fundamentar as hipóteses apresentadas, este capítulo apresenta uma revisão da literatura relacionada ao tema e ao problema de pesquisa. Primeiro é apresentada uma breve discussão tratando dos contratos de incentivo. Depois, tem-se a exposição sobre os principais aspectos acerca da orientação gerencial de curto prazo. Em seguida é apresentada uma visão geral da teoria da agência e sua relação com a mensuração de desempenho e o problema de congruência. Alguns aspectos da discussão teórica sobre a mensuração forward-looking e sua interação com os contratos de incentivo são tratados logo na sequência. O próximo tópico trata da discussão e definição do lucro econômico como um tipo específico de mensuração forward-looking. Finalmente, o capítulo é encerrado com uma nota sobre o uso do lucro residual em contratos.

\subsection{Contratos de Incentivo}

Os contratos de incentivo são acordos de agência que tentam alinhar os interesses entre o agente (empregado) e o principal (proprietário) através da vinculação da compensação do primeiro a uma ou mais medidas de desempenho definidas pelo segundo. Um dos principais objetivos desses contratos é prover incentivos (recompensas ${ }^{4}$ ) para que os empregados atuem no melhor interesse da empresa. (MILGROM \& ROBERTS, 1992; BRICKLEY et al, 2007; MAHER et al, 2008).

Segundo Fisher, Sprinkle e Walker (2008), os contratos de incentivo são utilizados por quase todas as organizações e desempenham quatro papéis básicos: i) induzir os empregados a alocar mais esforço na execução das tarefas e atividades; ii) direcionar a atenção deles para as tarefas e atividades que produzem os maiores retornos esperados para a organização, quando os empregados são responsáveis por múltiplas tarefas ou atividades; iii) incentivá-los a compartilhar informações privadas com os demais colegas sobre tarefas e atividades que realizam; e iv) atrair os empregados mais competentes a habilidosos para trabalhar na

\footnotetext{
${ }^{4}$ Conforme explicam Baker, Jensen e Murphy (1988), há várias formas de recompensas, tais como elogios e reconhecimento de seus superiores e colegas de trabalho, promessas implícitas de futuras oportunidades de promoção e até o sentimento de autoestima por ter alcançado metas estabelecidas. Todavia, o foco da teoria econômica tem sido o incentivo monetário (recompensas em dinheiro vinculadas ao desempenho).
} 
empresa. Para os autores, esta é certamente uma das razões para a escalada da remuneração dos executivos observada ao longo das últimas décadas.

Prendergast (2009) explica que as firmas fornecem incentivos para os seus empregados através das práticas de compensação (envolvendo o monitoramento, a avaliação de desempenho e a formulação de contratos) e usam diferentes mecanismos para aliar interesses. Os contratos de incentivo representam um componente importante do sistema de remuneração total de muitas companhias. De acordo com Indjejlklan (1999), pesquisas sobre compensação de executivos indicam que a avaliação de desempenho e as práticas de remuneração variam substancialmente entre empresas e indústrias. Por exemplo, alguns trabalhadores são predominantemente recompensados através de contratos explícitos que amarram a remuneração ao desempenho individual observado. Outros são recompensados com base em medidas de desempenho mais agregadas, tal como o lucro contábil, ou em medidas subjetivas de desempenho.

Segundo Aggarwal (2008), os planos anuais de compensação comumente adotados na prática podem ser divididos em componentes de curto e longo prazo. No primeiro grupo estão os salários fixos, bônus e outras compensações anuais. Os bônus representam medidas de incentivos e são tipicamente ligados às métricas de desempenho baseadas em informações contábeis, tais como lucro líquido, vendas ou lucro operacional. Os componentes de longo prazo geralmente incluem concessões de ações, concessões de opções de ações, planos de incentivo de pagamento de longo prazo, premiações, descontos em compras de ações preferenciais, contribuições para planos de benefícios, dentre outros.

De acordo com Scott (2009), em muitos casos, um contrato de incentivo é baseado ao mesmo tempo no lucro contábil e no preço da ação da companhia. Essa combinação faz com que, ao final de um período financeiro, a compensação total do gestor seja função do lucro líquido contábil e do retorno das ações. Além disso, os contratos de incentivo podem ser estabelecidos entre outros níveis hierárquicos dentro da firma, além da relação Proprietário/CEO. Por exemplo, é comum observar o estabelecimento de contratos entre e o CEO e os gestores divisionais. Conforme esclarecem Maher et al (2008), quase todas as grandes corporações descentralizadas oferecem aos gestores de centros de lucro ou de investimento bônus e outros incentivos financeiros, geralmente vinculados ao lucro contábil, que frequentemente representam de 25 a 50 por cento de seus salários. Todavia, nesse caso 
contratual específico, a mensuração de desempenho não pode ser feita com base no preço das ações da companhia (UBELHART, 1982; RAPPAPORT, 1983; RAPPAPORT 2001).

Os incentivos providos pelas organizações costumam assumir vários delineamentos contratuais. Bonner et al (2000) classificam os arranjos dos contratos de incentivo monetário em quatro categorias básicas: remuneração fixa; pagamento por tarefa; quota; e torneio. Essas categorias levam em conta se o pagamento está ligado ao nível global de desempenho ou ao nível de cada unidade individual de output. Bonner et al (2000) ensinam que os incentivos financeiros baseados em remuneração fixa, não vincula o pagamento a um desempenho global ou a uma unidade individual de produção. Esse esquema equivale ao salário fixo pago pelo tempo gasto na execução da tarefa.

O pagamento por tarefa consiste na remuneração por unidade de produção. No esquema de quotas, os indivíduos recebem uma remuneração fixa até certo nível meta de desempenho. Uma vez que alcançada esta meta, eles recebem um bônus geralmente variável. Por sua vez, o esquema de torneio vincula a recompensa financeira a rankings de desempenho, estabelecendo uma competição entre os indivíduos que fazem a mesma tarefa. Bonner et al (2000) esclarecem que cada uma dessas categorias induz o empregado a alocar níveis diferentes de esforço, de modo que nem todo incentivo produz o efeito desejado. O esforço do agente é multidimensional, por isso diferentes contratos de incentivo têm diferentes efeitos sobre essas dimensões.

Segundo Bonner e Sprinkle (2002), o esforço pode ser medido em três dimensões: i) duração - refere-se ao período de tempo dedicado a uma determinada tarefa em termos de recursos cognitivos e físicos; ii) intensidade - refere-se a quão forte o indivíduo trabalha ou à quantidade de atenção ele dedica à realização da tarefa ou atividade; e iii) direção - refere-se à tarefa ou atividade que o indivíduo escolhe se engajar. Representa aquilo que ele faz. Nesse sentido, num ambiente de múltiplas tarefas, os incentivos contingentes ao desempenho podem levar o indivíduo a direcionar a atenção para as tarefas ou atividades que estão sendo recompensadas diferencialmente, ou escolher se concentrar em apenas um aspecto delas.

$\mathrm{O}$ aspecto multidimensional do esforço pode ser uma das razões para o incentivo monetário nem sempre funcionar. Além disso, muitos estudos têm sugerido que fatores não econômicos influenciam as decisões dos agentes no que diz respeito à intensidade, duração e direção do 
esforço frente às tarefas que desempenham (BONNER et al, 2000; BONNER e SPRINKLE, 2002; FESSLER, 2003; ALEXANDER e FRANK, 2007; BERGER, 2009; BAILEY e FESSLER, 2011). No entanto, existe um considerável número de pesquisas documentando evidências da relação positiva entre incentivo monetário, alocação de esforço e desempenho na realização de tarefas. Por exemplo, uma meta-análise envolvendo 39 estudos (experimentos em laboratório, simulações e estudos de campo) realizada por Jenkins et al (1998) valida, de forma robusta, a hipótese de associação positiva entre incentivo monetário e desempenho. Além disso, Bonner et al (2000) revisaram 131 estudos experimentais e encontraram que em aproximadamente cinquenta por cento dos casos o incentivo monetário melhorou o desempenho na realização das tarefas.

Segundo Baker et al. (1988), a teoria econômica assume que alto desempenho exige maior esforço e leva à desutilidade por parte do trabalhador. Em função disso, é necessário que existam sistemas de recompensa que forneçam incentivos vinculados à produtividade. Os autores arguem que os incentivos monetários, apesar de serem criticados quando são utilizados para motivar os trabalhadores, são mais eficazes e induz o indivíduo a fazer exatamente aquilo que é solicitado, mas dependendo do arranjo contratual e da mensuração de desempenho adotada, o sistema de incentivo poderá ou não alcançar os objetivos que dele se espera.

Por vezes, o incentivo monetário gera resultados inesperados e contraproducentes por causa da dificuldade de especificar adequadamente o que as pessoas devem fazer e como o desempenho deve ser medido. Nesse sentido, Prendergast (2009) explica que o problema de comportamento disfuncional dos trabalhadores como resposta aos incentivos ocorre porque os contratos são incompletos, pois não podem especificar todos os aspectos relevantes do comportamento do trabalhador.

No entanto, muitos estudos sugerem que o delineamento cuidadoso de sistemas de incentivos pode ter efeito positivo para as empresas, tanto fazendo com que os empregados se dediquem mais à realização de suas tarefas, quanto melhorando o desempenho individual nelas. Isso ocorre porque o incentivo monetário ajuda a melhorar a qualidade da atenção dedicada à tarefa e a análise e utilização de informações disponíveis. Isso, por sua vez, permite aos indivíduos desenvolver melhores estratégias que os ajudem a tomar decisões mais consistentes com a maximização do resultado (SPRINKLE, 2000). Porém, o benefício do 
aumento do nível de esforço só interessará se sua direção for congruente com os objetivos do principal. Se o desempenho for mensurado com base em uma medida distorcida, a direção poderá ser incongruente. Por isso, em muitos casos é preferível compensar os agentes com base em uma remuneração fixa (HOLMSTRÖM e MILGROM, 1991). Logo, os contratos de incentivo e as métricas de desempenho não devem apenas motivar a intensidade do esforço do agente, mas também sua alocação de forma ótima (LAMBERT 2007).

\subsection{Orientação Gerencial de Curto prazo e o Problema do Horizonte}

Em muitas situações, o agente pode ter que alocar esforço em dois tipos de ação: a que produz efeito no curto prazo e a que produz efeito no longo prazo. Quando o agente tem preferência pelas ações que têm efeito no curto prazo, em detrimento da geração de resultados no longo prazo, diz-se que o seu comportamento é míope. Esse comportamento disfuncional representa um tradeoff entre alocação de esforço em ações de interesse do agente e ações de interesse do principal e é uma forma particular de manifestação do problema de congruência/distorção que pode estar relacionado à mensuração de desempenho.

A literatura tem conceituado miopia gerencial de várias maneiras. Por exemplo, Bhojraj e Libby (2005) a definem como sendo o comportamento de desistir de projetos com maiores fluxos de caixa para relatar externamente maiores ganhos a curto prazo, mas explicam que esse termo pode significar oportunismo gerencial, no sentido de representar as ações privadas que o gestor toma em seu interesse e que podem ser prejudiciais aos interesses dos acionistas.

A teoria da agência sugere que a miopia gerencial nasce como consequência direta dos problemas de risco moral e seleção adversa, vinculados à assimetria de informação entre agente e principal. Segundo Antia et al (2010), estudos teóricos envolvendo modelos analíticos de risco moral com assimetria de informação apontam que os gestores têm preferência por, e buscam, resultados de curto prazo que servem aos seus próprios interesses em detrimento dos resultados a longo prazo que seriam ideais para suas empresas. Isso ocorre quando eles tomam decisões que representam ótimas escolhas intertemporais pessoais, a partir de uma perspectiva gerencial, mas que podem ser escolhas intertemporais subótimas do ponto de vista da firma. 
Narayanan (1985) mostrou analiticamente que o gestor pode ter incentivos para tomar decisões que resultem em ganhos de curto prazo à custa do bem-estar dos acionistas quando ele tem informação confidencial sobre as decisões da empresa. Porém, se a informação que o gestor tem à disposição for de conhecimento comum, não necessariamente ele tomará decisões que sejam orientadas pelo lucro de curto prazo, mesmo quando sua compensação esteja amarrada ao desempenho atual e passado e os proprietários exigem lucros a curto prazo. Por outro lado, se o gestor possuir informações privadas ele tomará tais decisões subótimas para tentar maximizar o lucro no curto prazo.

São várias as explicações para viés de curto prazo no comportamento dos gestores. Narayanan (1985) cita os seguintes: i) pressão do mercado de capitais por lucros rápidos; ii) estrutura do sistema de incentivo; e iii) problema do horizonte de tempo no emprego. Conforme explicitam Bhojraj e Libby (2005), a pressão do mercado de capitais pode ser resultado de vários fatores, onde se destacam: a probabilidade de emissão de novas ações; o processo de mudança do controle societário através de compra de ações (takeover) e a pressão para cumprir as previsões dos analistas.

De acordo com Bhojraj e Libby (2005), estudos anteriores sugerem que o grau de comportamento míope será influenciado por incentivos do mercado de capitais que determinam em que extensão os gestores se preocupam mais com preços no curto prazo do que com o valor a longo prazo da empresa. Experimentalmente, os autores examinaram se os gestores se comportam de forma míope em resposta à pressão crescente do mercado de capitais dada a existência de conflito de agência entre os administradores e os acionistas. Bhojraj e Libby (2005) concluem que quando os agentes precisam escolher entre projetos onde existe um conflito entre o lucro de curto prazo e fluxo de caixa total, eles irão, frequentemente, fazer opções subótimas por projetos que maximizam lucros de curto prazo à custa da maximização do valor da empresa.

Além da pressão do mercado de capitais, a estrutura do sistema de incentivos também representa uma fonte importante de miopia gerencial. Rappaport (1978) argui que bônus e outras formas de incentivos são um motivador eficaz para fazer com que os executivos alcancem lucros por ação (resultado contemporâneo) cada vez maiores. Porém, estimular a geração de resultados no curto prazo muitas vezes influencia os gestores a renunciarem decisões de investimentos que poderiam beneficiar a empresa em vários períodos. 
Em um estudo teórico, Suay (1993) desenvolveu um modelo analítico para analisar a interação entre os incentivos gerenciais, investidores institucionais e investimento corporativo na presença de mercados de capitais eficientes e descobriu que, sob a hipótese de informação assimétrica, existe o potencial para a manipulação do mercado, tanto pelo administrador do fundo quanto pelo gestor da empresa na situação em que o administrador do fundo tem mais informações do que o mercado, mas é menos informado do que o gestor corporativo. De acordo com o modelo teórico desenvolvido por Suay (1993), o incentivo para manipular o mercado e a forma de equilíbrio nas decisões de investimentos depende do quão forte o sistema de incentivo dos dirigentes corporativos e dos gestores do fundo enfatizam o desempenho futuro em relação ao desempenho contemporâneo.

Dessa forma, Suay (1993) conclui que para o equilíbrio de investimento ótimo existir, duas condições gerais devem ser satisfeitas: i) o esquema de compensação do gestor corporativo deve ser suficientemente sensível para desempenho de longo prazo. Caso isso não ocorra, esse agente pode ter o incentivo para investir em projetos com VPL negativo, levando o mercado a acreditar que os mesmo têm VPL positivo; e ii) investimento ótimo requer que o contrato de compensação do gestor do fundo pese suficientemente o desempenho a longo prazo. Se isso não ocorrer o comportamento do investidor institucional pode influenciar negativamente o comprometimento do gestor com estratégias ótimas de investimento.

Outra questão vinculada à relação entre miopia gerencial e sistemas de incentivo gerencial diz respeito à métrica de desempenho utilizada quando a recompensa está atrelada ao resultado. Feltham e Xie (1994) explicam que o uso do lucro contábil como medida de desempenho é criticado por não refletir totalmente as consequências econômicas das ações do agente. Esses autores sugerem que isso ocorre porque tal métrica é de curto prazo em sua orientação e ignora os benefícios futuros de cada atividade desenvolvida pela empresa. Embora o lucro contábil possa ser modificado para torná-lo mais congruente, tais modificações são muitas vezes limitadas em função dos outros usos que dele são feitos (FELTHAM e XIE, 1994). De acordo com Huang (2006), as evidências documentadas pela literatura têm sugerido que contratos vinculados ao lucro contábil contemporâneo, e a ausência de qualquer incentivo de longo prazo, pode induzir os gestores a se comportar de forma míope sacrificando a criação de valor a longo prazo na empresa para aumentar suas compensações. 
Por exemplo, Wunsch (1992) testou empiricamente a relação entre a política de compensação de executivos e comportamento de investimentos de longo prazo para as 100 maiores empresas americanas no período de 1980-1989. Confirmando as previsões teóricas, o autor documentou uma relação estatisticamente significativa e positiva entre o pagamento de incentivo de longo prazo e investimentos em gastos de longo prazo na empresa. Por seu turno, Hoskisson et al (1993), com base em uma amostra de 184 grandes empresas americanas, encontrou evidências sugerindo que incentivos baseados no desempenho financeiro divisional contemporâneo são negativamente relacionados com o investimento total da empresa em gastos com pesquisa e desenvolvimento (P\&D). Além disso, os resultados também indicaram que a ênfase em incentivos de longo prazo pode reduzir a relação negativa entre esses incentivos financeiros e a intensidade do investimento em P\&D.

Nessa mesma direção, analisando uma mostra de 200 grandes empresas americanas, num painel de dados que cobriu o período de 1987 a 1993, Tyler (1995) também encontrou evidências da existência de relação negativa e estatisticamente significativa entre incentivos monetários dado ao CEO baseados em resultado financeiro de curto prazo e o nível de gastos em P\&D da empresa. Do mesmo modo, consistente com as predições da teoria da agência, o autor registrou uma relação positiva e estatisticamente significativa entre incentivo com base em retorno de mercado e gastos com P\&D.

Segundo Xu (2009), problemas de miopia conduzem a ações que melhoram o desempenho no curto prazo, mas destroem valor da empresa no longo prazo. Conforme dito no início desta seção, o comportamento míope dos gestores está associado ao problema do risco moral que ocorre por causa da assimetria de informação. Isso significa que os gestores são mais bem informados sobre as oportunidades de investimentos da empresa, mas os acionistas não podem avaliar plenamente o valor delas nem saber se as previsões dos gestores são confiáveis e se as decisões de investimentos que eles tomam são as melhores do ponto de vista da maximização do fluxo líquido de caixa futuro da empresa. Por isso, os acionistas têm que contar com informações disponíveis sobre o desempenho atual da empresa para estimar o valor das oportunidades de investimento, bem como avaliar as habilidades dos gestores em criar riqueza. Além disso, conforme explica Xu (2009), quando o horizonte do gestor no cargo é diferente do horizonte de investimento ótimo, ele pode querer fazer seu desempenho parecer mais valioso no curto prazo, mesmo que à custa da maximização do valor da empresa no longo prazo. Nesse caso, a fonte de miopia é o problema do horizonte. 
O problema do horizonte de tempo no emprego tem sido visto como uma fonte relevante para o comportamento míope dos gestores (TEHRANIAN e WAEGELEIN, 1985; NARAYANAN, 1985; DECHOW E SLOAN, 1991; DIKOLLI E VAYSMAN, 2006). Segundo Dikolli e Vaysman (2006), um agente pode ter horizonte de curto prazo no emprego por vários motivos. Por exemplo, ele pode estar perto da aposentadoria ou, simplesmente, ser avesso a diferir compensação. Ele pode ter pouca lealdade à organização onde trabalha e espera mudar de empresa em busca de melhores oportunidades. Mesmo sendo leal, caso exista um programa de desenvolvimento de carreira, o agente pode estar aguardando fazer rodízio em outra divisão da empresa e espera não se beneficiar das consequências futuras de suas ações atuais.

Em essência, o problema do horizonte surge porque a empresa tem uma vida útil longa e indefinida, enquanto o horizonte do gestor é função do período de exercício do seu cargo. Narayanan (1985) demonstrou analiticamente como o horizonte de tempo no emprego influencia o viés de curto prazo dos gestores. Segundo o autor, quanto maior o tempo de contrato, menor a probabilidade de que eles escolham projetos com retorno mais rápido que sejam subótimos. Porém, segundo Tehranian e Waegelein (1985), quando o gestor não tem direito sobre os retornos de longo prazo ele terá incentivos para investir em projetos com retornos de curto prazo, embora sejam menos rentáveis do que os projetos de longo prazo. Nesse caso, contratos atrelados a planos de incentivo de curto prazo podem agravar esse problema.

Os estudos empíricos têm adotado várias proxies para identificar o problema do horizonte. Por exemplo, Dechow e Sloan (1991) utilizaram o tempo no cargo para investigar uma amostra de CEOs e, empiricamente, encontraram evidências do problema de congruência entre o horizonte do agente e o do principal. Eles documentaram que quando os executivos estão em seus últimos anos do cargo gastam menos em Pesquisa e Desenvolvimento (P\&D) de novos produtos. Ainda nessa linha, Naveen (2006), através de um painel cobrindo um período de 10 anos e uma amostra de 6.714 empresas-ano, documentou que os CEOs reduzem os gastos com P\&D ao longo do seu tempo no cargo. Em outras palavras, a pesquisa identificou uma correlação negativa entre o tempo de exercício do cargo e o gasto em P\&D.

Wunsch (1992) utilizou a idade do gestor como proxy do problema do horizonte e testou também a hipótese de que os investimentos de longo prazo são negativamente relacionados 
aos contratos de incentivo de curto prazo. O autor identificou que a idade do CEO é um fator importante para o nível investimentos em gastos de longo prazo. A pesquisa conduzida por Wunsch (1992) documentou que a relação entre idade do CEO e investimentos em gastos de longo prazo era inicialmente positiva, mas quando o executivo chegava a uma idade próxima de 58 anos esta relação se tornava negativa. Do mesmo modo, Barker e Mueller (2002), investigando uma amostra de 172 empresas para avaliar como as características individuais dos CEOs se relacionavam com o gasto com P\&D, encontraram evidências de que esses gastos eram maiores em empresas onde os CEOs eram mais jovens e tinham parte de sua riqueza investida em ações da empresa. No modelo econométrico desenvolvido pelos autores, a idade do CEO foi o preditor mais forte e direto do gasto em P\&D.

Na mesma direção dos trabalhos já citados, Chowdhury (2012) também utilizou a idade do CEO como proxy para a miopia gerencial e sua relação com as decisões de investimento em ações de longo prazo das firmas. O autor documentou que os gestores mais velhos, em média, gastam menos em P\&D e despesas de capital. Na sua pesquisa, Chowdhury (2012) encontrou uma forte correlação negativa e estatisticamente significativa entre a idade do CEO e os gastos com $\mathrm{P} \& \mathrm{D}$, e uma correlação negativa e estatisticamente significativa entre a idade do CEO e as despesas de capital.

Por outro lado, analisando uma amostra de 3.717 contratos de trabalho de CEOs, no período de 1989 a 2008, Xu (2009) encontrou evidências de que empresas com contratos de curto prazo subinvestem enquanto que aquelas que mantinham contratos de horizonte mais longo investiam mais em gastos de capital e P\&D.

Em hipótese, o problema do horizonte é uma forte ameaça à criação de valor porque o gestor em iminência de deixar a empresa não tem incentivos para se engajar em ações que estejam alinhadas aos interesses de longo prazo dos proprietários. Isso se torna mais crítico quando é usado o mecanismo de recompensa atrelado ao lucro contábil, pois aumentam as chances do gestor abrir mão de projetos com maior VPL positivo, mas que apresentem menores lucros contábeis contemporâneos em favor de projetos com VPL menor ou negativo, mas que aumentam o lucro contábil contemporâneo. Coletivamente, os achados apresentados fornecem uma forte evidência empírica em favor dessa hipótese. 


\subsection{Teoria da Agência, Mensuração de Desempenho e Congruência}

A avaliação de desempenho é o procedimento pelo qual as organizações julgam a forma como estão atingindo suas metas e objetivos em termos de produtos gerados, recursos e esforços utilizados. Constitui-se em um instrumento de gestão e uma ferramenta de racionalização da ação administrativa. Além disso, cumpre dois papéis chaves no processo de controle gerencial vinculados à criação de incentivos (BRICKLEY et al, 2007): i) prover feedback aos empregados sobre o resultado do seu trabalho. Com isso, eles podem aprender com suas próprias experiências e obter informações de como melhorar o seu desempenho; e $i$ ) serve como parâmetro na determinação de premiações e punições dos empregados. Esse segundo aspecto é o que mais interessa na interação agente-principal discutida na teoria da agência.

A teoria da agência descreve a relação onde agente e principal são maximizadores de utilidade e agem sempre em seu melhor interesse. $\mathrm{O}$ agente é estritamente avesso ao risco e tem desutilidade em relação ao seu esforço. Por isso, a função utilidade do agente depende de duas variáveis: esforço e riqueza. A maximização dessa função depende de aumentar a riqueza e diminuir o esforço. Por isso, a teoria da agência, pressupõe que o agente irá se esquivar do trabalho a menos que seu esforço na realização da tarefa de alguma forma contribua para o aumento de sua riqueza e bem-estar. Dado isso, o incentivo contingente ao desempenho exerce um papel fundamental na motivação, pois os indivíduos têm utilidade para o aumento de riqueza e desutilidade para o aumento do esforço (BONNER e SPRINKLE, 2002).

Por outro lado, o principal é neutro ao risco e contrata o agente para desempenhar uma determinada tarefa ou um conjunto delas exercendo o máximo de esforço possível. Para tanto, firma-se um contrato onde se assume previamente que as duas partes têm as mesmas informações e crenças sobre o ambiente (estado da natureza). A teoria considera ainda que por ser muito oneroso, ou às vezes impossível, o principal não pode observar/monitorar diretamente as ações do agente, ele apenas pode verificar o resultado gerado. Nesse caso, por possuir mais informações privadas sobre suas reais habilidades, o agente tem a possibilidade de escolher, entre um conjunto de alternativas possíveis, qual nível de esforço empregará na execução da tarefa para a qual foi contratado. Independentemente da escolha, a decisão do agente terá impacto no bem-estar de ambas as partes (MILGROM \& ROBERTS, 1992; BRICKLEY et al, 2007). 
Desse cenário surgem dois problemas básicos: seleção adversa e risco moral. O primeiro ocorre porque o agente pode alegar possuir determinadas habilidades, mas o principal não pode verificá-las antes de contratá-lo. Nesse caso, o principal só pode conhecer o produto do trabalho do agente, mas não sabe se este produto é o mais apropriado do ponto de vista dos seus interesses, tendo em vista desconhecer quais são suas reais habilidades. O segundo ocorre exatamente porque o principal não pode observar diretamente o trabalho/ação do agente. Nesse caso, não se sabe se o agente está se esforçando adequadamente para cumprir suas tarefas ou se esquivando do trabalho. Essas questões estão na raiz do problema de congruência de objetivos decorrente do comportamento disfuncional dos gestores. Para lidar com esse problema a literatura aponta, basicamente, duas soluções possíveis: investir em sistemas de monitoramente ou contratar o agente com base no produto/resultado do seu trabalho.

No modelo básico de agência, como o resultado (output) da firma depende do esforço do agente e de um componente aleatório, para cada unidade de esforço é esperada uma produtividade marginal. $\mathrm{O}$ esforço e o componente aleatório do resultado não podem ser observados pelo principal, mas a produtividade sim. A teoria considera que, sendo contratável, o output gerado pelo esforço do agente é uma medida de desempenho objetiva. Para evitar que o agente se esquive do trabalho e forneça um nível inadequado de esforço, o principal pode recompensá-lo com base em sua produtividade. Esse modelo de contrato faz com que compensação e avaliação de desempenho sejam explicitamente relacionadas, tornando o pagamento do agente sensível ao seu desempenho (BRICKLEY et al, 2007). Por outro lado, essa configuração contratual impõe risco ao agente porque sua compensação passa a ser função do componente aleatório. Assumindo que o agente é avesso ao risco, o principal deverá recompensá-lo diferencialmente pelo risco imposto, gerando um alto custo de agência. Por isso, a mensuração de desempenho é uma questão saliente na teoria da agência (BAKER, 2002; LAMBERT, 2007) e sua escolha é uma importante etapa na definição do sistema de incentivo e recompensa da empresa (BANKER e THEVARANJAN, 2000).

Além de fazer frente aos custos de agência, o principal assume o papel de suprir capital, suportar risco e desenhar sistemas de recompensas por meio da escolha de mecanismos de avaliação e mensuração de desempenho, bem como da especificação da função que definirá a base sob a qual o agente será recompensado (LAMBERT, 2007). A tarefa de desenhar o sistema de recompensa torna-se mais complexa quando o agente enfrenta o desafio de 
alocação ótima de esforço em múltiplas tarefas. Nessa situação, a importância relativa colocada em diferentes mensurações de desempenho é determinada pela razão sensibilidade/ruído e por sua congruência (LAMBERT \& LAKER 1987; BANKER \& DATAR 1989; BUSHMAN \& INDJEJIKIAN, 1993; SLOAN, 1993; FELTHAM e XIE 1994; INDJEJIKIAN, e PENNO, 2000; DATAR, KULP e LAMBERT 2001; BUDDE 2007; LAMBERT 2007). Precisão se refere ao ruído (variância) e está relacionada ao componente aleatório da mensuração de desempenho (FELTHAM e XIE 1994). Sensibilidade mede a mudança no valor esperado da mensuração quando o nível de esforço do agente muda (BANKER e DATAR 1989).

A congruência promovida pela métrica de desempenho é um dos aspectos que mais interessa na formulação de contratos, pois tem efeito direto na intensidade de alocação de esforço entre as tarefas e na distorção da avaliação de desempenho. A literatura profissional em contabilidade gerencial costuma definir congruência em termos dos objetivos dos sistemas de controle gerencial. Nesse sentido, é rotulada como congruência de objetivos e se refere à compatibilização entre os interesses dos gestores com os interesses da empresa (ANTHONY e GOVINDARAJAN, 2002; ANTHONY e YOUNG, 2003; HORNGREN, DATAR e FOSTER, 2003; KAPLAN \& NORTON). A falta de congruência entre os objetivos do gestor e os objetivos da empresa é um exemplo clássico de problema de agência.

Segundo Yuan e Yu (2005), apesar de não existir uma uniformidade no conceito de congruência entre os trabalhos analíticos sobre agência, na linguagem mais teórica e formal ela é vista como uma característica esperada da mensuração de desempenho e se refere ao grau de correspondência entre o impacto da ação do agente sobre a medida de desempenho e o payoff esperado pelo principal. Em outras palavras, congruência ou congruidade é o grau com que a mensuração de desempenho reflete adequadamente o impacto da ação do agente.

Segundo Maedler (2008), a congruência envolve um tradeoff entre a intensidade e a alocação de esforço quando o principal pode escolher entre mais de uma alternativa de ação. Sua adequação depende fundamentalmente das medidas de desempenho que estão disponíveis para formulação de contratos. A intensidade se refere ao quanto dos esforços não revelados (escondidos) um agente fornece ao principal. Alocação se refere ao modo como ele distribui seu esforço entre as diversas tarefas. 
De acordo com Holmstrom (1979), a congruência está relacionada ao problema do risco moral na relação contratual da firma e pode surgir quando indivíduos se envolvem em partilha de riscos em condições tais que suas ações privadas afetam a distribuição de probabilidade do resultado gerado. A fonte desse problema é a assimetria de informação em função das ações do agente não poderem ser completamente observadas pelo principal. Nesse cenário, ainda de acordo com Holmstrom (1979), a solução natural para esse problema seria investir recursos para monitoramento e utilizar esta informação na formulação de contratos. Porém, nem sempre é viável o monitoramento completo, ou porque é impossível, ou é proibitivamente caro, conforme já explicitado anteriormente. Em muitas situações, o centro de interesse passa a ser o uso de estimadores imperfeitos das ações do agente.

A congruência depende fundamentalmente das métricas de desempenho que estão disponíveis para fins de contrato (BAKER, 1992). Dado que as ações e as habilidades do agente não podem ser diretamente observadas, a teoria da agência postula que os contratos devem ser estabelecidos com base em medidas de desempenho passíveis de verificação direta pelo principal e que concilie sensibilidade, precisão e congruência. No entanto, Lambert (2007) considera que num ambiente onde o agente é responsável por uma única tarefa, mantendo constantes os demais fatores, é preferível medidas de desempenho com ampla sensibilidade para as ações dos agentes, mas com baixo ruído (alta precisão). Todavia, essa preferência se torna mais complicada num ambiente de múltiplas ações, onde a congruência deve ser levada em conta, tendo em vista que, nesse caso, o interesse maior é a questão da intensidade e alocação de esforço entre as tarefas, e a distorção da mensuração de desempenho.

Distorção da mensuração de desempenho se refere à extensão com que o produto marginal da ação do agente em relação à métrica de desempenho difere do produto marginal de suas ações com respeito ao valor da empresa. Nesse sentido, é o inverso da congruência (ZHOU, 2006). A mensuração de desempenho terá baixa congruência se as ações do agente forem capazes de aumentá-la (ampliando o seu pagamento), mas ao mesmo tempo não afetar ou afetar negativamente o valor da empresa. Sendo assim, sensibilidade e precisão importam porque indicarão a extensão do incentivo que será fornecido ao agente (ABERNETHY et al, 2008).

Ao analisar teoricamente o papel da mensuração de desempenho em influenciar a direção e a intensidade do esforço do agente em um ambiente de múltiplas tarefas, Feltham e Xie (1994) concluem que uma mensuração perfeitamente congruente irá induzir o esforço à melhor 
direção, mas só será utilizada para induzir à melhor intensidade se não for ruidosa, ou seja, se for precisa. O ruído na mensuração cria risco para o agente e, por isso, ele deve ser compensado em função disso. $\mathrm{O}$ risco diz respeito à influência de fatores não controlados na mensuração de desempenho. Quanto mais sujeita à ação de fatores incontroláveis, mais ruidosa/imprecisa será a mensuração de desempenho. Sendo assim, segundo os autores, a falta de precisão enfraquece o sistema de incentivo que é usado.

Lambert e Larcker (1988) testaram empiricamente a associação entre sensibilidade e ruído ao examinarem se o uso relativo de dois sinais distintos (valor da ação ou desempenho de mercado e medidas contábeis) na mensuração de desempenho dos executivos está relacionado com a quantidade de ruído inerente aos dois sinais e a "sensibilidade" desses sinais para ações gerenciais. De acordo com os autores, os resultados são consistentes com a hipótese de que as empresas colocam relativamente mais peso sobre o desempenho de mercado (e menos peso sobre o desempenho contábil) nos contratos de compensação nas seguintes situações: $i$ ) a variância da mensuração contábil é relativamente elevada em relação à variação na mensuração do desempenho de mercado; ii) a empresa está experimentando altas taxas de crescimento em ativos e vendas; e iii) o valor das participações pessoais dos executivos nas ações de sua empresa é baixo.

De acordo com Gibbs et al(2009), para estreitar o foco da avaliação de desempenho e reduzir o risco do agente, em concordância com a teoria, a empresa pode usar os números contábeis (que são uma medida mais precisa), em vez de uma mensuração forward-looking (que por natureza é uma medida mais ruidosa). Todavia, isso muitas vezes resulta em incentivos distorcidos tendo em vista que os números contábeis são mais sensíveis à ação discricionária do agente. Ele pode ser capaz de utilizar conhecimento privado e manipular a mensuração de desempenho para aumentar seu pagamento (afora da expectativa de payoff bruto do principal) sem melhorar o valor da empresa (GIBBS et al, 2009). Portanto, a congruência esperada é consequência do equilíbrio entre sensibilidade e ruído (LAMBERT e LAKER 1987; BANKER e DATAR 1989; BUSHMAN e INDJEJIKIAN, 1993; SLOAN, 1993, FELTHAM e XIE, 1994).

Quando uma medida de desempenho é falha de alguma forma, e não existe outra alternativa, a empresa pode passar para um sistema de múltiplas métricas visando proporcionar melhores incentivos globais ao agente (GIBBS et al, 2009). Pelo critério da informatividade discutido 
por Holmstrom (1979), considerando que a performance da empresa é afetada por outros fatores além das ações dos gestores (variáveis aleatórias exógenas que impõem riscos aos contratos), pode ser útil incluir mensurações de desempenho adicionais nos contratos desde que elas possam dizer (informar) alguma coisa sobre o comportamento do agente. Todavia, a principal finalidade de medidas adicionais é reduzir o risco que deve ser imposto ao agente. Porém, tais medidas só induzirão o seu esforço à melhor direção e intensidade se também forem congruentes (FELTHAM e XIE, 1994).

Lambert (2007) explica que quando múltiplas medidas de desempenho estão disponíveis, a questão de como combiná-las de modo que se alcance um nível congruência apropriado se torna importante. Se não houver uma ponderação adequada do peso que deve ser dado a cada uma das várias medidas conjuntamente utilizadas no sistema de mensuração de desempenho, as ações do agente serão direcionadas para melhorar aquelas medidas com mais importância relativa em detrimento de outras. Naturalmente, esse processo pode levar à inadequações na alocação de esforços (distorção) em diversas tarefas e prejudica o desempenho financeiro e econômico da empresa no curto e no longo prazo. Além disso, o contrato de incentivo e o sistema de ponderação das métricas de desempenho não devem apenas motivar a intensidade das ações do agente, mas também a alocação das mesmas de forma apropriada (ótima). Porém, conforme ensinam Datar et al (2001), esse problema é complicado porque nem todas as medidas de desempenho são igualmente sensíveis às várias dimensões das ações do agente.

Conforme esclarece Lambert (2007), ao avaliar se uma dada medida de desempenho é informativa, é importante considerar quais são as outras informações disponíveis. Geralmente, as medidas que decorrem de variáveis controláveis pelos gestores são prováveis candidatas à medidas informativas, embora outras variáveis também possam ser úteis, particularmente aquelas que fornecem informações sobre o componente aleatório do resultado (LAMBERT, 2007). Esse aspecto leva ao que é considerada uma das principais questões vinculada à congruência da mensuração de desempenho em muitos estudos analíticos em agência: o tradeoff entre risco versus incentivo (HOLMSTROM, 1979; BANKER e DATAR, 1989; FELTHAM XIE, 1994; DATAR, KULP e LAMBERT 2001; BAKER, 2002; BUDDE, 2006), que consiste basicamente na escolha entre obter mais benefícios com o maior esforço do agente contra o custo de pagamento de maiores compensações. Quanto maior o risco imposto ao agente, maior será o custo do incentivo. Segundo a teoria da agência, o risco tem 
correlação com as incertezas do ambiente. Quanto mais incerto for o ambiente, mais custoso será incentivar o agente com base no seu desempenho.

Segundo Prendergast (1999), existe uma considerável literatura empírica procurando testar o tradeoff entre risco e incentivos a partir da premissa de que recompensar pelo desempenho aumenta o resultado, mas à custa da imposição de risco para o agente. Como consequência, isso implica salários mais elevados. Prendergast (1999) evidencia que essas pesquisas procuram avaliar se $i$ ) os incentivos baseados em resultado melhoram o desempenho do empregado; e ii) os tipos de contratos existentes variam em função da variância da métrica de desempenho adotada (essa questão está relacionada ao problema da distorção na mensuração do desempenho, ou seja, a importância dada à mensuração de desempenho varia em função da sua distorção?). Ainda segundo o autor, há muitas evidências sugerindo a existência de associação entre os resultados gerados pelos agentes e a utilização de contratos de incentivo baseados em desempenho, mas os indícios sobre a correlação entre o pagamento de incentivo e a distorção da mensuração de desempenho ainda são inconsistentes.

De acordo com Banker (2002), em muitos contratos a questão central não é o risco e sim a distorção na mensuração de desempenho que pode induzir ao pagamento de compensação por esforço alocado de forma não ótima. Esse problema, de fato, tem sido o grande foco da literatura de agência em ambiente multitarefa (BANKER, 2002). A importância relativa dada à métrica de desempenho deve ser função da sua capacidade de evitar recompensar o comportamento errado e não da sua capacidade de evitar risco do agente. Sendo assim, conforme prediz a teoria de agência, em ambiente multitarefa, os contratos de compensação ideais colocam menos peso sobre mensurações de desempenho distorcidas, a fim de melhorar a eficiência (congruência) na alocação dos esforços do agente entre as tarefas (BAKER, 1987 e 2002; ZHOU, 2006).

Feltham e Xie (1994) argumentam ainda que num ambiente de múltiplas tarefas, o problema do comportamento disfuncional (incongruente) sempre existirá tendo em vista que nenhum contrato será suficientemente completo para mensurar e controlar adequadamente todas as dimensões do desempenho do agente. A inclusão de medidas informativas adicionais pode ajudar em certas circunstâncias, mas não elimina o problema. Pelo contrário, conforme argumenta Prendergast, (1999), nesse caso o risco de distorção será maior tendo em vista que o agente tenderá a dar respostas disfuncionais ao incentivo oferecido, procurando priorizar 
aqueles aspectos do desempenho que estão sendo recompensados. Contudo, conforme defende Lambert (2001), uma solução para o problema de incongruência da medida de desempenho é complementá-la com outra que seja mais sensível à ação desejada do agente da maneira mais congruente possível.

A congruência é um tema de muito interesse na literatura de agência haja vista o grande número de trabalhos teóricos que se debruçam sobre essa questão (BANKER e DATAR 1989, FELTHA e XIE 1994; BUSHMAN, INDJEJIKIAN, e PENNO, 2000; DATAR, KULP e LAMBERT 2001; BAKER 2002; YUAN e YU, 2005; BUDDE 2007, GIBBS et al, 2009). Esses trabalhos, de vários modos, tentam avaliar os efeitos do desalinhamento das medidas de desempenho com o objetivo do principal.

Como pode ser visto, a congruência, em combinação com sensibilidade/precisão, é uma característica fundamental da mensuração de desempenho. Isso porque ela sinaliza o impacto da ação do agente. Por exemplo, em relação às decisões intertemporais, a mensuração de desempenho congruente indicará em que extensão a decisão de alocação de esforço dos gestores irá refletir as ações de longo prazo. Nesse caso, se o objetivo é a maximização do valor da empresa, existirá problema de congruência se a mensuração de desempenho for mais sensível às ações de curto prazo, pois ela estará incentivando o comportamento míope (disfuncional) e a destruição de valor.

\subsection{Contratos de Incentivo e Mensurações Forward-Looking}

Conforme esclarecem Dechow e Sloan (1991), os esquemas de compensação geralmente contêm provisões de incentivos, que relacionam a compensação do empregado ao desempenho de curto e de longo prazo da empresa, destinadas a encorajar os gestores a maximizar o valor da firma. De acordo com Baril (1986), os esquemas de incentivo contingentes ao desempenho de longo prazo podem influenciar o comportamento gerencial e ajudar a redirecionar o foco dos gestores para objetivos além do curto prazo. Alguns estudos têm documentado os efeitos da adoção de contratos amarrados à métrica de desempenho de longo prazo na variação da riqueza dos proprietários e nas decisões de gastos de capital e outros gastos discricionários de longo prazo (LARCKER, 1983; BRICKLEY et al, 1985; BARIL, 1986; CHENG, 2004; Xu, 2009). 
Larcker (1983) examinou empiricamente a associação entre a adoção de contratos de incentivo e mudanças no nível de investimento de capital na empresa. Ele documentou que as empresas de adotavam contratos pautados em planos de desempenho de longo prazo experimentaram um aumento estatisticamente significativo do investimento de capital após a aprovação do plano, além de uma reação positiva do mercado de capitais quando a adoção do plano foi divulgada.

Em consonância com o trabalho de Larcker, Baril (1986) também encontrou evidências sobre a associação entre planos de longo prazo e níveis de gastos de capital. Na pesquisa realizada por esse autor, foi encontrada associação estatística entre adoção de planos de compensação de longo prazo e aumentos inesperados nos níveis de gastos de capital durante o ano de adoção e nos dois anos seguintes.

Gaver e Gaver (1995) identificaram uma associação entre o conjunto de oportunidades de investimento e as práticas de compensação das empresas que negociam ações em bolsa. Empiricamente, eles encontraram que parte significativa da remuneração dos executivos de empresas em crescimento decorre dos planos de incentivo de longo prazo. Os autores concluíram que a maior assimetria de informação entre acionista e gestor leva as empresas a enfatizar contratos de incentivo de longo prazo a fim de motivar os gestores a agir no interesse de seus acionistas. Segundo os autores, os resultados da pesquisa são consistentes com a hipótese de que esse tipo de contrato motiva os gestores a tomarem medidas que procuraram e exploraram novas oportunidades de investimento.

No entanto, planos de incentivo de longo prazo funcionam bem quando não existe o problema de horizonte de tempo no emprego e se espera que o gestor permaneça na empresa durante um longo período de tempo. Todavia, quando o horizonte no emprego é curto, a questão é: como motivar o agente a investir em projetos com retornos de longo prazo, quando ele não tem direito sobre os mesmos já que não estará na firma quando tal retorno ocorrer?

O principal meio de lidar com a visão de curto prazo dos gestores tem sido a formulação de contratos de incentivo que suplementam o lucro contábil com outras medidas que levam em consideração as consequências futuras das ações contemporâneas dos agentes (FELTHAM e XIE 1994; DIKOLLI e VAYSMAN, 2006). Dikolli e Vaysman (2006) explicam que existem duas possibilidades de prover os gestores com incentivos para alocar esforço em ações de 
longo prazo: compensá-los com base em mensurações de desempenho forward-looking, ou com base no retorno das ações.

De acordo com Dikolli (1998) mensurações de desempenho forward-looking são métricas que refletem direcionadores do desempenho futuro da empresa. Para Hang (2006), essas medidas servem para ajustar o retorno do investimento futuro com as despesas geradas pelo investimento atual, sendo, portanto, útil para o propósito de mitigar o comportamento disfuncional dos gestores em relação às decisões míopes de alocação de recursos.

Dikolli (2001) aponta que tendências recentes na avaliação de desempenho sugerem o crescimento do uso de medidas que refletem direcionadores de desempenho futuro. Estas medidas incluem métricas não financeiras e financeiras de natureza forward-looking. $\mathrm{O}$ autor desenvolve um modelo teórico para explicar as condições econômicas que criam uma demanda por medidas dessa natureza, com e sem um contexto de mercado de capitais. Dikolli (2001) postula que quando o empregado tem um longo horizonte de tempo no emprego, contratos de incentivo ótimos deverão colocar menos peso em mensurações forward-looking, pois, nesse caso, seus objetivos já estão alinhados com os objetivos dos proprietários. Sendo assim, estabelecer contratos com base em medidas contemporâneas e planos de desempenho de longo prazo pode ser suficiente para garantir que o agente aloque esforços para ações que aumentam a rentabilidade da empresa no futuro. Todavia, segundo o autor, a demanda por mensurações forward-looking, ou mensurações de desempenho de longo prazo, depende mais da sensibilidade e do ruído dessas medidas.

Por outro lado, quando o horizonte de tempo no emprego do agente é de curto prazo, Dikolli (2001) argue que o uso de mensurações forward-looking em contratos, em relação às recompensas convencionais pautados no desempenho financeiro contemporâneo, pode ser uma maneira mais custo-efetiva e oportuna de incentivar os esforços por ações que levam em conta o desempenho futuro da empresa e ajuda a mitigar o problema de engajamento do agente em comportamento míope, porque pode induzir a alocação de esforço de forma mais eficiente entre as atividades com efeito de curto prazo e longo prazo. Portanto, o autor assume explicitamente que a importância dada à mensuração forward-looking depende do horizonte de tempo do agente. 
Farrell et al (2008) encontram evidências de que o efeito da incorporação de mensurações forward-looking em contrato de incentivo depende do horizonte de tempo do empregado. Os autores conduziram um experimento em que compararam o esforço sobre as ações de longo prazo entre empregados com horizonte de tempo curto e àqueles que tinham horizonte longo, submetidos a dois tipos de contratos: forward-looking ou contemporâneos. Os resultados indicaram claramente que o uso do contrato forward-looking, em oposição ao contrato contemporâneo, tem um efeito maior sobre os esforços de longo prazo em empregados com curto horizonte de tempo no empresa.

Adicionalmente, Farrell et al (2008) identificaram que, além de servir como instrumento para mitigar problemas de agência, o uso de mensuração forward-looking em contratos também cumpre uma ação gerencial importante quando o horizonte de tempo do empregado na empresa é longo. Os autores encontraram evidências de que a incorporação desse tipo de métrica pode desempenhar o papel de influenciar e facilitar a tomada de decisão, melhorando o desempenho gerencial, pois contratos com mensuração forward-looking, de forma mais explicita, clarifica para os agentes a maneira mais apropriada de alocar esforços através de múltiplos períodos e múltiplas atividades, simplificando o processo cognitivo de decisão.

Num outro experimento, Berger (2009), considerando a situação onde os agentes não tinham problema de curto horizonte de tempo no emprego, investigou como os diferentes contratos de incentivo que incluem objetivos contemporâneos e objetivos forward-looking motivam os gestores a tomar decisões congruentes com os objetivos de longo prazo da organização, quando lidam com tarefas de complexidade variável (alta, média e baixa). Os resultados apresentados por Berger (2009) mostraram que, em situação de tarefa de baixa complexidade, os indivíduos têm melhor desempenho quando apenas o objetivo contemporâneo é recompensado no contrato de incentivo em relação à situação onde tanto o objetivo forwardlooking quanto o contemporâneo são recompensados. Por outro lado, no caso de tarefas de alta complexidade, os indivíduos têm melhor desempenho quando ambos objetivos são recompensados, mas somente na situação em que é dado maior peso à meta contemporânea. Ou seja, o estudo sugere que o efeito da mensuração forward-looking na alocação de esforço tem mais dependência da complexidade da tarefa.

Dikolli e Vaysman (2006) explicam que quando se formulam contratos de incentivo diretamente sobre medidas forward-looking devem ser considerados fatores tais como: custo 
de produção da medida, timing, confiabilidade, efeitos específicos sobre as ações gerenciais e o efeito do ruído inerente no comportamento gerencial. Além disso, o modelo teórico proposto Dikolli (2001) sugere duas propriedades importantes das mensurações de desempenho forward-looking que explicam a sua utilidade potencial em contratos: $i$ ) elas podem substituir métricas de curto e longo prazo para induzir de forma mais eficiente o esforço de longo prazo do agente, levando ao aumento da riqueza do principal, e ii) elas podem resolver o problema de miopia do agente.

Portanto, tanto os estudos teóricos quanto os empíricos sugerem que mensurações de desempenho de natureza forward-looking têm propriedades que interassam para fins de contrato. No entanto, a definição de qual tipo de mensuração forward-looking utilizar dependerá do tipo de problema que está sendo abordado.

\subsection{O Lucro Econômico Visto como uma Mensuração Forward-Looking}

O conceito de lucro econômico derivado da microeconomia, de acordo com Scapens (1978), difere do conceito de renda econômica usualmente utilizada no debate contábil sobre o lucro e sua mensuração. Segundo o autor, na teoria microeconômica, o lucro econômico é definido como o excesso de benefícios sobre os custos das atividades produtivas em cada período quando todos os custos relevantes são mensurados em termos de seus custos de oportunidade. Por sua vez, a renda econômica é produto do capital e deriva do valor presente dos futuros fluxos líquidos de caixa (benefícios futuros esperados) da empresa. Todavia, o conceito econômico de lucro guarda uma forte relação formal com o conceito neoclássico de renda econômica ${ }^{5}$.

A origem do conceito de lucro ou renda econômica está associada aos estudos sobre juros, capital e renda dos economistas Irving Fisher (1867-1947) e John Richard Hicks (19041989). Ao longo dos anos o conceito de capital e renda desenvolvidos por eles tem sido a base para a definição e mensuração do lucro na contabilidade. É a partir das proposições desses economistas que capital é definido como o valor presente dos fluxos de caixa líquidos futuros, e renda econômica representa o montante que pode ser consumido em um período sem diminuir o valor econômico do capital. Especificamente, Fisher (1930) definiu a renda

\footnotetext{
${ }^{5}$ Neste trabalho, ambos serão tratados como sinônimos.
} 
econômica como o fluxo de serviços gerado pelo capital através do tempo. Segundo Most (1982), o conceito de renda de Fisher está associado à ideia de valorização do capital visto como a soma de uma série de receitas líquidas futuras descontadas, ou a diferença entre o valor presente do fluxo de caixa líquido futuro em dois pontos distintos no tempo. Com incerteza, mudanças no valor atual poderiam também resultar de outros fatores, como a revisão da estimativa das receitas futuras. Sob esta abordagem, o lucro econômico pode ser pensado como o resultante da mudança do valor corrente dos ativos e passivos ao longo do tempo (STERLING, 1979; KIDA e HICKS, 1986; GUERREIRO, 1989; LEWIS e PENDRILL, 2004).

Originalmente, o conceito de renda apresentado por Fisher (1930) diz respeito à renda individual, sendo definida como uma série de eventos experimentados pelas pessoas. Disso deriva o conceito de renda prazer (psíquica). Para Fisher (1930) renda, na verdade, corresponde a tudo aquilo que o ser humano pode consumir e ter prazer. Todavia, como essa forma de renda é abstrata e não pode ser medida diretamente, o autor avança para o conceito de renda real, que se refere aos eventos físicos finais externos (meio de vida) que propiciam os prazeres internos para os indivíduos. Por último, o autor expõe a ideia do custo de vida como uma forma de mensurar monetariamente a renda real. Fisher (1930) considera que o custo de vida total (significando os pagamentos monetários daquilo que o indivíduo consome para ter prazer) é um item negativo, representa mais um gasto que renda propriamente, mas é a melhor medida prática dos itens positivos de renda real.

De acordo com Fisher (1930), renda prazer, renda real e custo de vida são três estágios distintos de renda que são paralelos entre si, mas não estão exatamente sincronizados no tempo. Nesse sentido, o autor chama a atenção para o fato de que a única discrepância temporal que realmente importa é a que ocorre quando o dinheiro gasto não é para o uso temporário atual de algum objeto, mas para todos os seus possíveis usos futuros. A verdadeira renda periódica de tais objetos é, aproximadamente, equivalente ao custo dos serviços prestados por eles em cada período. Por isso, o cálculo da renda deveria sempre considerar o valor dos serviços e nunca o valor dos objetos prestadores desses serviços.

Além dos já citados, Fisher (1930) avança mais um degrau na sua definição de renda. Como visto, o custo de vida corresponde aos pagamentos monetários para bens de consumo. No entanto, segundo o autor, o dinheiro que o indivíduo recebe para fazer frente aos seus gastos 
representa sua renda monetária. Nas palavras de Fisher (1930), a renda monetária individual inclui todo o dinheiro recebido que não é destinado a reinvestimento. Isso quer dizer que nesse conceito de renda está incluído apenas o dinheiro recebido, prontamente disponível e destinado a ser gasto. $\mathrm{O}$ excedente de renda monetária em relação à renda real é investimento e irá ajudar a fazer frente ao custo de vida futuro. Nesse caso, a renda futura descontada (capitalizada) será capital (bens de capital) e a ligação entre ambos (renda e capital) se dá através da taxa de juros. Convém notar, nesse ponto, que a renda real poderá ser menor, igual ou maior que a renda monetária. Sendo assim, Fisher (1930) pondera que o conceito apropriado de renda, para satisfazer tanto a teoria econômica quanto a prática contábil, deve considerar como renda, no seu sentido mais elementar, todos os usos, serviços ou usufrutos gastos como custo de vida, mesmo que esses gastos sejam superiores à renda monetária.

Em síntese, para Fisher (1930) a renda possui três estágios sucessivos:

- Renda prazer ou subjetiva (ou psicológica): que consiste nas experiências ou sensações agradáveis que os indivíduos podem sentir. Representa uma entidade psicológica e, portanto, não pode ser medida diretamente;

- Renda objetiva ou real (medida pelo custo de vida): que representa o nosso meio de vida. Esta renda pode ser medida pelo custo de vida, que é a medida monetária da renda real; e

- Renda monetária: que representa o dinheiro recebido por uma pessoa para fazer frente ao seu custo de vida.

Para Fisher (1930), a renda monetária é a mais familiar para as pessoas, a renda prazer é a mais fundamental, e a renda real é a mais prática para fins contábeis. Além disso, a renda deriva dos bens de capital, mas o valor da renda não deriva do valor dos bens de capital. Por outro lado, o valor do capital é derivado do valor da renda.

Para Fisher (1930), até que se saiba quanta renda um bem de capital fornecerá, não é possível estabelecer nenhuma avaliação desse capital, pois o valor presente de qualquer bem é o que os compradores estão propensos a dar e os vendedores estão dispostos a aceitar por ele. Porém para a decisão de quanto dar e aceitar pelo bem é necessário conhecer com antecedência qual o valor estimado dos benefícios futuros que o bem produzirá e a taxa de juro estimada pela qual esses valores futuros poderão ser descontados e trazidos a valor presente. Demais a mais, 
Fisher (1930) considera que o custo de produção de bens de capital, como qualquer custo, é um item negativo futuro de renda e, como tal, deve ser descontado como se fosse um item positivo futuro. $\mathrm{O}$ autor argumenta ainda que, em determinado ponto do tempo, quando o valor está sendo computado, apenas os custos futuros podem entrar na avaliação de um bem. Custos passados não têm influência direta sobre o valor, e o valor de um bem de capital é o valor descontado dos seus serviços futuros.

Por seu turno, Hicks (1946), também inicia seu conceito de renda a partir da renda individual e diz que esta é o fluxo constante de receitas/ganhos, mantidas inalteradas as condições econômicas (taxa de juro e preços), que se espera receber ao longo do tempo, e o seu cálculo serve para indicar quanto a pessoa pode consumir sem empobrecer. Em outras palavras, segundo o autor, o significado central da renda do indivíduo é o valor máximo que ele pode consumir durante um período e ainda esperar que sua situação econômica no final do período seja a mesma do começo. No entanto, segundo Hicks (1946), se as condições econômicas não se mantiverem inalterada ao longo do tempo (por exemplo, com mudança da taxa de juro e variação de preços), esse conceito central pode ser empregado através de três aproximações, a saber:

- Renda N..$^{\circ} 01$ : representa a quantia máxima que se pode gastar durante um período, quando há uma expectativa de manter inato o valor do capital, em termos monetários.

- Renda N..$^{\circ}$ 02: representa a quantia máxima que o indivíduo pode gastar durante um período, e ainda espera poder gastar em cada período subsequente, mas com esperança de alteração na taxa de juros.

- Renda N. ${ }^{\circ}$ 03: representa a quantia máxima de dinheiro que o indivíduo pode gastar em um período, e ainda espera poder gastar, em termos reais, em cada período subsequente, quando se espera que os preços aumentem.

Hicks (1946) considera que nenhuma das três definições apresentadas representa uma boa aproximação do conceito central, pois tratam do quanto o indivíduo pode gastar e não consumir. A implicação disso é que se uma parte do gasto individual for destinada a aquisição de bens de consumo duráveis, isso fará com que o gasto seja maior que o consumo. Por outro lado, quando parte do consumo atual é o serviço de bens duráveis adquiridos em períodos passados, o consumo será maior que a gasto. Nesse caso, a única maneira de identificar se alguém está tão bem hoje quanto estava ontem é avaliando quanto ela destinou de sua riqueza 
para o consumo. Segundo Hicks (1946), somente quando a aquisição de novos bens de consumo é exatamente igual ao uso dos antigos é que se pode comparar o consumo com o gasto, e avaliar se o indivíduo continua hoje tão bem como estava ontem.

Hicks (1946) explica ainda que para calcular a renda é necessário descobrir um "fluxopadrão" de recebimentos cujo valor presente seja igual ao valor do fluxo de receitas efetivamente esperado. Isso consiste na suposição de que os montantes de receitas não variem no tempo, porém o montante de receita efetivamente esperado poderá variar. Então, a mensuração da renda, em todos os conceitos propostos (N. $.^{\circ} 01, N .^{\circ} 02$ e N. $\left.{ }^{\circ} 03\right)$, consiste na substituição de um fluxo de receitas efetivamente esperado por um fluxo-padrão, através de uma forma padrão definida, utilizando-se o pressuposto de que a renda é o quanto a pessoa receberia se fosse considerado um fluxo-padrão do mesmo valor presente que a receita efetivamente esperada. Nesse caso, uma expectativa de aumento nessas receitas futuras, provocará um aumento no valor presente da expectativa de fluxo de receitas efetivamente esperado, tornando-o maior que o valor presente de seu antigo fluxo-padrão. Uma variação nas taxas de juros, além de provocar alteração no valor presente do fluxo de receita efetivamente esperado, provocará uma alteração no valor presente do antigo fluxo-padrão, provocando efeito sobre a renda.

Uma observação feita por Hicks (1946) merece ser destacada. De acordo com o autor, a definição central de renda representa uma mensuração ex ante, pois se refere àquilo que se pode consumir durante um período, portanto, corresponde a uma expectativa. Caso a renda não seja efetivada conforme esperado, no final do período a expectativa será maior ou menor do que o previsto, de modo que se terá um ganho ou uma perda não prevista. Todavia, se esse ganho ou essa perda for acrescentado à renda ex ante, encontrar-se-á a renda ex post, e esta corresponderá ao valor do consumo do indivíduo mais acréscimo ou diminuição do valor monetário de sua perspectiva durante o período. Isso significa consumo mais acumulação (ou diminuição) de capital. Porém, como o objetivo do cálculo da renda é auxiliar o indivíduo a tomar decisões sobre o futuro, a renda ex post é irrelevante nesse sentido. Hicks (1946) postula que a renda relevante deve excluir ganhos imprevistos. Nesse caso, é preciso computá-los como um aumento de renda nos períodos futuros.

Vários autores extrapolam o conceito central de renda individual de Hicks para a firma. Por exemplo, Solomons (1961) diz que, com uma pequena modificação, esse conceito pode ser 
utilizado para mensurar a lucro da empresa. Nesse caso, o lucro da firma seria a quantia correspondente ao aumento do seu patrimônio líquido durante o período, ajustado pelos aumentos de capital feitos pelos proprietários e dividendos distribuídos. Edwards e Bell (1961) explicam que, na ausência de distribuição de dividendos e aporte de capital pelos proprietários, a mensuração do lucro da firma corresponde à diferença entre o valor presente das receitas líquidas futuras do final do período menos o valor presente das receitas líquidas futuras do início do período. Jaedicke e Sprouse (1972) definem o lucro da empresa como a importância máxima que poderia ser distribuída como dividendos aos acionistas sem diminuição dos recursos da firma.

Por sua vez, Guerreiro (1989) explica que, do ponto de vista econômico, capital é o valor descontado dos fluxos de caixa líquidos futuros e o lucro representa a quantia máxima que uma firma pode distribuir ao final do período e continuar tão bem quanto estava no início do período, mantendo o capital intacto. Guerreiro (1989) considera ainda que o lucro é gerado quando há um incremento no patrimônio líquido da empresa. Todavia, se quisermos calcular o lucro econômico como uma variação do patrimônio líquido, é preciso mensurar todos os ativos da empresa com base nos seus fluxos de caixa líquidos futuros esperados.

Hendriksen e Breda (1999) ensinam que a definição de capital como o fluxo de serviços futuros capitalizado e a renda como o uso desses serviços não permite confusão entre os dois termos. Todavia, sua aplicação para as empresas assume significados ligeiramente diferentes. Lucro é o resultado obtido com o uso do capital. Capital continua sendo estoque de riqueza capaz de gerar serviços futuros, porém lucro é o fluxo de benefícios acima do necessário para manter o capital constante. Além disso, no conceito e mensuração do lucro da empresa como um todo, o capital é formado por todos os recursos financeiros originados dos credores e acionistas, sendo o lucro o resultado obtido por todos os fornecedores de capital à empresa, incluído juros pagos a credores e os lucros distribuídos aos acionistas.

Muitos autores, ancorados nas ideias de Fisher (1930) e Hicks (1946), advogam que o lucro econômico nada mais é do que a variação na renda da empresa mensurada de um período para o outro e que, portanto, seu cálculo pode ser derivado do valor presente das receitas líquidas futuras esperadas. Na verdade, a mensuração do lucro econômico pode ser provinda tanto do valor presente líquido ou apenas do valor presente (VP). Elliott e Elliott (2011) explicam que o valor presente é uma técnica utilizada para valorar um fluxo de caixa no futuro ou para 
mensurar o valor monetário de um estoque de capital existente em termos de uma previsão $a d$ infinitum do fluxo de caixa. Essa técnica constitui a natureza do lucro e capital na teoria econômica que começou com Irving Fisher (1930) e que se consolidou com a ideia proposta por John Hicks (1946) de que o lucro ou renda econômica é aquilo que a firma ou o indivíduo pode consumir sem reduzir seu estoque de capital de modo que esteja tão bem hoje quanto estava ontem.

Sendo assim, Besanko et al (2009) esclarecem que o conceito de lucro econômico pode ser pensado como uma mensuração anualizada do valor presente líquido (VPL) da empresa, pois operacionalmente o cálculo dessas métricas são semelhantes. Especificamente na situação onde o fluxo de caixa periódico é constante e o investimento tem vida útil infinita, o VPL da empresa corresponde ao valor presente do lucro econômico gerado pelos investimentos durante seu tempo de vida. Segundo os autores, essa situação é válida inclusive no caso em que os fluxos de caixa não são constantes e/ou a vida útil do investimento é finita.

Kreitzman e Williams (2008) também associam o lucro econômico ao VPL da empresa. Para os autores, a firma é uma combinação de projetos de investimentos (portfólio de projetos) e os lucros econômicos auferidos por ela podem ser medidos pela comparação entre os investimentos e os fluxos de caixa gerados em suas operações. Nesse caso, é possível utilizar o método de fluxo de caixa descontado para derivar o lucro econômico da firma. Os autores explicam que, através desse método, um projeto ou o valor econômico de uma firma é o resultado do seu fluxo de caixa líquido e representa a diferença entre as receitas brutas menos os desembolsos relativos a todos os insumos consumidos nas operações, descontados pelo custo de oportunidade do capital investido e adicionado de qualquer valor residual ao final do projeto e os acréscimos de capital.

Kreitzman e Williams (2008) apresentam o seguinte exemplo para demonstrar que o lucro econômico pode ser derivado pelo método de fluxo de caixa descontado:

\footnotetext{
Considere um único projeto com uma vida finita que termina no período $T$, com todo fluxo de caixa ocorrendo no final do período $t$, onde $0 \leq t \leq T$. Nesse exemplo $\prod_{t}$ representa o lucro total do projeto no período $t$ e corresponde ao fluxo de caixa operacional menos a depreciação econômica. $R_{t}$ é o fluxo de caixa no período $t$, $I_{t-1}$ é o valor do capital mensurado no fim do período $t-1$ e no início de $t . \Delta I_{t}$ é a depreciação econômica ocorrida durante o período $t$, onde $\Delta I_{t}<0$. Supõe-se que não existem novos investimentos em qualquer período, o valor do capital no fim $t$ pode ser calculado como $I_{t}=\Delta I_{t}+I_{t-1}$, e a relação entre $\prod_{t}, \mathrm{R}_{t}$ e $\Delta_{t}$ é dada pela equação:
} 


$$
\prod_{t}=R_{t}+\Delta I_{t}
$$

Considerando um custo de oportunidade do capital $k$, que se assume ser constante no tempo, é possível calcular o lucro econômico $\pi_{t}$ no período t por:

$$
\pi_{t}=\prod_{t}-k I_{t-1}
$$

Substituindo-se (1) em (2) tem-se:

$$
\pi_{t}=R_{t}-k I_{t-1}+\Delta I_{t}
$$

Por outro lado, o valor total do lucro do projeto menos o valor do investimento inicial corresponde à definição tradicional do VPL, a saber:

$$
V P L=\sum_{t=1}^{T} \frac{R_{t}}{(1+k)^{t}}+\frac{I_{T}}{(1+k)^{T}}-I_{0}
$$

Onde $I_{0}$ representa o valor residual do investimento feito no início do projeto.

Agora, substituindo (1) em (4), tem-se:

$$
V P L=\sum_{t=1}^{T} \frac{\prod_{t}-\left(I_{t}-I_{t-1}\right)}{(1+k)^{t}}+\frac{I_{T}}{(1+k)^{T}}-I_{0}
$$

Usando a definição de lucro econômico em (2) é possível transformar (5) para:

$$
V P L=\sum_{i=1}^{T} \frac{\pi_{t}}{(1+k)^{t}}-\sum_{t=1}^{T} \frac{I_{t}}{(1+k)^{t}}+\sum_{i=1}^{T} \frac{I_{t-1}}{(1+k)^{t-1}}+\frac{I_{T}}{(1+k)^{T}}-I_{0}
$$

Cancelando-se o segundo, terceiro, quarto e quinto termos em (6), obtém-se:

$$
V P L=\sum_{i=1}^{T} \frac{\pi_{t}}{(1+k)^{t}}
$$

Quadro 1 - Derivação do Lucro Econômico pelo Método de Fluxo de Caixa Descontados - Exemplo 1 Fonte: Adaptado de Kreitzman e Williams (2008)

A partir da demonstração de Kreitzman e Williams (2008), o lucro econômico periódico do projeto pode ser calculado diretamente de (7), bastando multiplicar o VPL por $k$, ou então subtrair da receita líquida de $t$ a depreciação econômica, calculada como $V P L_{t}-V P L_{t-1}$. Desse modo, o lucro econômico do período poderia ser definido por:

$$
L E_{t}=\left(V P L_{t-1}\right) k
$$

ou então,

$$
L E_{t}=\pi_{t}-\left(V P L_{t}-V P L_{t-1}\right)
$$


Outro aspecto levantado por Kreitzman e Williams (2008), diz respeito à questão da depreciação do ativo base (investimento). Conforme fica evidenciado na fórmula padrão do VPL, o cálculo do lucro econômico independe da estimativa da depreciação econômica. Comparando-se (3) e (4), é possível observar que o lucro econômico $\pi_{t}$ depende do cálculo de $\Delta I_{t}$, que poderá sofrer erros de estimativas. Entretanto, o VPL não depende de medidas contábeis ou cálculo de depreciação econômica, pois a mensuração do lucro total do projeto é feita de forma mais direta. Conforme apresentado em (5), uma vez que o VPL definido é independente das estimativas de depreciação econômica, a fórmula em (7) evidencia que o valor presente do lucro econômico total do projeto é igual ao VPL. Então, as estimativas de depreciação econômica não afetarão o valor presente do lucro econômico total. Essa é uma diferença crítica entre derivar o lucro econômico do valor presente do lucro residual ${ }^{6}$ ex ante e do valor presente das receitas líquidas futuras esperadas. $\mathrm{O}$ valor presente dos lucros residuais futuros só será equivalente ao VPL se for adotado esquema apropriado de depreciação e mensuração do ativo base ao longo da vida útil desse investimento.

Magni (2008) também fornece uma demonstração para provar que o lucro econômico e o VPL sustentam uma forte relação formal. Para o autor, VPL e lucro econômico são nomes diferentes para a mesma ideia, e a maximização de um é equivalente à ideia de maximização do outro. O lucro econômico é a diferença entre o lucro factual que o empreendedor recebe e o lucro contrafactual que ele deveria receber se investisse em outro negócio alternativo. Para sustentar suas argumentações o autor apresenta a seguinte prova, a partir de uma situação hipotética de um único período que pode ser generalizado para $n$ períodos:

Considere $W^{0}$ o custo do investimento e $W^{1}$ o resultado final no tempo $1 . W^{1}-W^{0}$ é o lucro que pode ser reformulado como: $r W^{0} \operatorname{com} r=\frac{W^{1}-W^{0}}{W^{0}}$ sendo a taxa de retorno. Considere também $i$ a taxa relativa de retorno de um negócio alternativo e $W^{0}(1+i)-W^{0}=i W^{0}$ o custo de oportunidade dessa alternativa.

Logo, o lucro econômico $\pi$ é dado por:

$$
\pi=r W^{0}-i W^{0}
$$

O lucro econômico em (1) pode ser expresso como a diferença entre dois valores futuros, ou seja:

$$
\pi=W^{1}-W^{0}(1+i)
$$

Sob esta perspectiva $\pi$ corresponde ao VPL, dado pela expressão:

$$
V P L=-W^{0}+\frac{W^{1}}{1+i}
$$

Então, o lucro econômico apresenta uma forte relação formal com o VPL, pois o VPL é o valor presente de (1) ou

\footnotetext{
${ }^{6}$ A próxima seção apresenta uma nota sobre o uso do lucro residual em contratos de incentivo.
} 
equivalente ao valor presente de (2) conforme apresentado a seguir:

$$
N P V=\frac{r}{1+i}=\frac{1}{1+i}\left(r W^{0}-i W^{0}\right)
$$

Quadro 2 - Derivação do Lucro Econômico pelo Método de Fluxo de Caixa Descontados - Exemplo 2 Fonte: Adaptado de Magni (2008)

Na mesma linha que Kreitzman e Williams (2008) e Magni (2008), Demski (2008) também argui que o conceito de lucro econômico, derivado da teoria econômica, corresponde à variação no valor presente da empresa ou ao valor presente da sequência de futuras transações no caixa da empresa. Isso implica que todas as receitas e custos futuros são tratados em termos de seu valor presente. Com isso, o valor presente reflete o fluxo de caixa que ocorre além do período $t$. Então, no período $t$, o valor do fluxo de caixa que fica é simplesmente o $\mathrm{VP}_{t}$. Sendo assim, o lucro econômico da firma pode ser definido, também, como a mudança do valor presente do fluxo de caixa líquido mais o fluxo de caixa do período $t$, se for assumida as seguintes suposições:

- os fluxos de caixa futuros que são descontados são fluxos de caixa entre a firma e seus proprietários;

- a firma mantém zero caixa no balanço

- todo o investimento feito pelos proprietários é convertido em fatores de produção que poderão representar saída de caixa no período $t$ e além de $t$.

Para exemplificar seus argumentos Demski (2008) apresenta o seguinte caso:

Considere a situação de uma empresa que opera em apenas três períodos, utiliza três fatores de produção $\left(z_{1}, z_{2}\right.$ e $z_{3}$ ), fabrica dois produtos $\left(q_{1}\right.$ e $\left.q_{2}\right)$, onde os preços de mercado a vista dos fatores são $P_{1}, P_{2}$ e $P_{3}$, e os preço de mercado a vista de venda dos produtos são $\hat{P}_{1}$ e $\hat{P}_{2}$. O primeiro e o terceiro fatores são pagos no período $t=0$, e o segundo fator é pago no período $t=1$. O produto $q_{1}$ é produzido, vendido e recebido no período $t=1$ e o produto $q_{2}$ é produzido, vendido e recebido em $t=2$. Com base nessas informações, tem-se o seguinte fluxo de caixa:

Fluxo de Caixa para Múltiplos Períodos

\begin{tabular}{l|c|c|c}
\hline & $\mathbf{t = 0}$ & $\mathbf{t}=\mathbf{1}$ & $\mathbf{t}=\mathbf{2}$ \\
\hline Fator 1 & $-P_{1} z_{1}$ & & \\
Fator 2 & & $-P_{2} z_{2}$ & \\
Fator 3 & $-P_{3} z_{3}$ & $\hat{P}_{1} q_{1}$ & \\
Produto 1 & & & $\hat{P}_{1} q_{1}$ \\
Produto 2 & & $\hat{P}_{1} q_{1}-P_{2} z_{2}$ & $\hat{P}_{1} q_{1}$ \\
\hline Fluxo de Caixa Líquido $(\mathbf{F C})$ & $-P_{1} z_{1}-P_{3} z_{3}$ &
\end{tabular}

Com base nos dados da tabela acima, a empresa incorre no seguinte custo econômico $C$ total e receita total $R$, considerando uma taxa de desconto $r$ : 


$$
\begin{gathered}
C=P_{1} z_{1}+P_{2} z_{2}(1+r)^{-1}+P_{3} z_{3} \\
R=\hat{P}_{1} q_{1}(1+r)^{-1}+\hat{P}_{2} q_{2}(1+r)^{-2}
\end{gathered}
$$

Disso, tem-se o seguinte lucro econômico (I) no período $t$ :

$$
I_{0}=\hat{P}_{1} q_{1}(1+r)^{-1}+\hat{P}_{2} q_{2}(1+r)^{-2}-P_{1} z_{1}-P_{2} z_{2}(1+r)^{-1}-P_{3} z_{3}
$$

Isso posto, observa-se que o lucro econômico tem uma forte correspondência com VP do fluxo de caixa líquido futuro, dado por:

$$
V P_{0}=F C_{1}(1+r)^{-1}+F C_{2}(1+r)^{-2}
$$

Logo, pode-se reescrever o lucro econômico no período $t=0$ como:

$$
I_{0}=V P_{0}+F C_{0}
$$

Considerando os três períodos, tem-se:

Lucro Econômico Período a Período

\begin{tabular}{lc|r}
\hline & VPL DOS FLUXOS DE CAIXA & LUCRO ECONÔMICO \\
\hline $\mathrm{t}=0$ & $V P_{0}=F C_{1}(1+r)^{-1}+F C_{2}(1+r)^{-2}$ & $I_{0}=V P_{0}+F C_{0}{ }^{*}$ \\
$\mathrm{t}=1$ & $V P_{1}=F C_{2}(1+r)^{-1}$ & $I_{1}=V P_{1}-V P_{0}+F C_{1}$ \\
$\mathrm{t}=2$ & $V P_{2}=0$ & $I_{1}=V P_{2}-V P_{1}+F C_{2}$ \\
\hline$*$ como o & $F C_{o}$ é negativo e representa o investimento inicial feito pelos \\
proprietários, o lucro econômico no período $t=0$ corresponde ao cálculo padrão do \\
VPL.
\end{tabular}

Nesse exemplo, VP no período $t=2$ é zero porque a empresa encerra suas operações nesse momento. Desse modo, a soma do lucro econômico nos três períodos é igual à soma dos fluxos de caixa.

Quadro 3 - Derivação do Lucro Econômico pelo Método de Fluxo de Caixa Descontado - Exemplo 3 Fonte: Adaptado de Demski (2008)

Demski (2008) acrescenta ainda que o lucro econômico, significando a variação no valor presente do fluxo líquido de caixa futuro, representa o custo dos recursos disponibilizados à empresa. Nesse contexto, a taxa de juro r corresponde ao preço de mercado desses recursos e o $\mathrm{VP}_{\mathrm{t}}$ o seu montante. Ambos, geralmente, são bem conhecidos e isso torna o cálculo do lucro econômico, período a período, uma tarefa sem muita dificuldade.

Conforme explica Guerreiro (1989, p.190) “A principal tarefa na mensuração do lucro econômico consiste em comparar o valor capitalizado dos recebimentos líquidos futuros no início e no final do período. O lucro só aparece quando existe um incremento do valor capitalizado". Ainda de acordo com o autor, essa maneira de mensurar o lucro corresponde à quantia máxima que a empresa pode distribuir no final do período em forma de dividendos e ainda manter o capital intacto (igual ao que era no início do período). A mensuração conforme 
proposto nos quadro 1, 2 e 3 expressa bem essa abordagem. O lucro econômico, como equivalente à variação do VPL ou VP, é uma mensuração ex ante e serve como preditor da rentabilidade futura. Sendo assim, tem natureza forward-looking.

Por fim, conforme explica Scapens (1978), o objetivo de maximização do lucro econômico levará a decisões idênticas àquelas que conduziriam à maximização do valor econômico da firma. Com seu uso, o objetivo de maximização da riqueza econômica poderia ser alcançado por meio de uma política de maximização do lucro econômico em cada período. Segundo o autor, essa política irá levar os gestores a tomar as decisões compatíveis com a maximização do valor presente do fluxo de benefícios líquidos futuros. Por esta razão, deve ser dada cuidadosa atenção a essa métrica quando da escolha da medida de avaliação de desempenho e a formulação de sistemas de recompensa.

\subsection{Uma Nota Sobre o uso do Lucro Residual em Contratos}

Muitos autores têm advogado o uso do lucro residual ${ }^{7}$ em contratos de incentivo e na avaliação de desempenho, especialmente quando o foco são os centros de investimentos ou unidades descentralizadas da empresa (REICHELSTEIN, 1997 e 2000; ROGERSON, 1997 e 2008; DUTTA e REICHELSTEIN, 1999, 2002 e 2005; HOGAN e LEWIS, 2000; BASTIAN, 2005; HOGAN e LEWIS, 2005; PFEIFFER e SCHNEIDER, 2007). A alegação é que o valor presente do lucro residual é consistente com a regra do valor presente líquido dos fluxos de caixa futuro da empresa. No entanto, conforme explica Egginton (1995), é possível mostrar que o valor presente do lucro residual ex ante ao longo da vida útil de um projeto é igual ao valor presente líquido, mas a coerência periódica é alusiva e depende de cálculo do ativo base (investimento) e do esquema de depreciação adotado. A despeito das várias alternativas já apresentadas, o autor considera que a mensuração e o critério de depreciação do ativo base é um problema intratável, pois não existe um consenso sobre o método correto de calcular a depreciação desse ativo ${ }^{8}$.

Por ser supostamente consiste com o método do valor presente líquido, o principal argumento teórico em favor do lucro residual tem sido que ele é a única medida de desempenho capaz de

\footnotetext{
${ }^{7}$ O Economic Value Added - EVA é a métrica de lucro residual mais comumente utilizada na prática, segundo a literatura pesquisada.

${ }^{8}$ Note-se que com o lucro econômico, conforme discutido na seção 2.5, o problema da definição do ativo base e da depreciação deixa de existir.
} 
alcançar total congruência de objetivos entre os empregados e proprietários, pois ao recompensar para lucros residuais acima do custo do capital próprio, ela fornece o incentivo necessário para que os gestores foquem nas decisões operacionais e de investimentos que aumentam a riqueza da empresa (ROGERSON, 1997; REICHELSTEIN, 1997; REICHELSTEIN, 2000; REICHELSTEIN e DUTTA, 2005). Se o gestor for recompensado com base no lucro residual, o valor presente de seus bônus será proporcional ao valor presente líquido criado pelas suas decisões de investimento. Por isso, é esperado que o gestor escolha o nível de investimento que maximiza o valor presente líquido da empresa (SCHULTZE e WEILER, 2008).

Todavia, apesar de o lucro residual apresentar interessantes propriedades para sua incorporação em contratos de compensação, a principal crítica ao seu uso é o fato de que seu cálculo deriva de ajustes das demonstrações contábeis tradicionais. Segundo esclarece Wallace (1996), muitos dos defensores do lucro residual concordam que as informações contábeis são por demais conservadoras e backward-looking como proxy para as variáveis lucro e capital investido utilizadas no cálculo do lucro residual. Por natureza, o lucro residual é uma métrica contemporânea, pois ajusta o lucro contábil do período pela dedução do custo médio ponderado do capital sem levar em consideração o valor presente líquido do fluxo de benefícios futuros.

Além disso, Ezzamel (1979) explica que o fato do lucro residual utilizar mensurações contábeis tradicionais acarreta profundas implicações sobre sua utilidade, pois todos os vícios desse modelo de mensuração acabam implicitamente refletidos nessa métrica. $\mathrm{O}$ autor alega ainda que a maioria destas limitações pode ser evitada com o uso de modelos de fluxo de caixa descontado porque, em teoria, esses modelos provêem uma técnica mais apropriada para medir o desempenho. Adicionalmente, importa salientar que o lucro residual difere significativamente do conceito de lucro econômico que ele tenta se aproximar, tendo em vista que não considera as mudanças não realizadas nos ativos tangíveis ocorridas durante o período, tampouco o goodwill econômico (WALLACE, 1996). 


\section{METODOLOGIA}

O presente capítulo apresenta as hipóteses e os aspectos metodológicos da pesquisa. Descreve o desenho experimental, a tarefa realizada pelos participantes e os procedimentos de exploração e análise dos dados, bem como os procedimentos estatísticos utilizados para testar as hipóteses. Indica ainda a sensibilidade, o poder estatístico e o tamanho do efeito definidos a priori.

\subsection{Hipóteses}

Conforme discutido no capítulos 2 desse trabalho, alguns estudos analíticos e empíricos sugerem que mensurações de desempenho forward-looking possuem propriedades que importam quando o objetivo é incentivar o agente a alocar mais esforço em ações que influenciam a capacidade de criação de valor da firma no longo prazo. Dada a natureza forward-looking do lucro econômico, os indivíduos que receberem incentivo monetário com base nessa mensuração de desempenho irão agir de forma mais congruente com os objetivos de longo prazo da firma, mesmo na presença do problema do horizonte. No contexto da presente pesquisa, isso implica que os agentes recompensados com base no lucro econômico irão se esforçar mais alocando mais recursos em ações que afetam o desempenho futuro da empresa. Considerando que o esforço é um construto multidimensional (LIBBY e LIPE, 1992; BONNER e SPRINKLE, 2002), as seguintes predições podem ser formuladas:

H1 (a) - o tempo dedicado às ações de longo prazo será maior quando os indivíduos estiverem subordinados ao contrato de incentivo contingente ao lucro econômico;

H1 (b) - a intensidade do esforço dedicada às ações de longo prazo será maior quando os indivíduos estiverem subordinados ao contrato de incentivo contingente ao lucro econômico; e

H1 (c) - o montante de recursos financeiros alocado nas ações de longo prazo será maior quando os indivíduos estiverem subordinados ao contrato de incentivo contingente ao lucro econômico.

De acordo com Bonner et al (2000), o incentivo monetário motiva o aumento do esforço promovendo a melhoria no desempenho na realização das tarefas. Por outro lado, as métricas 
forward-looking podem facilitar o processo de tomada de decisão, clarificando para os agentes as estratégias que eles devem adotar para maximizar os objetivos de longo prazo da empresa (FARREL et al 2008). Então, considerando esses dois aspectos, é possível predizer que, no contexto desta pesquisa, o uso do lucro econômico irá melhorar a qualidade das decisões de investimentos nas ações de longo prazo. Com base nisso, é formulada a seguinte hipótese:

H2 - o desvio entre a decisão de investimento tomada pelos dos indivíduos e as decisões ótimas de investimento da empresa será menor quando eles estiverem subordinados ao contrato de incentivo baseado no lucro econômico.

As hipóteses formuladas foram testadas através de um experimento em laboratório desenvolvido especificamente para esse fim. A opção pelo método experimental se justifica, pois, segundo Gall et al (2006), esse recurso metodológico fornece o mais rigoroso mecanismo para realização de estudo de causalidade, além de permitir investigar questões que são difíceis de tratar com dados de campo (SPRINKLE e WILLIAMSON, 2007).

O experimento utilizado foi baseado numa simulação que tenta representar um modelo básico e simplificado do mundo real envolvendo a decisão de alocação de recursos em ações contemporâneas que afetam o desempenho da firma no longo prazo, considerando as seguintes suposições: o proprietário (principal) delega as escolhas dos investimentos (esforço) para o gestor (agente). Este último, por sua vez, exercerá um nível de esforço que aumentará ou diminuirá o fluxo líquido de caixa futuro da firma. Assume-se que os gestores são mais bem informados que o proprietário sobre as oportunidades de investimentos, e que eles têm informações privadas sobre o seu comprometimento em relação à tarefa contratada, mas os proprietários não têm como observar diretamente o esforço do gestor.

No experimento proposto, além da situação de controle, onde os indivíduos receberam uma compensação fixa, o seguinte problema de agência foi emulado: dependendo do tipo de contrato que esteja sendo oferecido, o principal aumenta seu payoff, mas o agente diminuirá sua compensação e aumentará seu esforço na realização da tarefa, ou o agente aumenta sua compensação e diminui o seu esforço em detrimento do aumento da riqueza (utilidade) do principal. Nessa configuração experimental, o conflito de agência é caracterizado pelo tradeoff que o agente enfrenta entre alocar mais esforço para tentar maximizar o fluxo de 
caixa futuro da empresa ou minimiza seu esforço, investindo menos nas ações de longo prazo para tentar maximizar sua compensação.

\subsection{Descrição do Experimento}

No experimento, o participante desempenha o papel de gerente de loja em uma grande rede especializada em serviços de reprografia (vista como um centro de investimentos) e tem como única tarefa alocar um orçamento fixo em duas atividades consideradas essenciais para o sucesso da empresa. A alocação de recursos nessas atividades afeta tanto o lucro contábil contemporâneo quanto o fluxo de caixa líquido futuro da loja. As atividades recebem as seguintes denominações:

ATIVIDADE I - Serviço de Atendimento ao Cliente e;

ATIVIDADE II - Recrutamento, Seleção, Treinamento e Qualificação de Pessoal.

Antes da execução da tarefa, o participante tem acesso a uma tela no computador com a descrição completa dessas atividades e como elas impactam o desempenho atual e futuro da loja bem como o detalhamento da tarefa que ele deverá realizar. Similar a estratégia adotada por Kelly (2007) e Berger (2009), o sujeito deverá alocar um orçamento fixo de 30.000 lubras (unidade monetária do experimento) entre as duas atividades obedecendo a seguinte regra:

- Os montantes dos investimentos devem ser múltiplos de 1.000;

- O participante poderá alocar qualquer valor entre 1.000 e 29.000 lubras em cada atividade; e

- Devem ser investidas, pelo menos, 1.000 lubras em cada atividade.

No início da sessão experimental, o participante tem acesso às informações sobre a empresa. Nessa fase, é comunicado que em nenhuma hipótese o gerente fica mais de um período (exercício financeiro) na mesma loja - cada loja equivale a um exercício financeiro. Então, a cada período, ele atua em uma loja diferente. Essa característica do experimento é o que determina o problema do horizonte, pois nesse caso, o participante não espera estar na loja para "usufruir" dos benefícios futuros gerados pela sua decisão de investimento. 
Uma vez que o participante escolhe o valor dos investimentos em cada uma das atividades ele deve validar essa decisão. Ao fazer isso, automaticamente o participante vai para outra loja. No início da simulação é informado que o objetivo primário do gerente é maximizar o fluxo líquido de caixa futuro da loja. Para realizar a tarefa, o participante utiliza um sistema de informação (simulador) que ajuda a analisar qual a combinação ótima de investimento nas atividades. Esse sistema disponibiliza as seguintes informações:

- os investimentos que o participante fez nas lojas em que já tenha sido gerente;

- simulação do Lucro Líquido do Exercício (previsão);

- simulação do Fluxo de Caixa Líquido para os próximos períodos.

É informado ao participante que a previsão do Fluxo de Caixa Líquido para os próximos períodos é função dos gastos feitos no período corrente (atual) e que tais gastos diminui o lucro líquido do período da loja no período atual. Além disso, é demonstrado que quanto maior for o investimento nas atividades I e II, menor será o lucro líquido da loja no período em que ele é gerente. Por outro lado, quanto maior for a previsão de fluxo de caixa líquido para os próximos períodos, maior será o lucro líquido nos próximos períodos. Portanto, o participante deve entender que o lucro líquido do período também depende dos gastos realizados pelo gerente anterior.

O montante investido em cada atividade não tem efeito estritamente linear sobre o fluxo de caixa líquido futuro. A partir de certo nível de alocação de recursos em cada uma das atividades, o efeito marginal no fluxo de caixa é decrescente. Com esta configuração, o participante terá que avaliar qual o nível ótimo de investimento que irá maximizar o fluxo de caixa líquido da loja e lidar com o problema de evitar investimentos com VPL negativo (sobreinvestimento), ou perder oportunidade de investimento (subinvestimento). Essa característica do experimento é consistente com os trabalhos desenvolvidos por Kelly (2007) e Berger (2009). Segundo Berger (2009), o efeito negativo dos investimentos acima do nível ótimo em dimensões forward-looking sobre o lucro reflete a natureza não linear entre essas dimensões e o desempenho documentado em estudos anteriores.

Antes de começar o experimento o participante pôde praticar em duas lojas. O objetivo desse estágio era fazer com que o sujeito se familiarizasse com o software da simulação. $O$ experimento foi configurado para ter doze períodos/lojas $(2+10)$. Em cada período o efeito 
não-linear do investimento sobre o fluxo líquido de caixa e o lucro líquido é diferente (existe uma função matemática diferente para cada loja/período ${ }^{9}$ ). Isso garante que não haja efeito memória em função do processo de aprendizagem com a simulação para a escolha do nível ótimo de investimento.

Antes de iniciar a simulação, foram passadas as instruções sobre o uso do software do experimento. O quadro 01 mostra o texto básico inicial dessa etapa que aparece na tela do computador.

\begin{abstract}
Na parte superior desse software você deverá clicar na função EXPERIMENTO. Em seguida, irá aparecer uma tela indicando o seu número de participação e os campos onde você deverá indicar qual o montante de recursos que você pretende alocar em cada uma das atividades. Após definir o montante a ser aplicado nas atividades, você poderá clicar no botão SIMULAR INVESTIMENTOS para saber qual será a PREVISÃO do Lucro Líquido para o período em que você está gerenciando a loja e a PREVISÃO do Fluxo de Caixa Líquido para o próximo período. Você poderá fazer quantas simulações desejar antes de tomar sua decisão de investimento. Note que depois de definido o montante de recurso a ser alocado, você deverá validar sua decisão clicando no botão GRAVAR INVESTIMENTOS. Depois de gravado, você não poderá alterar o valor alocado e passará imediatamente para um próximo período em uma nova loja.
\end{abstract}

\title{
ATENÇÃO:
}

Ao longo da simulação você poderá ser solicitado a responder a algumas perguntas na internet. Por isso, é possível que surjam algumas páginas para você acessar. Caso isso ocorra, você só poderá continuar na simulação após preencher as informações solicitadas na internet.

A QUALQUER MOMENTO VOCÊ PODERÁ VOLTAR A ESTA TELA DE INFORMAÇÕES. PORTANTO, NUNCA FECHE ESSA TELA.

Você será informando quando o experimento acabar.

MUITO OBRIGADO PELA SUA PARTICIPAÇÃO!

AGORA: Na barra de ferramentas clique em EXPERIMENTO para iniciar a simulação Quadro 4 - Instruções sobre o uso do software do experimento

O experimento está estruturado em três etapas: i) treinamento - compreendendo duas lojas; ii) realização da tarefa antes da implantação do sistema de incentivo - compreendendo cinco lojas; e iii) realização da tarefa depois da implantação do sistema de incentivo - envolvendo mais cinco lojas. Existem dois sistemas de incentivos, um baseado no lucro líquido do período e outro no lucro econômico.

\footnotetext{
${ }^{9} \mathrm{Na}$ verdade, depois da fase de treinamento, nas lojas/períodos de 15 as funções matemáticas são efetivamente diferentes. Todavia, essas mesmas funções voltam a se repetir nas lojas/períodos de 6 a 10, em ordem diferente. Essa característica do experimento garante que os níveis ótimos de investimentos sejam iguais antes e depois da manipulação experimental. Isso que dizer que se o participante identificar o ponto ótimo de investimento em todas as lojas a soma do valor investimento nas atividades I e II nas lojas/períodos de 1 a 5 será igual à soma do valor investido nas lojas/ períodos de 6 a 10.
} 
O participante recebe uma compensação fixa de 1.500 lubras por loja/período, com exceção da fase de treinamento. Cada 1.500 lubras equivalem a $\mathrm{R} \$ 1,00$ (um real). Quando o participante estiver subordinado ao sistema de incentivo baseado no lucro líquido do período ele recebe um bônus de 5,85\% sobre essa mensuração de desempenho. Desse modo, na terceira etapa do experimento, um grupo de participantes recebe um salário fixo mais um bônus em função do lucro líquido do período.

Por outro lado, quando estiver subordinado ao sistema de incentivo baseado no lucro econômico, o participante recebe um bônus de 4,5\% sobre o lucro econômico estimado. Logo, na terceira fase do experimento outro grupo recebe 1.500 lubras de salário fixo por período mais um bônus em função do lucro econômico estimado.

No experimento, o lucro econômico corresponde à variação no valor presente líquido dos futuros fluxos de caixa esperados pela loja. A taxa de desconto (custo de oportunidade) é de $15 \%$. Já o lucro contábil é o resultado diferencial entre receitas e custos medidos em termos históricos, sem levar em consideração o custo de oportunidade. A previsão do lucro econômico é informada automaticamente aos participantes que estiverem sob o contrato baseado nessa métrica toda vez que eles simulam suas decisões de investimento. No caso dos participantes que estão vinculados ao bônus com base no lucro contábil, quando eles validam a decisão de investimento, antes de passar para a próxima loja, é informado quanto foi o lucro líquido do período efetivamente realizado. Impende salientar que no cálculo desse lucro existe um componente aleatório de modo que ele sempre será diferente da previsão que é feita na fase da simulação. O valor do lucro líquido efetivamente realizado é igual para todos os participantes.

Consistente com os trabalhos de Kely (2007), Farrell et al 2008 e Berger (2009), para assegurar que os participantes compreenderam adequadamente o funcionamento da simulação, após lerem todas as instruções sobre o experimento e realizar a fase de treinamento (primeira etapa), eles são solicitados a responder a um teste de múltipla escolha na web envolvendo aspectos da tarefa a ser realizada. Os participantes só prosseguem no experimento depois que respondem a todas as questões propostas. Esse controle serve para avaliar se os sujeitos conseguiram assimilar adequadamente a tarefa. 
Depois de responder ao teste de múltipla escolha, os participantes recebem uma senha para poder continuar a sessão experimental na segunda etapa. Nessa fase, eles atuam em cinco lojas (cinco períodos) recebendo uma compensação fixa de 1.500 lubras, independentemente do desempenho. Ao final dessa etapa, os participantes são novamente direcionados à internet para receber informações sobre o novo sistema de recompensa que a empresa adotará a partir dos próximos períodos. Os participantes só podem continuar no experimento se concluírem esse procedimento. Apenas dois grupos são comunicados sobre esse novo componente da compensação. Um grupo de participantes é informado sobre o incentivo com base no lucro econômico e o outro sobre o incentivo baseado no lucro líquido do período (lucro contábil). O terceiro grupo representa o controle e não passa por essa etapa na web.

Concluindo a segunda etapa na internet, os participantes recebem uma nova senha para continuar no experimento. Nessa terceira etapa, eles atuam em mais cinco lojas. Nessa fase, quando as decisões são validadas, o simulador informa o montante da bonificação que eles têm direito a receber, além do salário fixo. Após a validação da decisão de investimento na $12^{\circ}$ loja, o sistema comunica o montante acumulado de bônus e o encerramento do experimento. Nesse momento, os participantes retornam à internet para responder ao questionário com as questões demográficas e duas questões de controle (sobre a realidade e a dificuldade da tarefa).

\subsection{Desenho Experimental}

\subsubsection{Validade interna e externa}

Gall et al (2006) alertam para o fato de que o aspecto central do experimento é o estabelecimento de um adequado controle capaz de permitir avaliar com segurança qualquer efeito tratamento. Isso é importante porque, mesmo sendo um poderoso desenho de pesquisa, seus resultados podem ser refutados em função de vários fatores que podem ameaçar sua validade interna e externa (GALL et al, 2006). Segundo Churchill (1987), a validade interna se refere à capacidade do experimento em assegurar que o efeito tratamento observado devese à variável experimental e não a outros fatores estranhos ao experimento. A validade externa diz respeito à capacidade do experimento em assegurar que efeito observado possa ser generalizado para toda a população em estudo. 
Tull (1990) aponta as seguintes ameaças capazes de afetar a validade interna de um experimento:

- Maturação: representa os processos biológicos e psicológicos que sistematicamente variam com o passar do tempo, independente de eventos externos específicos.

- História: refere-se a qualquer variável ou evento, diferente daqueles manipulados pelo pesquisador, que ocorre entre a pré e a pós mensuração e afeta o valor da variável dependente.

- Instrumentação: refere-se às mudanças no instrumento de mensuração ao longo do tempo.

- Seleção (viés de seleção): erros de seleção ocorrem no momento em que os grupos formados, de acordo com os objetivos do experimento, são inicialmente desiguais em relação à variável dependente.

- Mortalidade: refere-se à perda (devido à recusa ou impossibilidade em continuar participando do experimento) de respondentes de diferentes grupos.

- Interação: ocorre no momento em que a pré-mensuração muda a sensibilidade ou receptividade dos respondentes em relação às variáveis independentes.

- Erros de reação: ocorrem na medida em que a artificialidade de algumas situações experimentais ou o comportamento do pesquisador enfatizam, moderam ou alteram qualquer efeito causado pela variável em tratamento.

- Tempo de Mensuração: quando a pós-mensuração é feita em uma dimensão inapropriada para indicar o efeito do tratamento experimental.

Para lidar com as ameaças apontadas anteriormente, utilizou-se um desenho experimental de fator único entre sujeitos, pré-pós tratamento com grupo de controle (CHURCHILL, 1987; TULL, 1990; MALHOTRA, 2001; GALL et al, 2006). Simbolicamente, o experimento teve o seguinte desenho, de acordo com Malhotra (2001):

$\begin{array}{llll}\text { GC: } & \text { (R) } \mathrm{O}_{1} & & \mathrm{O}_{2} \\ \text { GE: } & \text { (R) } \mathrm{O}_{3} & \mathrm{X} & \mathrm{O}_{4}\end{array}$

Onde: 
- $\mathrm{O}$ - é processo de observação ou mensuração de unidades de teste

- $\mathrm{X}$ - é o tratamento (tipo de contrato de incentivo)

- $\mathrm{GE}$ - são os grupos experimentais

- $\mathrm{GC}$ - é o grupo de controle

- $\mathrm{R}$ - é a indicação que a alocação dos sujeitos ao grupo é de forma randomizada (aleatória)

Nesse desenho, o viés de seleção é controlado pela designação aleatória dos sujeitos aos grupos. Os efeitos dos elementos estranhos ao experimento são controlados por:

$$
\left(\mathrm{O}_{2}-\mathrm{O}_{1}\right)=\text { Variáveis Estranhas }
$$

E o resultado do experimento (efeito do tratamento) é dado por:

$$
\text { Efeito Tratamento }=\left(\mathrm{O}_{2}-\mathrm{O}_{1}\right)-\left(\mathrm{O}_{4}-\mathrm{O}_{3}\right)
$$

À luz da opção de desenho experimental apresentada, e considerando a classificação de Tull (1990), a pesquisa realizada está potencialmente sujeita às seguintes ameaças: erros de reação e interação. Além dos procedimentos de rotina no momento da aplicação do experimento, não foi possível desenvolver nenhum ação específica para controlar ou medir o efeito dessas ameaças nos resultados do experimento.

A principal ameaça à validade externa de um experimento diz respeito ao processo de seleção da amostra que foi utilizada no estudo. O critério básico para que os resultados de um experimento possam ser generalizados é que os mesmos derivem de uma amostra representativa da população em estudo. A escolha de uma amostra com esta característica é função dos objetivos da pesquisa, das características da população objeto de estudo, das informações disponíveis e do sistema de referência (YAMANE, 1967). A amostra do estudo é não probabilística e foi selecionada por conveniência e acessibilidade aos participantes, portanto é não representativa de uma população alvo. Naturalmente, isso tem implicações na validade externa dos resultados que não podem ser generalizados para além dos participantes do estudo. 


\subsubsection{Poder estatístico, Tamanho do Efeito e Tamanho da Amostra}

Segundo Lipsey e Hurley (2009), para assegurar que as conclusões sobre o efeito de um tratamento estejam corretas, além da validade, é fundamental que o experimento tenha sensibilidade ou poder estatístico, ou seja, capacidade de detectar um efeito (diferença entre condição de tratamento e controle), se de fato ele existir. A alta validade interna é o principal meio para garantir a sensibilidade do desenho experimental. Por outro lado, usualmente, a decisão sobre a existência ou não de um efeito tratamento é baseada em regras estatísticas (LIPSEY e HURLEY, 2009).

O poder estatístico tem relação com quatro fatores (LIPSEY e HURLEY, 2009): tamanho da amostra; nível da probabilidade na qual se aceitará que um efeito é estatisticamente significativo (nível alfa - $\alpha$ ); teste estatístico; e tamanho de efeito. O poder está associado aos tipos de erros (erro do tipo I e erro do tipo II) que podem ser cometidos quando se decide sobre a existência ou não de efeito tratamento.

Para fazer a estimativa do tamanho da amostra e reduzir a probabilidade de ocorrência do erro tipo II, foi escolhido, $80 \%$ de poder estatístico, nível de significância de 5\%, conforme a orientação padrão da literatura, e um efeito de tamanho grande ${ }^{10}$. O poder e o tamanho do efeito adotados são usuais em pesquisas em ciências sociais e comportamentais (COHEN, 1988). Portanto, considerando que o principal teste estatístico utilizado nessa tese foi a análise de regressão múltipla, ficou definido um tamanho de amostra total, a priori, de 90 sujeitos. Os cálculos foram realizados através do software estatístico G-power 3.1.

\subsubsection{Variáveis Principais}

\subsubsection{Variáveis Dependentes}

Para testar as hipóteses da pesquisa, as seguintes variáveis dependentes foram mensuradas:

\footnotetext{
${ }^{10}$ A opção pelo tamanho do efeito grande está baseada na meta-análise desenvolvida por Jenkins et al (1998). Nesse trabalho, os autores fizeram uma análise estatística para avaliar a relação entre incentivo financeiro e desempenho a partir de 39 estudos anteriores sobre esse tema (o mesmo da presente tese) e encontraram um tamanho de efeito de 0.34. De acordo com Cohen (1988), esse é um efeito grande. O principal teste utilizado na meta-análise foi a análise de regressão.
} 
1. Temp - corresponde ao tempo gasto na execução da tarefa e representa a duração do esforço

2. Simula - representa a quantidade de vezes que o participante simulou a combinação ótima de investimento, sendo a proxy para intensidade do esforço.

3. Invest - corresponde ao montante de lubras alocado nas atividades e serve como proxy da direção do esforço. No caso do experimento, o participante pode optar por investir o máximo de recursos nas duas atividades, investir o mínimo, investir em apenas uma ou nas duas atividades. Investir mais nas atividades I e II significa que a direção do esforço é para as ações de longo prazo. Por outro lado, investir menos significa que a direção do esforço é para as ações de curto prazo.

4. Desv - corresponde à diferença, em valor absoluto, entre o fluxo de caixa da decisão de investimento do participante e o fluxo de caixa ótimo. Essa métrica serve para avaliar a qualidade das decisões de investimento realizadas pelos participantes e foi a proxy para o desempenho na realização da tarefa. Quanto mais próximo de zero, maior é qualidade das decisões e melhor o desempenho.

\subsubsection{Variáveis Independentes}

O tipo de contrato de incentivo (com três níveis: lucro econômico - representando a mensuração forward-looking; lucro contábil - representando a mensuração contemporânea; e salário fixo - representando o grupo de controle) é a única variável independente do experimento.

Para fins dessa pesquisa, a variável independente foi operacionalizada através de variáveis dummies representadas da seguinte maneira:

- Eco - assume valor 1 significando que o participante está subordinado ao contrato de incentivo baseado no lucro econômico e 0 nas demais situações.

- Cont - assume valor 1 significando que o participante está subordinado ao contrato de incentivo baseado no lucro contábil e 0 nas demais situações.

- Fixo - assume valor 1 significando que o participante está subordinado ao regime de salário fixo e 0 nas demais situações. 


\subsubsection{Sujeitos}

Foram sujeitos da pesquisa alunos regularmente matriculados nos cursos de graduação em Ciências Contábeis, Administração e Economia da Universidade de São Paulo e alunos de Ciências Contábeis da Universidade Federal da Bahia. Foram escolhidos estudantes universitários desses cursos, pois os mesmos têm relativamente maior facilidade de compreender as exigências da tarefa que foi designada na simulação e familiaridade com alguns conceitos de economia, contabilidade e finanças que geralmente são explorados na grade curricular desses cursos.

O uso de estudantes de graduação é consistente com outros estudos experimentais em contabilidade envolvendo contratos de incentivo(CHOW, 1983; WALLER e CHOW, 1985, SHIELDS e WALLLER, 1988; SCHOTTER e WEIGELT, 1992; MAULDIN, 1997; FREDRICKSON et al, 1999; SPRINKLE 2000; KELLY 2007; FARRELL et al 2008; SCHULZ et al, 2008; BERGER, 2009; DENISON et al, 2011; KELLY 2009). Além disso, estudantes não têm muitas ideias preconcebidas sobre um tipo de contrato apropriado e o nível de incentivo oferecido no presente experimento tende a ser mais significativo para eles (MAULDIN, 1997).

\subsubsection{Condição de controle}

Num primeiro momento, os sujeitos foram designados aleatoriamente para os três grupos: um de controle e dois experimentais. Durante os cinco primeiros períodos todos os participantes, independentemente do grupo, recebem apenas um salário fixo de 1.500 lubras (ou $\mathrm{R} \$ 1,00$ ) por período.

A partir do sexto período (excluindo os dois períodos de treinamento), os grupos experimentais começam a receber um incentivo monetário variável adicional baseado no desempenho (mensurado ou através do lucro líquido do período ou do lucro econômico). Nessa etapa, o grupo de controle continua a perceber um salário fixo. Adicionalmente, os participantes que pertenciam ao grupo de controle receberam uma compensação adicional de $\mathrm{R}$ \$ 5,00 pela colaboração no experimento, mas eles só ficaram sabendo desse aditivo no momento de receber o pagamento final. 


\subsubsection{Pré-teste}

O experimento foi pré-testado antes de ser aplicado em sua forma definitiva. Esse procedimento ocorreu em uma sessão experimental realizada um mês antes da coleta de dados final. Nesta etapa, participaram 20 sujeitos de acordo com a seguinte composição: 8 no grupo subordinado ao contrato de incentivo baseado no lucro contábil; 6 no grupo subordinado ao contrato vinculado ao lucro econômico; e 6 no grupo de salário fixo.

A partir das informações coletadas no pré-teste, foram incluídos na aplicação final do experimento os seguintes ajustes:

1. Contagem do tempo gasto na realização da tarefa;

2. Alteração do valor do orçamento de investimento de 20.000 lubras para 30.000 lubras;

3. Alteração no layout do simulador;

4. Inclusão de esclarecimentos adicionais nas instruções sobre a tarefa;

5. Alteração do valor a ser pago aos participantes (acréscimos de mais $\mathrm{R} \$ 5,00$, em média, na aplicação final);

6. Alteração das funções matemáticas utilizadas para calcular o valor do lucro líquido do período e do fluxo líquido de caixa futuro.

\subsubsection{Procedimentos para realização das Sessões Experimentais}

O experimento foi administrado em sua forma definitiva em três sessões, uma nas dependências da FEA/USP, na cidade de São Paulo e duas na Faculdade de Ciências Contábeis da Universidade Federal da Bahia em Salvador. O procedimento de aplicação seguiu o seguinte protocolo:

1. Os participantes foram convidados através de e-mail para participar do experimento.

2. Os participantes se inscreveram através de um formulário eletrônico na web e indicaram o horário da sessão experimental que gostariam de participar.

3. Com base nas inscrições online, os participantes foram alocados aleatoriamente aos três grupos - dois experimentais e um de controle. 
4. No dia da aplicação do experimento, os estudantes chagaram ao laboratório de informática, se identificaram e foram designados ao setor do laboratório que acomodava as máquinas configuradas de acordo com o grupo a que pertenciam.

5. Depois que todos os alunos já estavam acomodados em seus respectivos lugares foi feita a última checagem para verificar se estavam todos no grupo para qual haviam sido sorteados.

6. O coordenador da sessão explicou a natureza do experimento e leu todas as instruções necessárias para a realização da tarefa.

7. Após tirar algumas dúvidas dos participantes, o procedimento experimental foi iniciado.

8. Ao final da sessão, os participantes eram instruídos a procurar o coordenador da sessão para receber o pagamento pela participação. O pagamento foi feito mediante a assinatura de um recibo declarando quanto o participante recebeu.

\subsection{Tratamento, Análise de Dados e Teste de Hipótese}

Dado que a robustez dos resultados depende seriamente das ações que são tomadas para coleta, tratamento, exploração e análise de dados, os seguintes procedimentos foram adotados:

1. Inicialmente, as informações coletadas foram organizadas em planilhas eletrônicas e procedimentos específicos foram adotados para a identificação de dados faltantes, incompletos e com valores atípicos (outliers) de modo a "limpar" a base de dados. Nessa fase as seguintes decisões foram tomadas: sujeitos com dados incompletos e/ou dados inconsistentes foram excluídos da análise, caso não houvesse justificativa plausível para serem mantidos.

2. Organização e sumarização dos dados em tabelas, gráficos, diagramas e quadros.

3. Apuração das estatísticas descritivas, tais como médias, desvio-padrão, distribuição de frequência e medidas de assimetria e achatamento.

4. Padronização dos dados, quando foi necessário.

5. Realização de procedimentos para avaliar a adequabilidade de utilização de testes estatísticos paramétricos na análise dos dados. Nessa etapa foram utilizados os testes de Kolmogorov-Smirnov e Shapiro-Wilk e análise gráfica para avaliação do pressuposto da normalidade, em conjunto com o teste Levene, para avaliar o pressuposto de homogeneidade da variância. Nessa fase a seguinte decisão foi tomada: 
dados com comportamento muito diferente desses pressupostos foram submetidos à transformação de Box-Cox ou outra função matemática apropriada (logaritmo, raiz quadrada, etc.) para tentar a normalização, linearização e homogeneização da variância. Os dados que não puderam ter suas distribuições suavizadas para atender às exigências de normalidade e homogeneidade também foram submetidos a teste estatístico não paramétrico.

Além dos procedimentos supracitados, foi adotado o procedimento de análise de regressão múltipla para testar formalmente as hipóteses, utilizando o seguinte modelo geral:

$$
y=\beta_{0}+\beta_{1}(D t)+\beta_{2}(E c o)+\beta_{3}(C o n t)+\beta_{4}(E c o * D t)-\beta_{5}(C o n t * D t)+\varepsilon_{i}
$$

Onde:

i. $\quad \boldsymbol{y}$ é a variável dependente do modelo e representa o valor médio de alguma das variáveis mensuradas no estudo (Invest, Temp, Simula e Desv);

ii. Os $\boldsymbol{\beta}$ 's são os parâmetros do modelo, onde $\boldsymbol{\beta}_{\mathbf{0}}$ representa o valor esperado da variável em estudo ao se analisar o grupo de controle antes do tratamento, $\boldsymbol{\beta}_{1}$ indica como a variável em estudo se comporta depois da manipulação experimental e mensura a diferença (antes e depois) dentro do grupo de controle, $\boldsymbol{\beta}_{2}$ mensura o efeito marginal de pertencer ao grupo de tratamento subordinado ao lucro econômico antes da manipulação experimental, $\boldsymbol{\beta}_{3}$ mensura o efeito marginal de pertencer ao grupo de tratamento subordinado ao lucro contábil antes da mensuração experimental, $\boldsymbol{\beta}_{4}$ e $\boldsymbol{\beta}_{5}$ é a diferença das diferenças (diferença dentro do grupo de controle menos a diferença dentro dos grupos de tratamento) e mede o efeito do tratamento nas variáveis em estudo.

iii. $\quad \varepsilon_{i}$ é o termo de erro do modelo estocástico; e

iv. Dt é uma variável dummy que será 1 quando os dados forem referentes ao póstratamento e 0 quando os dados se referirem ao período pré-tratamento.

v. Eco e Cont são variáveis dummies que representam o impacto de se estar nos grupos de tratamento vinculado lucro econômico ou ao lucro contábil, respectivamente. Será igual 1 quando o sujeito estiver em um dos grupos de tratamento e zero em outra situação. 
Pelo fato dos dados terem sido coletados para vários participantes/unidades em 10 períodos diferentes (dados longitudinais - conjunto de observações nas mesmas unidades em vários momentos) todas as regressões foram estimadas utilizando a técnica de análise de regressão para dados em painel com efeito fixo. Foram realizados testes formais para diagnosticar problemas de autocorrelação (se os termos de erro no modelo não eram distribuídos de forma independente) e heteroscedasticidade (se os termos de erro no modelo não eram identicamente distribuídos). A heteroscedasticidade foi diagnosticada através do teste Wald e a autocorrelação dos resíduos pelo teste Durbin-Watson, conforme sugerido por Verbeek, (2000).

Nos casos em que foram detectados os problemas de heteroscedasticidade e/ou autocorrelação e estes não puderam ser resolvidos com os procedimentos usuais, tais como a transformação dos dados e/ou defasagem de dados, utilizou-se a estimativa robusta dos erros padrão através do método HAC (Heteroskedasticity and Autocorrelation Consistent), nos casos em que os modelos de regressão apresentaram problemas de heteroscedasticidade e autocorrelação conjuntamente, conforme sugerido por Arellano (2003) e discutido em Cameron e Trivedi (2005). Nos casos onde foram identificados apenas problema de heteroscedasticidade optouse pelo erro padrão robusto estimado através do método PCSE (Panel-Corrected Standard Errors) proposto por Beck and Katz (1995) e discutido em Greene (2003).

A opção do teste de hipóteses através da análise de regressão com dados em painel se baseou nas seguintes vantagens conferidas pelo modelo, de acordo Cameron e Trivedi (2005):

- dado que os dados são oriundos de mensurações repetidas, a regressão com dados em painel confere maior precisão e eficiência às estimativas como resultado do aumento do número de observações decorrente de combinação ou agrupamento de vários períodos de tempo de dados para cada indivíduo;

- no caso do modelo de efeito fixo, permite controlar a heterogeneidade, se existir, individual não observada que pode ser correlacionada com os regressores, mitigando o problema de viés em função de variáveis omitidas não incluídas no modelo;

- os dados em painel permite aprender mais sobre a dinâmica do comportamento individual que pode ser fundamental para a compreensão de certos fenômenos. 


\section{RESULTADOS: ANÁLISE E DISCUSSÃO}

Este capítulo mostra os resultados do experimento realizado. Começa apresentando as informações demográficas dos participantes e os controles feitos para os grupos pré e pós tratamento. Depois, evidencia os resultados dos testes das hipóteses formuladas no capítulo 3, bem como a análise de robustez através do procedimento de teste não paramétrico. Logo em seguida, é apresentada uma análise do poder estatístico e do tamanho do efeito baseados na análise de regressão múltipla.

\subsection{Informações Demográficas dos Participantes}

A amostra final contabilizou 76 sujeitos, mas no total 90 estudantes fizeram parte do experimento. A exclusão de 14 participantes da análise final ocorreu por dois motivos. Primeiro, o computador não registrou corretamente os dados das decisões de 12 estudantes, pois o aplicativo não funcionou adequadamente devido à versão do sistema operacional instalado nos microcomputadores. Segundo, dois estudantes foram excluídos porque demonstraram, de forma sistemática, que não entenderam as instruções sobre a tarefa e os parâmetros da simulação (não fizeram simulação alguma; alocaram 50\% do orçamento em cada uma das atividades sem fazer simulação das decisões; não leram as instruções; erraram mais de duas questões de controle que foram elaboradas para avaliar o entendimento dos participantes sobre a simulação).

$\mathrm{Na}$ amostra final, $58 \%$ dos participantes eram homens e $42 \%$ mulheres. A maioria era estudante de Ciências Contábeis (66), 4 estudavam Economia, 4 eram estudantes de Administração e 2 cursavam Relações Internacionais. Em média, os participantes tinham 22 anos, $51 \%$ disseram que trabalhavam ou estagiavam e $49 \%$ disseram que no momento apenas estudavam. Os participantes receberam, em média, $\mathrm{R} \$ 16,52$. Todos esses dados estão evidenciados na tabela 1 .

Além dos 90 estudantes que participaram das sessões experimentais regulares, 20 outros fizeram parte do pré-teste do experimento, mas as informações demográficas sobre este grupo não são apresentadas nesse trabalho. Os dados coletados serviram apenas para fazer ajustes no protocolo experimental e no software da simulação. 
Tabela 1 - Informações Demográficas dos Participantes

\begin{tabular}{l|c|c}
\hline GÊNERO & Quantidade & Percentual \\
Feminino & 32 & $42 \%$ \\
Masculino & 44 & $58 \%$ \\
Total & $\mathbf{7 6}$ & $\mathbf{1 0 0 \%}$ \\
& & \\
CURSO DE GRADUAÇÃO & 66 & $87 \%$ \\
Ciências Contábeis & 4 & $5 \%$ \\
Economia & 4 & $5 \%$ \\
Administração & 2 & $3 \%$ \\
Relações Internacionais & $\mathbf{7 6}$ & $\mathbf{1 0 0 \%}$ \\
Total & & \\
TRABALHAVAM OU & & \\
ESTAGIAVAM & 39 & $51 \%$ \\
Sim & 37 & $49 \%$ \\
Não & $\mathbf{7 6}$ & $\mathbf{1 0 0 \%}$ \\
Total & \multicolumn{2}{|c}{} \\
OUTRAS INFORMAÇÕES & 22 anos \\
Idade média & & \\
Valor médio recebido & & \\
\hline Fonte: Elaborado pelo autor com base nos dados da pesquisa &
\end{tabular}

\subsection{Avaliação Pré e Pós- Experimental dos Grupos}

Dos 76 participantes que compuseram a amostra final, depois da distribuição aleatória, 25 foram alocados ao grupo de tratamento vinculado ao lucro contábil (tratamento 1), 25 foram alocados ao grupo de tratamento vinculado ao lucro econômico (tratamento 2) e 26 foram alocados ao grupo de controle. Antes de iniciar o experimento, os participantes tiveram a oportunidade simular dois períodos de treinamento e depois responderam a um questionário para avaliar o entendimento deles sobre as principais características da simulação. Nesta etapa, todos os sujeitos da amostra final responderam corretamente as quatro questões propostas, portanto, não foi identificada divergência entre os grupos.

Após a realização do experimento, os participantes reponderam ao questionário pósexperimental que continha duas questões de controle para checar a opinião deles sobre a realidade e a dificuldade da simulação. Essa conferência foi feita através de duas proposições, a saber:

- Enunciado 1: Eu achei essa simulação bastante realista; e

- Enunciado 2: Quão difícil você acha que é cumprir a tarefa de investir nas duas atividades? 
As respostas foram coletadas através de uma escala do tipo likert variando de 1 a 7 . No primeiro enunciado, Discordo totalmente equivale a 1 e Concordo totalmente equivale a 7. No segundo, Muito fácil é igual a 1 e Muito difícil é igual a 7. A tabela 2 apresenta as estatísticas descritivas das respostas obtidas para o conjunto dos participantes e a tabela 3 evidencia as estatísticas por grupo.

Tabela 2 - Estatística Descritiva das Questões Pós-experimento para Todos os Participantes da Amostra Final

\begin{tabular}{l|r|r|r|r|r}
\hline & $\mathrm{N}$ & Mínimo & Maximo & Média & Desvio Padrão \\
\hline Realidade & 76 & 1 & 7 & 4,26 & 1,380 \\
Dificuldade & 76 & 1 & 7 & 4,13 & 1,379 \\
\hline
\end{tabular}

Fonte: Elaborado pelo autor com base nos dados da pesquisa

Tabela 3 - Estatística Descritiva das Questões Pós-experimento Por Grupo

\begin{tabular}{l|l|r|r|r|r|r}
\hline & $\mathrm{N}$ & Média & $\begin{array}{r}\text { Desvio } \\
\text { Padrão }\end{array}$ & Mínimo & Maximo \\
\hline \multirow{5}{*}{ Realidade } & Contábil & 25,00 & 4,32 & 1,41 & 1,00 & 6,00 \\
& Econômico & 25,00 & 4,16 & 1,46 & 1,00 & 7,00 \\
& Fixo & 26,00 & 4,31 & 1,32 & 2,00 & 7,00 \\
& Total & 76,00 & 4,26 & 1,38 & 1,00 & 7,00 \\
\hline \multirow{5}{*}{ Dificuldade } & Contábil & 25,00 & 3,84 & 1,52 & 1,00 & 6,00 \\
& Econômico & 25,00 & 4,48 & 1,42 & 1,00 & 7,00 \\
& Fixo & 26,00 & 4,08 & 1,16 & 2,00 & 6,00 \\
& Total & 76,00 & 4,13 & 1,38 & 1,00 & 7,00 \\
\hline
\end{tabular}

Fonte: Elaborado pelo autor com base nos dados da pesquisa

As estatísticas mostram que as médias e os desvios padrão dos grupos são bem próximos, sugerindo haver homogeneidade entre eles. Para checar se isso ocorre do ponto de vista estatístico, foi conduzido um teste de análise de variância (ANOVA de um fator) e um equivalente não paramétrico - teste de Kruskal Wallis H (ANOVA em ordens). As tabelas 4 e 5 registram os resultados dos respectivos procedimentos.

Tabela 4 - Resultados da ANOVA de um Fator para as Questões Pós-experimental

\begin{tabular}{l|l|r|r|r|r|r}
\hline \multicolumn{2}{l}{} & $\begin{array}{r}\text { Soma dos } \\
\text { Quadrados }\end{array}$ & $\begin{array}{r}\text { Graus de } \\
\text { Liberdade }\end{array}$ & $\begin{array}{r}\text { Quadrados } \\
\text { Médios }\end{array}$ & F & P-valor \\
\hline \multirow{3}{*}{ Realidade } & Entre os Grupos & 0,40 & 2,00 & 0,20 & 0,10 & 0,90 \\
& Dentro dos Grupos & 142,34 & 73,00 & 1,95 & & \\
& Total & 142,74 & 75,00 & & & \\
\hline \multirow{3}{*}{ Dificuldade } & Entre os Grupos & 5,24 & 2,00 & 2,62 & 1,39 & 0,26 \\
& Dentro dos Grupos & 137,45 & 73,00 & 1,88 & & \\
& Total & 142,68 & 75,00 & & & \\
\hline
\end{tabular}

Fonte: Elaborado pelo autor com base nos dados da pesquisa 
5 - Teste Kruskal Wallis H para as Questões Pós-experimental

\begin{tabular}{l|r|r}
\hline & Realidade & Dificuldade \\
\hline Qui-quadrado & 0,41 & 2,75 \\
Graus de Liberdade & 2,00 & 2,00 \\
P-valor & 0,81 & 0,25 \\
\hline
\end{tabular}

Fonte: Elaborado pelo autor com base nos dados da pesquisa

Os testes estatísticos convergem para o mesmo resultado (p-valores em cada uma das questões acima do nível de significância de 0,05), sugerindo não haver diferença estatística entre os grupos. Esses resultados indicam que o procedimento de atribuição aleatória dos sujeitos aos grupos manteve a homogeneidade entre eles e que, provavelmente, a manipulação experimental não alterou a percepção dos participantes sobre os aspectos avaliados. Todavia, uma avaliação mais robusta necessitaria de uma comparação das respostas antes e depois da manipulação experimental e isso não foi feito. Por último, observa-se que as respostas para o primeiro enunciado indicam que a opinião dos participantes fica em torno da opção "nem concordo, nem discordo" sobre a afirmação de que a tarefa é realista. Do mesmo modo, as respostas para o segundo enunciado também sinalizam que os sujeitos não consideram a tarefa "nem fácil, nem difícil".

\subsection{Testes de Hipóteses}

Muitos estudos têm documentado que o incentivo contingente ao desempenho tem influência no comportamento econômico dos indivíduos e pode induzi-los a dedicar mais esforço na realização das tarefas que lhes são designadas e, como consequência, a melhorar o desempenho. No entanto, várias evidências também sugerem que se a mensuração de desempenho utilizada como base para as recompensas não for congruente, no sentido de compatibilizar os interesses do principal com aqueles do agente, a firma poderá ter que suportar um custo contratual desfavorável. Num ambiente em que o problema de horizonte esteja presente, essa questão se torna mais aguda, pois os agentes naturalmente têm incentivos para agir de maneira a comprometer a capacidade de a organização criar valor no longo prazo, por priorizarem as ações que melhoram o desempenho no curto prazo.

As hipóteses da presente pesquisa foram formuladas em torno da questão se o uso do lucro econômico em contratos de incentivo influencia o comportamento do agente motivando-o a agir de forma congruente com os objetivos de longo prazo da empresa quando existe o 
problema do horizonte. No contexto deste trabalho, agir de forma congruente significa dedicar mais esforço à tarefa e tomar decisões mais consistentes com o objetivo de maximização do valor presente líquido do fluxo de caixa futuro da empresa. As próximas seções mostram os resultados estatísticos que servem para avaliar se o lucro econômico alcançou os objetivos pretendidos.

\subsubsection{Estatísticas Descritivas das Variáveis Dependentes}

Antes de analisar os resultados das hipóteses testadas, convém apresentar as estatísticas descritivas das variáveis que serviram como substituto para o esforço (Simula, Temp e Invest) e o desempenho (Desv) no experimento. A tabela 6 apresenta os resultados separados por grupo e a tabela 7 sumariza o comportamento das médias dentro de cada grupo. Os gráficos da tabela 7 são evidenciados logo na sequência.

Tabela 6 - Estatística Descritiva por Grupo

\begin{tabular}{|c|c|c|c|c|c|}
\hline GRUPO & Variáveis Dependentes & Mínimo & Máximo & Média & Desvio-padrão \\
\hline \multirow{4}{*}{ 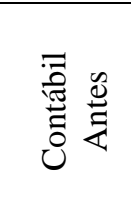 } & Desv & $-40.798,87$ & 0,00 & $-2.575,76$ & $6.694,11$ \\
\hline & Simula & 1,00 & 109,00 & 22,44 & 14,43 \\
\hline & Temp & 0,00 & 9,00 & 2,98 & 1,39 \\
\hline & Invest & $2.000,00$ & $30.000,00$ & $24.544,00$ & $5.373,93$ \\
\hline \multirow{4}{*}{ 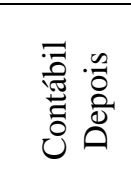 } & Desv & $-204.764,95$ & 0,00 & $-15.923,14$ & $26.781,40$ \\
\hline & Simula & 0,00 & 48,00 & 14,75 & 9,11 \\
\hline & Temp & 0,00 & 9,00 & 2,65 & 1,95 \\
\hline & Invest & $2.000,00$ & $30.000,00$ & $21.792,00$ & $9.055,65$ \\
\hline \multirow{4}{*}{ 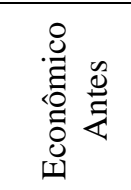 } & Desv & $-66.106,63$ & 0,00 & $-5.715,75$ & $11.205,51$ \\
\hline & Simula & 0,00 & 54,00 & 17,95 & 12,34 \\
\hline & Temp & 0,00 & 6,00 & 2,83 & 1,41 \\
\hline & Invest & $2.000,00$ & $30.000,00$ & $22.968,00$ & $7.431,34$ \\
\hline \multirow{4}{*}{ 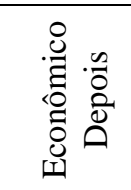 } & Desv & $-193.526,88$ & 0,00 & $-5.759,91$ & $23.037,47$ \\
\hline & Simula & 0,00 & 43,00 & 19,68 & 10,63 \\
\hline & Тетр & 0,00 & 9,00 & 2,86 & 1,93 \\
\hline & Invest & $19.000,00$ & $30.000,00$ & $27.648,00$ & $2.724,61$ \\
\hline \multirow{4}{*}{ 宏 导 } & Desv & $-51.427,23$ & 0,00 & $-6.895,93$ & $11.611,81$ \\
\hline & Simula & 0,00 & 73,00 & 14,82 & 11,67 \\
\hline & Temp & 0,00 & 8,00 & 2,37 & 1,18 \\
\hline & Invest & $2.000,00$ & $30.000,00$ & $22.230,77$ & $8.562,17$ \\
\hline \multirow{4}{*}{ 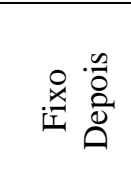 } & Desv & $-82.301,51$ & $7.702,68$ & $-11.648,15$ & $18.648,84$ \\
\hline & Simula & 0,00 & 33,00 & 11,94 & 8,66 \\
\hline & Тетр & 0,00 & 7,00 & 2,13 & 1,49 \\
\hline & Invest & $2.000,00$ & $30.000,00$ & $23.600,00$ & $7.454,88$ \\
\hline
\end{tabular}

Fonte: Elaborado pelo autor com base nos dados da pesquisa

Nota: Tabela elaborada a partir dos dados não padronizados. Os valores representam a média em cada período/loja 
Tabela 7 - Resumo das Médias das Variáveis Dependentes por Período/Loja

\begin{tabular}{l|c|c|c|c|c|c}
\hline \multirow{2}{*}{ VARIÁVEIS DEPENDENTES } & \multicolumn{2}{c|}{ CONT } & \multicolumn{2}{c|}{ ECON } & \multicolumn{2}{c}{ FIXO } \\
\cline { 2 - 7 } & Antes & Depois & Antes & Depois & Antes & Depois \\
\hline Desvio do Fluxo de Caixa Ótimo (Desv) & $-2.575,76$ & $-15.923,14$ & $-5.715,75$ & $-5.759,91$ & $-6.895,93$ & $-11.648,15$ \\
Número de Simulações (Simula) & 22,44 & 14,75 & 17,95 & 19,68 & 14,82 & 11,94 \\
Valor do investimento (Invest) & $24.544,00$ & $21.792,00$ & $22.968,00$ & $27.648,00$ & $22.230,77$ & $23.600,00$ \\
Tempo Dedicado à tarefa (Temp) & 2,98 & 2,65 & 2,83 & 2,86 & 2,37 & 2,13 \\
\hline
\end{tabular}

Nota: O tempo foi medido em minutos.

Fonte: Elaborado pelo autor com base nos dados da pesquisa

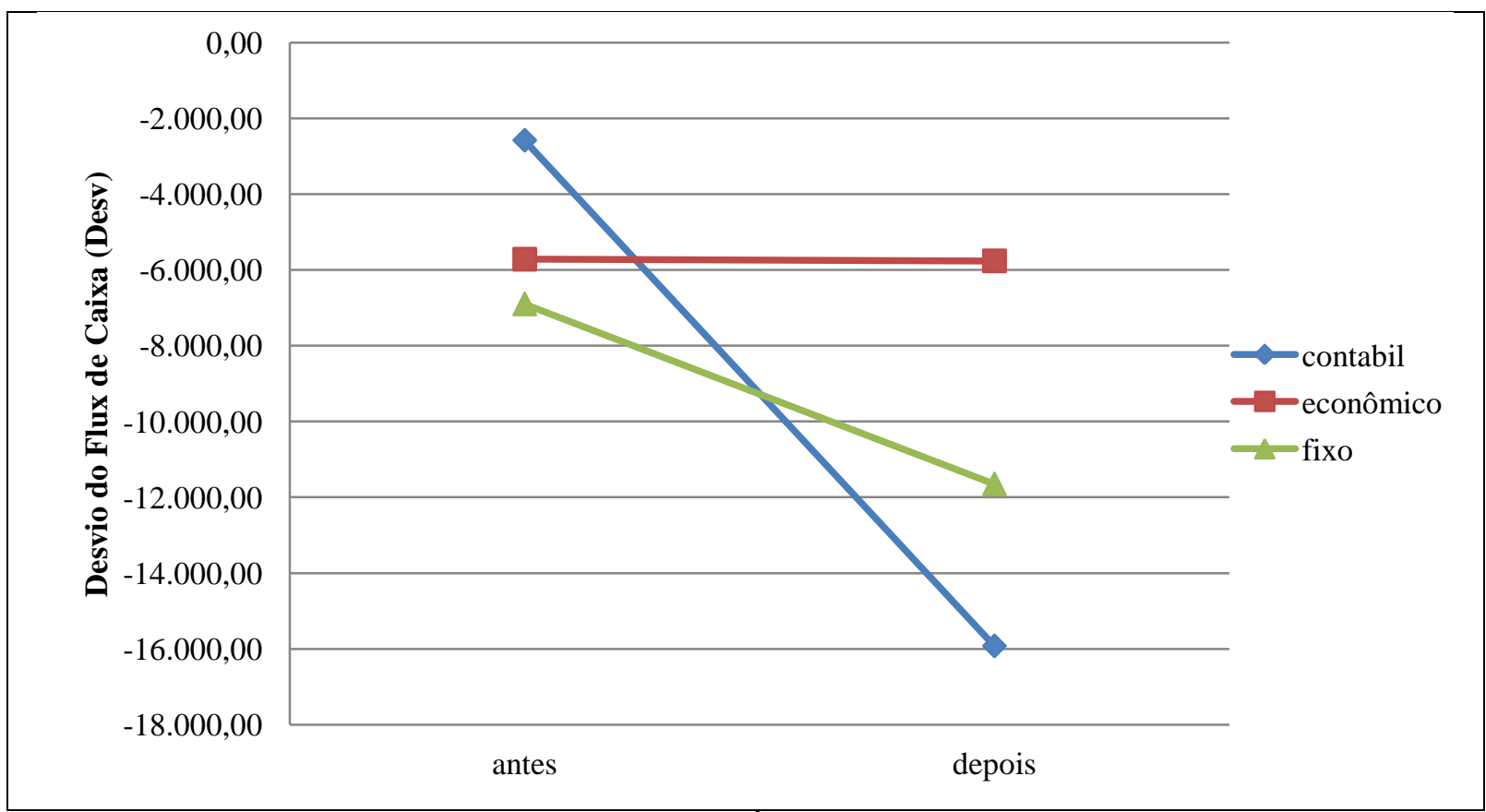

Gráfico 1 - Desvio do Fluxo de Caixa Ótimo - Antes e Depois do Tratamento

Fonte: Elaborado pelo autor com base nos dados da pesquisa

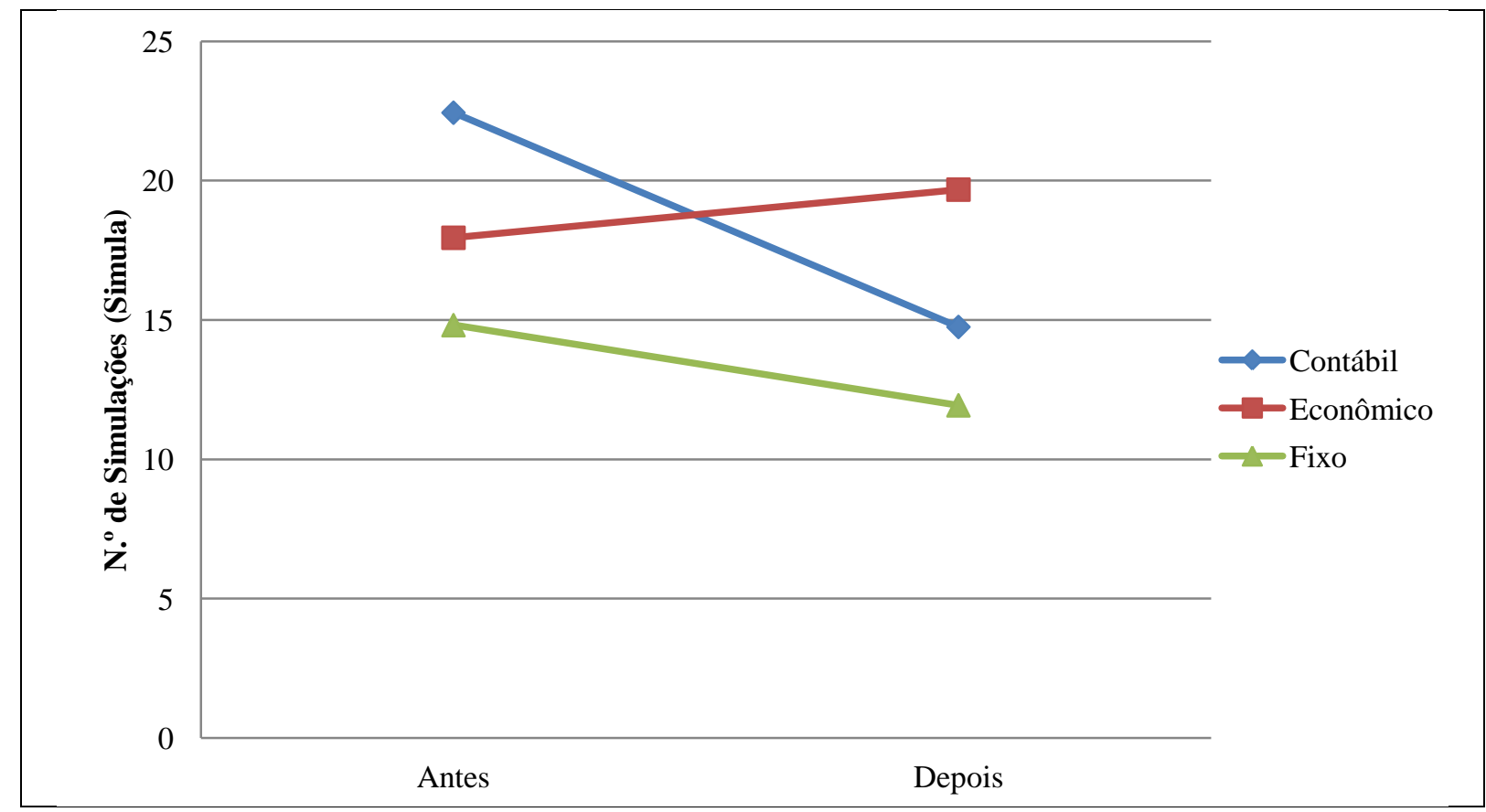

Gráfico 2 - Número de Simulações - Antes e Depois do Tratamento

Fonte: Elaborado pelo autor com base nos dados da pesquisa 


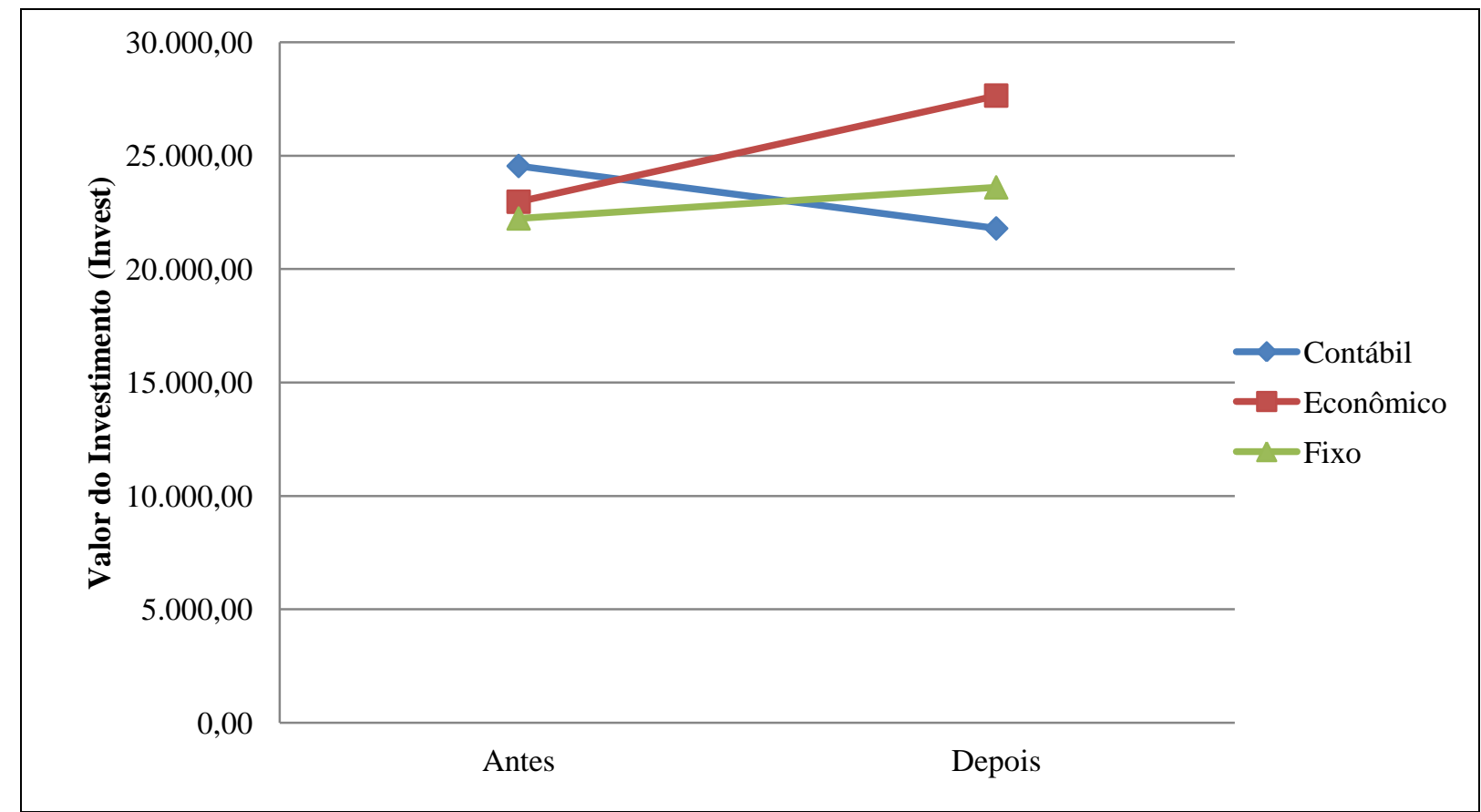

Gráfico 3 - Valor do investimento - Antes e Depois do Tratamento

Fonte: Elaborado pelo autor com base nos dados da pesquisa

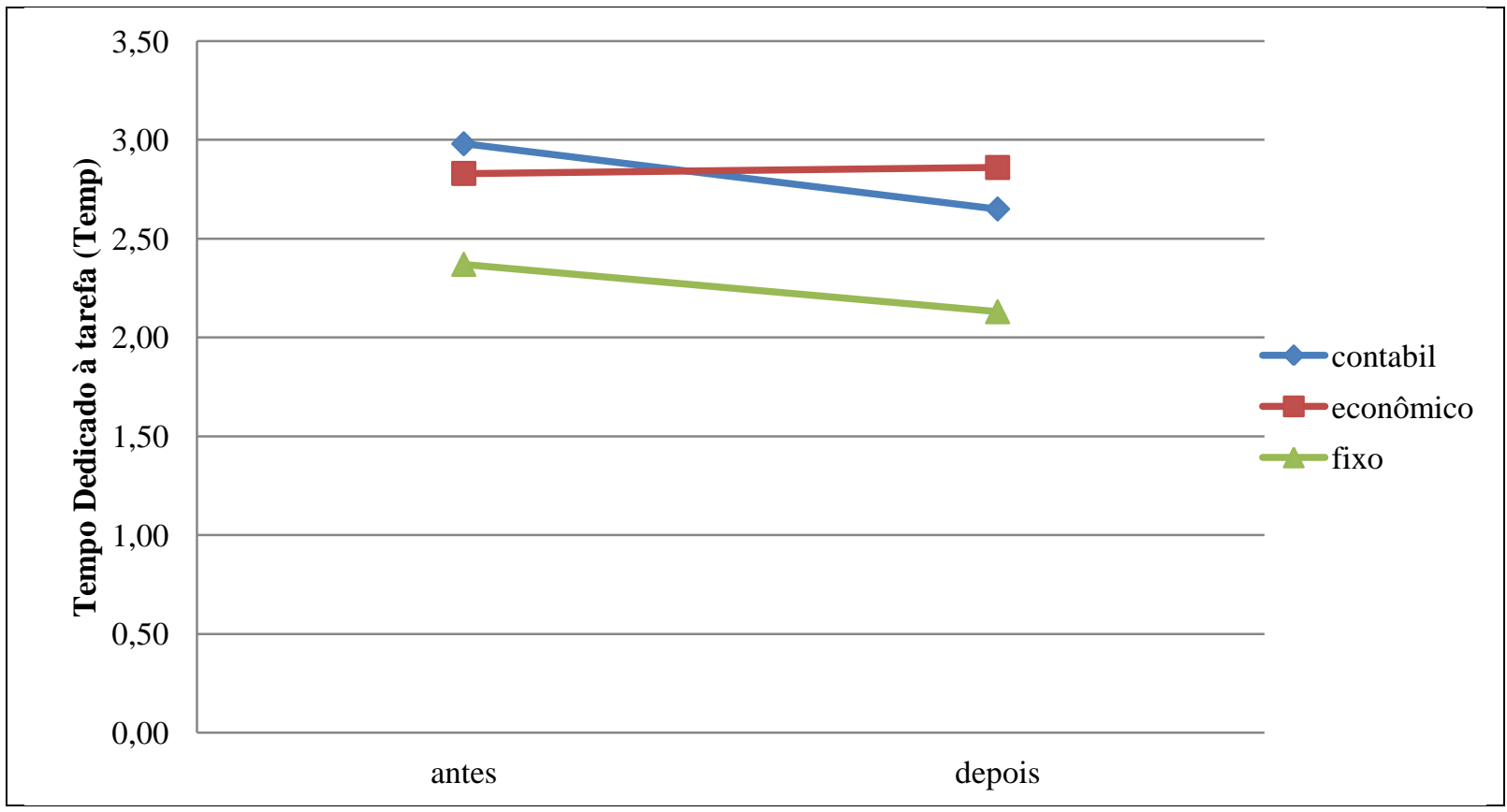

Gráfico 4 - Tempo Dedicado à tarefa - Antes e Depois do Tratamento

Fonte: Elaborado pelo autor com base nos dados da pesquisa

Numa avaliação preliminar, os resultados, tanto das tabelas quanto dos gráficos, sugerem que as médias declinaram entre o antes e o depois do tratamento no grupo subordinado ao contrato de incentivo vinculado ao lucro contábil. Em relação ao grupo de controle, esse declínio só não foi observado na variável Invest. Ao mesmo tempo, o grupo de tratamento subordinado ao lucro econômico apresentou aumento em todas as médias depois do tratamento. Nota-se, 
portanto, que o comportamento do grupo de tratamento que recebe compensação com base no lucro contábil apresenta um comportamento bastante diferente dos demais. Todavia, até este estágio, não é possível dizer se as diferenças observadas entre os grupos são sistemáticas e estatisticamente significativas, ou se elas decorrem meramente do acaso. Por isso, pode ser conveniente avaliar preliminarmente os contrastes ${ }^{11}$ dentro dos grupos para saber se essas diferenças antes e depois do tratamento têm significância estatística. A tabela 8 fornece os resultados das comparações para cada uma das variáveis em estudo.

Tabela 8 - Resultado do Teste de Contraste Dentro dos Grupos

\begin{tabular}{|c|c|c|c|c|c|}
\hline \multicolumn{3}{|c|}{ Contrastes } & \multirow{2}{*}{$\begin{array}{r}\begin{array}{r}\text { Valor dos } \\
\text { Contrastes }\end{array} \\
0,33\end{array}$} & \multirow{2}{*}{$\begin{array}{r}\text { Erro Padrão } \\
0,20\end{array}$} & \multirow{2}{*}{$\begin{array}{r}\begin{array}{r}\text { P-valor } \\
\text { (bicaudal) }\end{array} \\
0,1016\end{array}$} \\
\hline \multirow{6}{*}{ Тетр } & \multirow{3}{*}{$\begin{array}{l}\text { Assumindo } \\
\text { igualdade de } \\
\text { Variância }\end{array}$} & Cont antes - Cont depois & & & \\
\hline & & Eco antes - Eco depois & $-0,02$ & 0,20 & 0,9046 \\
\hline & & Fixo antes - Fixo depois & 0,24 & 0,20 & 0,2247 \\
\hline & \multirow{3}{*}{$\begin{array}{l}\text { Assumindo } \\
\text { desigualdade } \\
\text { de Variância }\end{array}$} & Cont antes - Cont depois & 0,33 & 0,21 & 0,1272 \\
\hline & & Eco antes - Eco depois & $-0,02$ & 0,21 & 0,9107 \\
\hline & & Fixo antes - Fixo depois & 0,24 & 0,17 & 0,1543 \\
\hline \multirow{6}{*}{ Simula } & \multirow{3}{*}{$\begin{array}{l}\text { Assumindo } \\
\text { igualdade de } \\
\text { Variância }\end{array}$} & Cont. antes - Cont. depois & 7,69 & 1,43 & 0,0000 \\
\hline & & Eco. antes - Eco. depois & $-1,73$ & 1,43 & 0,2270 \\
\hline & & Fixo antes - Fixo depois & 2,88 & 1,40 & 0,0404 \\
\hline & \multirow{3}{*}{$\begin{array}{l}\text { Assumindo } \\
\text { desigualdade } \\
\text { de Variância }\end{array}$} & Cont antes - Cont depois & 7,69 & 1,53 & 0,0000 \\
\hline & & Eco antes - Eco depois & $-1,73$ & 1,46 & 0,2367 \\
\hline & & Fixo antes - Fixo depois & 2,88 & 1,27 & 0,0250 \\
\hline \multirow{6}{*}{ Invest } & \multirow{3}{*}{$\begin{array}{l}\text { Assumindo } \\
\text { igualdade de } \\
\text { Variância }\end{array}$} & Cont antes - Cont depois & $2.752,00$ & 899,68 & 0,0023 \\
\hline & & Eco antes - Eco depois & $-4.680,00$ & 899,68 & 0,0000 \\
\hline & & Fixo antes - Fixo depois & $-1.369,23$ & 882,21 & 0,1211 \\
\hline & \multirow{3}{*}{$\begin{array}{l}\text { Assumindo } \\
\text { desigualdade } \\
\text { de Variância }\end{array}$} & Cont antes - Cont depois & $2.752,00$ & 941,84 & 0,0039 \\
\hline & & Eco antes - Eco depois & $-4.680,00$ & 707,94 & 0,0000 \\
\hline & & Fixo antes - Fixo depois & $-1.369,23$ & 995,71 & 0,1703 \\
\hline \multirow{6}{*}{ Desv } & \multirow{3}{*}{$\begin{array}{l}\text { Assumindo } \\
\text { igualdade de } \\
\text { Variância }\end{array}$} & Cont antes - Cont depois & $13.347,38$ & $2.247,93$ & 0,0000 \\
\hline & & Eco antes - Eco depois & 44,16 & $2.247,93$ & 0,9843 \\
\hline & & Fixo antes - Fixo depois & $4.752,22$ & $2.204,28$ & 0,0314 \\
\hline & \multirow{3}{*}{$\begin{array}{l}\text { Assumindo } \\
\text { desigualdade } \\
\text { de Variância }\end{array}$} & Cont antes - Cont depois & $13.347,38$ & $2.469,10$ & 0,0000 \\
\hline & & Eco antes - Eco depois & 44,16 & $2.291,35$ & 0,9846 \\
\hline & & Fixo antes - Fixo depois & $4.752,22$ & $1.926,76$ & 0,0144 \\
\hline
\end{tabular}

Nota: i) o teste de contrastes foi feito através do procedimento de análise de variância ANOVA de um fator, cujo fator é o tipo de contrato de incentivo; ii) a análise foi conduzida considerando um nível de significância de 5\%; iii) Cont antes e Cont depois representa o grupo de tratamento vinculado ao lucro contábil antes e depois do tratamento, Eco antes e Eco depois representam o grupo de tratamento vinculado ao lucro econômico antes e depois do tratamento e Fixo antes e Fixo depois representa o grupo de controle antes e depois do tratamento; iv) Temp, Simula, Invest e Desv são as variáveis dependentes do experimento.

Fonte: Elaborado pelo autor com base nos dados da pesquisa.

\footnotetext{
${ }^{11}$ Os contrastes são comparações dentro dos grupos experimentais realizados com base no procedimento de análise de variância de um fator. Optou-se por realizar contrastes planejados e não testes post hoc porque são assumidas hipóteses especificas em relação à direção das diferenças entre os grupos.
} 
A análise dos contrastes revela que em todos os grupos a variável Temp não apresentou diferença significativa depois da manipulação experimental (p-valores acima do nível de significância de 5\%). Em relação ao grupo de tratamento vinculado ao lucro econômico, as variáveis Simula e Desv também não mostraram diferença estatística entre o antes e depois do tratamento. No grupo vinculado ao lucro contábil, excluída a primeira, todas as variáveis apresentaram diferença estatisticamente significativa. Para o grupo de controle essa diferença foi detectada nas variáveis Simula e Desv.

Dado que nem todos os pressupostos para utilização de testes paramétricos foram atendidos, os mesmos contrastes realizados através da ANOVA foram feitos utilizando o teste não paramétrico para diferença de médias emparelhadas de Wilcoxon. Os resultados são apresentados na tabela 9 .

Tabela 9 - Resultados do Teste Não Paramétrico Wilcoxon para as Variáveis Dependentes

\begin{tabular}{l|c|c|c|c|c|c|c|c|c|c|c|c|c}
\hline & \multicolumn{4}{|c}{ CONTÁBIL } & \multicolumn{4}{c|}{ ECONÔMICO } & \multicolumn{5}{c}{ FIXO } \\
\cline { 2 - 14 } & Temp & Simula & Invest & Desv & Temp & Simula & Invest & Desv & Temp & Simula & Invest & Desv \\
\hline $\mathrm{Z}$ & $-1,93$ & $-5,76$ & $-2,16$ & $-6,49$ & $-0,09$ & $-2,15$ & $-5,58$ & $-2,68$ & $-1,69$ & $-3,56$ & $-1,55$ & $-2,22$ \\
\hline $\begin{array}{l}\text { P-valor } \\
\text { (bicaudal) }\end{array}$ & 0,053 & 0,000 & 0,031 & 0,000 & 0,930 & 0,032 & 0,000 & 0,007 & 0,090 & 0,000 & 0,122 & 0,026 \\
\hline
\end{tabular}

Nota: i) o teste foi feito comparando, dentro dos grupos, a situação antes e depois do tratamento; ii) a análise foi conduzida considerando um nível de significância de 5\%; iii) CONTÁBIL representa o grupo de tratamento vinculado ao lucro contábil antes e depois do tratamento, ECONÔMICO representa o grupo de tratamento vinculado ao lucro econômico antes e depois do tratamento e FIXO representa o grupo de controle antes e depois do tratamento; iv) Temp, Simula, Invest e Desv são as variáveis dependentes do experimento. Fonte: Elaborado pelo autor com base nos dados da pesquisa.

Como se percebe, os resultados da tabela 9 sugerem que dentro do grupo de tratamento vinculado ao lucro contábil todas as variáveis apresentaram significância estatística. No grupo vinculado ao lucro econômico apenas a variável Temp não teve significância, e no grupo de controle as variáveis Temp e Invest não apresentaram diferença estatística. Esses resultados divergem um pouco do teste paramétrico (ANOVA), mas ambos são apenas exploratórios.

Todavia, os contrastes não informam claramente se o contrato de incentivo teve ou não efeito no comportamento dos indivíduos. Para detectar esse efeito, se houver, é necessário comparar a diferença na média de cada grupo de tratamento com a diferença na média do grupo de controle. Esse procedimento foi realizado através da técnica de análise de regressão múltipla, utilizando o método de diferença em diferença. Através desse método, comparam-se os grupos de tratamento e de controle antes e depois da intervenção. Para tanto, calcula-se a 
diferença na média das variáveis dependentes antes e depois da intervenção para cada grupo, tratado e não tratado. A diferença entre estas duas diferenças é o efeito estimado do incentivo.

\subsubsection{O Efeito do Lucro Econômico sobre o Esforço: Hipóteses H1(a), H1(b) e H1(c)}

Conforme descrito no capítulo 3, as hipóteses foram testadas através do procedimento estatístico de análise de regressão múltipla. Ao todo, foram desenvolvidos cinco modelos de regressão estimados em dados em painel de efeito fixo e correção para heteroscedasticidade. Formalmente, foi utilizado o teste de especificação de Hausman, conforme proposto por Greene (2003), para avaliar qual modelo de dados em painel melhor se ajustaria aos dados. Todavia, mesmo naquelas situações onde o teste estatístico indicou o modelo de efeitos aleatórios como o mais apropriado, optou-se por apresentar os resultados com base no modelo de efeitos fixos ${ }^{12}$. Após a especificação dos modelos, foram realizados os testes para avaliar a estrutura dos dados e diagnosticar possíveis problemas em relação à autocorrelação e heteroscedasticidade. Os resultados de todos os testes (especificação e diagnóstico) estão nos apêndices desse trabalho.

As três primeiras hipóteses se referem ao comportamento dos participantes em relação à decisão de alocação do esforço na realização da tarefa proposta. Conforme sugerem Libby e Lipe (1992) e Bonner e Sprinkle (2002), o esforço é um construto que pode ser mensurado em mais de uma dimensão (duração, intensidade e direção). A hipótese H1(a) trata da duração do esforço e declara que haverá aumento no tempo dedicado à tarefa quando os sujeitos estiverem subordinados ao contrato de incentivo baseado no lucro econômico, mesmo na presença do problema do horizonte. Essa predição foi avaliada através de uma análise de regressão múltipla onde o contrato de incentivo é a variável explicativa e o tempo que o indivíduo dedicou à tarefa (Temp) é a variável dependente, com base no seguinte modelo:

$$
T e m p=\beta_{0}+\beta_{1}(D t)+\beta_{2}(E c o)+\beta_{3}(\text { Cont })+\beta_{4}(E c o * D t)-\beta_{5}(C o n t * D t)+\varepsilon_{i}(\operatorname{modelo} 1)
$$

O teste de hipótese foi feito sobre o coeficiente da variável $\boldsymbol{E} \boldsymbol{c o} * \boldsymbol{D} \boldsymbol{t}$, sendo a constante $\boldsymbol{\beta}_{\boldsymbol{0}}$ a referência para as análises. A regressão foi processada com base em dados em painel de efeito

\footnotetext{
${ }^{12}$ Impende salientar que os resultados de todas as regressões são robustos para qualquer modelo de dados em painel. Tanto nos modelos de efeitos fixos quanto nos modelos de efeitos aleatórios e MQO agrupado (pooled) os resultados são iguais em termos de significância estatística e sinal dos coeficientes das variáveis de interesses. $\mathrm{O}$ apêndice 6 mostra os resultados de todos os modelos bem como o diagnóstico das regressões.
} 
fixo. Na avaliação dos pressupostos, foi detectado possível problema com relação à heteroscedasticidade. Em função disso, optou-se pela correção através da estimação do modelo com erros padrão robustos. A tabela 10 apresenta os resultados para a primeira hipótese.

Tabela 10 - Modelo 1: Resultados da Regressão em Dados em Painel para a Variável Temp (tempo dedicado à tarefa)

\begin{tabular}{lccccc}
\hline & Coeficiente & Erro Padrão & razão- $t$ & $p$-valor & \\
\hline Const & 2,72105 & 0,32564 & 8,3560 & $<0,00001$ & $* * *$ \\
Dt & $-0,238462$ & 0,465902 & $-0,5118$ & 0,60894 & \\
Cont*Dt & $-0,0895385$ & 0,147301 & $-0,6079$ & 0,54348 & \\
Eco*Dt & 0,262462 & 0,174812 & 1,5014 & 0,13372 & \\
\hline
\end{tabular}

Nota: i) $* * *$ significativo a 1\%; ii) dados em Painel com Efeito Fixo e erros padrão robustos estimados pelo método PCSE (Panel-Corrected Standard Errors) de Beck e Katz; iii) valor da estatística F = 4,9616, com pvalor $=0,0000$ e $\mathrm{R}^{2}=0,3624$; iv) o intercepto (constante) reflete a mensuração da variável em estudo para $\mathrm{o}$ grupo de controle antes do tratamento; v) $\boldsymbol{D} \boldsymbol{t}$ é uma variável dummy que assume valor 1 quando os dados se referem ao período pós-tratamento e 0 para o período pré-tratamento. Representa o valor marginal da variável em estudo para o grupo de controle depois do tratamento; vi) $\boldsymbol{C o n t} \boldsymbol{*}_{\boldsymbol{D} \boldsymbol{t}}$ indica o efeito do tratamento quando o lucro contábil é a mensuração de desempenho; Eco*Dt indica o efeito do tratamento quando o lucro econômico é a mensuração de desempenho; vii) a variável dependente Temp representa o tempo médio, por loja, que o participante dedicou a realização da tarefa.

Fonte: Elaborado pelo autor com base nos dados da pesquisa.

Com base na tabela 7, observa-se que a variável Temp variou de 2,98 para 2,65 (diferença de $-0,33$ ou $-11,07 \%$ ) no grupo vinculado ao lucro contábil, de 2,83 para 2,86 (diferença de 0,03 ou 1,06\%) no grupo vinculado ao lucro econômico e de 2,37 para 2,13 (diferença de -0,24 ou $-10,13 \%)$ no grupo de controle. Da tabela 9, sabe-se que nenhuma dessas diferenças é significativa, sugerindo que o tratamento (incentivo com base no desempenho) não teve efeito no comportamento dos indivíduos.

Por sua vez, considerando os dados da regressão, quando se avalia o efeito do tratamento confrontando a diferença dentro do grupo de controle contra a diferença dentro do grupo de tratamento vinculado ao lucro econômico (diferença das diferenças), através do coeficiente da variável $\boldsymbol{E} \boldsymbol{c o} * \boldsymbol{D} \boldsymbol{t}$, nota-se que o efeito marginal do incentivo no tempo dedicado à tarefa não é estatisticamente significativo $(0,2625$; $\mathrm{p}$-valor $=0,0,1337)$. Do mesmo modo, o coeficiente da variável Cont ${ }^{*} \boldsymbol{D} \boldsymbol{t}$ não tem significância $(-0,0895$; $\mathrm{p}$-valor $=0,5435)$. Considerando que o grupo de controle antes da manipulação experimental é a base para comparações e que ele também não sofreu alteração ao longo do tempo, pois o coeficiente da variável $\boldsymbol{D} \boldsymbol{t}$ foi não significativo $(-0,2385$ com $\mathrm{p}$-valor $=0,6089)$, os resultados sugerem que incentivo monetário vinculado ao lucro econômico não teve o efeito esperado. Com base nisso, portanto, não foi encontrado suporte para H1(a). 
No entanto, para saber o real significado do resultado dessa dimensão do esforço é importante avaliar o comportamento nas demais dimensões (intensidade e direção), pois é possível que elas tenham sofrido modificação em função do tratamento e isso esteja relacionado com o tempo dedicado à tarefa. Por isso, considerando o resultado do teste da primeira hipótese, é importante examinar se o padrão identificado se repete nos demais indicadores do esforço.

A hipótese H1(b) trata da intensidade do esforço e declara que haverá aumento nessa dimensão quando os sujeitos estiverem subordinados ao contrato de incentivo baseado no lucro econômico, mesmo na situação onde o problema do horizonte esteja presente. Para avaliar essa predição, foi conduzida uma nova análise de regressão múltipla cuja medida do esforço (variável dependente) é o número de vezes que o indivíduo utilizou o simulador para tentar descobrir qual o montante de investimento maximizaria o fluxo de caixa líquido futuro da loja (Simula). O teste foi feito a partir do seguinte modelo:

$$
\text { Simula }=\beta_{0}+\beta_{1}(D t)+\beta_{2}(E c o)+\beta_{3}(\text { Cont })+\beta_{4}(E c o * D t)-\beta_{5}(C o n t * D t)+\varepsilon_{i}(\operatorname{modelo} 2)
$$

Como em H1(a), o teste de hipótese foi em cima do coeficiente da variável $\boldsymbol{E} \boldsymbol{c o} * \boldsymbol{D} \boldsymbol{t}$, tendo como referência a constante $\boldsymbol{\beta}_{\boldsymbol{0}}$. A regressão foi processada em dados em painel com efeito fixo. $\mathrm{Na}$ avaliação dos pressupostos, observou-se possível problema com a heteroscedasticidade, por isso os erros padrão foram estimados de maneira robusta. A tabela 11 apresenta os resultados do modelo relativos ao segundo indicador do esforço.

Tabela 11 - Modelo 2: Resultados da Regressão em Dados em Painel para a Variável Simula

\begin{tabular}{lccccc}
\hline & Coeficiente & Erro Padrão & \multicolumn{2}{c}{ razão- $t$} & \multicolumn{2}{c}{$p$-valor } \\
\hline Constante & 18,3553 & 0,820375 & 22,3742 & $<0,00001$ & $* * *$ \\
Dt & $-2,87692$ & 0,911855 & $-3,1550$ & 0,00168 & $* * *$ \\
Cont*Dt & $-4,81108$ & 1,3306 & $-3,6157$ & 0,00032 & $* * *$ \\
Eco*Dt & 4,60492 & 1,22359 & 3,7634 & 0,00018 & $* * *$ \\
\hline
\end{tabular}

Nota: i) *** significativo a 1\%; ii) dados em Painel com Efeito Fixo e erros padrão robustos estimados pelo método PCSE (Panel-Corrected Standard Errors) de Beck e Katz; iii) valor da estatística F = 12,7289, com pvalor $=0,0000$ e $\mathrm{R}^{2}=0,5932$; iv) o intercepto (constante) reflete a mensuração da variável em estudo para $\mathrm{o}$ grupo de controle antes do tratamento; v) $\boldsymbol{D} \boldsymbol{t}$ é uma variável dummy que assume valor 1 quando os dados se referem ao período pós-tratamento e 0 para o período pré-tratamento. Representa o valor marginal da variável em estudo para o grupo de controle depois do tratamento; vi) Cont ${ }^{*} \boldsymbol{D} \boldsymbol{t}$ indica o efeito do tratamento quando o lucro contábil é a mensuração de desempenho; Eco*Dt indica o efeito do tratamento quando o lucro econômico é a mensuração de desempenho; vii) a variável dependente Simula corresponde ao número de vezes que o participante simulou para tentar identificar o valor ótimo dos investimentos nas atividades.

Fonte: Elaborado pelo autor com base nos dados da pesquisa 
Como visto no teste de contrastes (tabela 8), apenas o grupo vinculado ao lucro contábil e o de controle apresentaram diferenças significativas na média da variável Simula depois do tratamento. Todavia, a análise de regressão mostra que o incentivo teve efeito em ambos os grupos de tratamento tendo em vista que os coeficientes das variáveis $\boldsymbol{C o n t} * \boldsymbol{D} \boldsymbol{t}$ e $\boldsymbol{E c \boldsymbol { c o }} * \boldsymbol{D} \boldsymbol{t}$ são significativos do ponto de vista estatístico $(-4,8111$ com p-valor $=0,0003$ e 4,6049 com pvalor $=0,0002$, respectivamente). Com isso, os resultados do modelo 2 sugerem que o incentivo contingente ao resultado influencia o comportamento dos indivíduos, independentemente do contrato. No entanto, na situação onde o problema do horizonte está presente, o lucro econômico foi o único que motivou o comportamento congruente, pois induziu ao aumento na intensidade do esforço. Logo, conforme prediz a teoria, foi encontrado suporte para a hipótese H1(b).

Além disso, os resultados do modelo 2 mostram ainda que o sinal do coeficiente para a variável Cont*Dt é negativo, indicando que, diferentemente do grupo vinculado ao lucro econômico, os participantes incentivados com base no lucro contábil diminuíram a intensidade do esforço mais do que o grupo de controle $(-2,8769$ com p-valor $=0,0017)$. Esse comportamento incongruente é o previsto pela teoria e sugere que os participantes priorizaram se esforçar menos e maximizar seus benefícios. No contexto do experimento, dado que o agente é avesso ao esforço e maximizador de riqueza, ao compensar com base no lucro contábil contemporâneo se incentiva à diminuição na intensidade da tarefa uma vez que os participantes desse grupo não precisariam se esforçar para achar o nível ótimo de investimento visando maximizar sua recompensa. Para tanto, bastaria investir o mínimo possível e simular nenhuma ou poucas vezes.

Finalmente, a tabela 12 apresenta os resultados para H1(c), referente à direção do esforço. Nessa hipótese é predito que o incentivo com base no lucro econômico fará com que o agente aloque mais recursos nas ações de longo prazo. Conforme explicam Bonner e Sprinkle (2002), o incentivo monetário vinculado ao desempenho deveria direcionar o esforço para a tarefa ou atividade que está sendo recompensada. Isso significa que, porque o lucro econômico é uma mensuração de desempenho congruente, os participantes irão alocar o máximo de recursos nas atividades I e II até atingir o ponto ótimo. O teste desta hipótese também foi feito com base na análise de regressão múltipla em dados em painel com efeito fixo, de acordo com o seguinte modelo: 


$$
\text { Invest }=\beta_{0}+\beta_{1}(D t)+\beta_{2}(E c o)+\beta_{3}(\text { Cont })+\beta_{4}(E c o * D t)-\beta_{5}(C o n t * D t)+\varepsilon_{i}(\operatorname{modelo} 3)
$$

Esse modelo também apresentou indícios de problemas em relação à heteroscedasticidade dos dados, por isso o mesmo foi estimado com erros padrão robusto.

Tabela 12 - Modelo 3: Resultados da Regressão em Dados em Painel para a Variável Invest (Valor dos investimentos nas atividades)

\begin{tabular}{lccccc}
\hline & Coeficiente & Erro Padrão & razão- $t$ & \multicolumn{2}{c}{$p$-valor } \\
\hline Const & $23.234,2$ & 838,93 & 27,6949 & $<0,00001$ & $* * *$ \\
Dt & $1.369,23$ & 1228,44 & 1,1146 & 0,26541 & \\
Cont*Dt & $-4.121,23$ & 499,53 & $-8,2502$ & $<0,00001$ & $* * *$ \\
Eco*Dt & $3.310,77$ & 490,14 & 6,7547 & $<0,00001$ & $* * *$ \\
\hline
\end{tabular}

Nota: i) $* * *$ significativo a 1\%; ii) dados em Painel com Efeito Fixo e erros padrão robustos estimados pelo método PCSE (Panel-Corrected Standard Errors) de Beck e Katz; iii) valor da estatística F = 9,4728, com pvalor $=0,000$ e $\mathrm{R}^{2}=0,5204$; iv) o intercepto (constante) reflete a mensuração da variável em estudo para o grupo de controle antes do tratamento; v) Dt é uma variável dummy que assume valor 1 quando os dados se referem ao período pós-tratamento e 0 para o período pré-tratamento. Representa o valor marginal da variável em estudo para o grupo de controle depois do tratamento; vi) $\boldsymbol{C o n t} \boldsymbol{*}_{\boldsymbol{D} \boldsymbol{t}}$ indica o efeito do tratamento quando o lucro contábil é a mensuração de desempenho; Eco*Dt indica o efeito do tratamento quando o lucro econômico é a mensuração de desempenho; vii) a variável dependente Invest representa o valor médio do investimento, por loja, nas atividades I e II.

Fonte: Elaborado pelo autor com base nos dados da pesquisa

Consistente com os resultados de $\mathrm{H} 1(\mathrm{~b})$, os dados mostram que em relação à dimensão "direção do esforço" o contrato de incentivo influenciou o comportamento dos indivíduos, pois os betas das variáveis $\boldsymbol{E} \boldsymbol{c o} * \boldsymbol{D} \boldsymbol{t}$ e $\boldsymbol{C o n t} * \boldsymbol{D} \boldsymbol{t}$ apresentam significância estatística (3.310,77 com $\mathrm{p}$-valor $=0,0000 \mathrm{e}-4.121,23 \mathrm{com}$-valor $=0,0000$, respectivamente). Isso sugere que o incentivo motivou os agentes a direcionar o esforço para aumentar a mensuração de desempenho e consequentemente a recompensa. Porém, porque o lucro contábil é uma mensuração de desempenho incongruente, os agentes vinculados a ela direcionaram seus esforços para ações de curto prazo abandonando alternativas de investimento com VPL positivo, conforme previsto pela teoria, enquanto que os participantes vinculados ao lucro econômico direcionaram o esforço para as ações de longo prazo. Com isso, os resultados dão suporte para a $\mathrm{H} 1(\mathrm{c})$.

Coletivamente, os resultados das hipóteses H1(a), H1(b) e H1(c) indicam que o incentivo monetário tem influência nas decisões de alocação de esforço dos indivíduos. Visando facilitar a análise dessa assertiva, foi desenvolvida uma escala de mensuração do construto esforço a partir das três dimensões utilizadas como aproximações do mesmo. Essa nova variável (denominada de $\boldsymbol{E}$ sforc) corresponde à soma dos valores padronizados das variáveis 
Tempo, Simula e Invest. A tabela 13 registra os resultados do efeito do incentivo monetário nessa nova mensuração do esforço.

Tabela 13 - Modelo 4: Resultados da Regressão em dados em Painel para a Variável Esforc (Mensuração do Esforço)

\begin{tabular}{lccccl}
\hline & Coeficiente & Erro Padrão & razão- $t$ & $p$-valor & \\
\hline Const & 0,106402 & 0,281623 & 0,3778 & 0,70569 & \\
Dt & $-0,206212$ & 0,411702 & $-0,5009$ & 0,61662 & \\
Cont*Dt & $-1,02466$ & 0,15505 & $-6,6086$ & $<0,00001$ & $* * *$ \\
Eco*Dt & 1,00462 & 0,230994 & 4,3491 & 0,00002 & $* * *$ \\
\hline
\end{tabular}

Nota: i) *** Significativo a 1\%; ii) dados em Painel com Efeito Fixo e erros padrão robustos estimados pelo método PCSE (Panel-Corrected Standard Errors) de Beck e Katz; iii) valor da estatística F = 11,5655, com pvalor $=0,0000$ e $\mathrm{R}^{2}=0,5698$; iv) o intercepto (constante) reflete a mensuração da variável em estudo para o grupo de controle antes do tratamento; v) Dt é uma variável dummy que assume valor 1 quando os dados se referem ao período pós-tratamento e 0 para o período pré-tratamento. Representa o valor marginal da variável em estudo para o grupo de controle depois do tratamento; vi) Cont $* \boldsymbol{D} \boldsymbol{t}$ indica o efeito do tratamento quando o lucro contábil é a mensuração de desempenho; $\boldsymbol{E} \boldsymbol{c o} * \boldsymbol{D} \boldsymbol{t}$ indica o efeito do tratamento quando o lucro econômico é a mensuração de desempenho; vii) a variável dependente $\boldsymbol{E s f o r c}$ corresponde à mensuração do construto esforço através da soma dos valores padronizados das variáveis Tempo, Simula e Invest.

Fonte: Elaborado pelo autor com base nos dados da pesquisa

Considerando os resultados do modelo 4, observa-se claramente que o contrato com base no lucro econômico promoveu o aumento do esforço (o beta da variável $\boldsymbol{E} \boldsymbol{c o} * \boldsymbol{D} \boldsymbol{t}$ é significativo e positivo: 1,0046 e p-valor $=0,0000)$. Por outro lado, o contrato baseado no lucro contábil motivou a diminuição do esforço em relação às ações de longo prazo (o beta da variável Cont $* \boldsymbol{D} \boldsymbol{t}$ é significativo e negativo: $-1,0247$ e p-valor $=0,0000)$. Esse achado é compatível com as predições da teoria da agência e já eram esperados em função dos resultados dos modelos 1, 2 e 3. Agora, resta saber se o aumento do esforço leva a melhoria no desempenho da tarefa. A próxima seção trata dessa questão.

\subsubsection{O Efeito do Lucro Econômico sobre o Desempenho: Hipótese H2}

Muitos estudos sugerem que quando o incentivo monetário motiva o esforço é esperado que haja melhora no desempenho da tarefa. Sendo assim, no caso do experimento desenvolvido, os participantes deverão melhorar suas decisões de investimentos, tomando como referência a maximização do fluxo de caixa futuro, quando submetidos ao contrato de incentivo baseado no lucro econômico. Para avaliar essa predição, uma hipótese foi formulada - H2 - e esta postula que as decisões dos indivíduos vinculados ao lucro econômico irão desviar menos das decisões ótimas de investimentos. Essa hipótese foi avaliada com base na seguinte regressão:

$$
D e s v=\beta_{0}+\beta_{1}(D t)+\beta_{2}(E c o)+\beta_{3}(C o n t)+\beta_{4}(E c o * D t)-\beta_{5}(C o n t * D t)+\varepsilon_{i} ; \text { e (modelo 4) }
$$


Nesse modelo, a variável Desv é a mensuração, em termos absolutos, do quanto a decisão do participante desviou da decisão ótima de investimento. A regressão foi conduzida com base em dados em painel de efeito fixo e erros padrão robustos. No diagnóstico desse modelo também foi detectado possível problema em relação a heteroscedasticidade. A tabela 14 evidencia os resultados da regressão.

Tabela 14 - Modelo 5: Resultados da Regressão em Dados em Painel para a Variável Desv (Desvio absoluto da decisão ótima de investimento)

\begin{tabular}{lccccl}
\hline & Coeficiente & Erro Padrão & razão-t & \multicolumn{2}{c}{$p$-valor } \\
\hline Const & $-5.086,6$ & $1.156,76$ & $-4,3973$ & 0,00001 & $* * *$ \\
Dt & $-4.752,22$ & $1.928,72$ & $-2,4639$ & 0,01399 & $* *$ \\
Cont*Dt & $-8.595,16$ & $1.268,51$ & $-6,7758$ & $<0,00001$ & $* * *$ \\
Eco*Dt & $4.708,06$ & $2.388,89$ & 1,9708 & 0,04915 & $* *$ \\
\hline
\end{tabular}

Nota: i) $* *$ significativo a $5 \%$ e *** significativo a $1 \%$; ii) dados em Painel com Efeito Fixo e erros padrão robustos estimados pelo método PCSE (Panel-Corrected Standard Errors) de Beck e Katz; iii) valor da estatística $\mathrm{F}=5,9795$, com p-valor $=0,000$ e $\mathrm{R}^{2}=0,4065$; iv) o intercepto (constante) reflete a mensuração da variável em estudo para o grupo de controle antes do tratamento; v) $\boldsymbol{D} \boldsymbol{t}$ é uma variável dummy que assume valor 1 quando os dados se referem ao período pós-tratamento e 0 para o período pré-tratamento. Representa o valor marginal da variável em estudo para o grupo de controle depois do tratamento; vi) Cont $* \boldsymbol{D} t$ indica o efeito do tratamento quando o lucro contábil é a mensuração de desempenho; $\boldsymbol{E} \boldsymbol{c o}$ * $\boldsymbol{D} \boldsymbol{t}$ indica o efeito do tratamento quando o lucro econômico é a mensuração de desempenho; vii) a variável dependente Desv corresponde à diferença absoluta entre o fluxo de caixa da decisão de investimento do participante e o fluxo de caixa ótimo.

Fonte: Elaborado pelo autor com base nos dados da pesquisa

Da tabela 7, sabe-se que a variável Desv variou de -2.575,76 para -15.923,14 (diferença de $13.347,38$ ou $518,19 \%$ ) no grupo vinculado ao lucro contábil, de $-5.715,75$ para $-5.759,91$ (diferença de -44,16 ou 0,77\%) no grupo vinculado ao lucro econômico e de -6.895,93 para 11.684,15 (diferença de $-4.752,22$ ou 68,91\%) no grupo de controle. Com base nesses dados, nota-se que o grupo vinculado ao lucro econômico quase não apresentou alteração nessa mensuração de desempenho. No entanto, quando se exclui a parte da variação relativa ao grupo de controle, observam-se nos resultados da regressão os seguintes betas para os grupos experimentais vinculados ao lucro contábil e ao lucro econômico, respectivamente: $-8.595,16$ $($ com p-valor $=0,0000)$ e 4.708,06 (com p-valor $=0,0492)$.

Todas as diferenças marginais são significativas indicando que houve efeito incentivo. Isso ocorreu porque, como o grupo de controle é a base de comparação, era esperado que os grupos de tratamento caminhassem na mesma direção daquele, caso não fossem submetidos à manipulação experimental. Em outras palavras, o desvio médio do grupo vinculado ao lucro econômico deveria ser igual a $-10.467,97$ (da soma: $-5.715,75$ - 4.752,22), mas o valor foi de - 
$5.759,91$. No grupo vinculado ao lucro contábil o valor médio do desvio deveria ser igual a 7.327,98 (da soma: $-2.57,76-4.752,22$ ), mas foi de $-15.923,14$. Note-se que os coeficientes marginais 4.708,06 e -8.595,16 correspondem à diferença das diferenças.

Como os indivíduos subordinados ao lucro econômico mantiveram praticamente o mesmo desvio do fluxo de caixa ótimo depois do incentivo monetário, observa-se o efeito do tratamento indicando que essa mensuração forward-looking motivou a melhoria no desempenho em relação às decisões de investimentos. Por outro lado, como no grupo vinculado ao lucro contábil o desvio aumentou mais do que no grupo de controle, conclui-se que essa mensuração contemporânea de desempenho é distorcida e motivou a piora na qualidade das decisões. Portanto, de acordo com os resultados documentados, a hipótese H2 foi suportada.

\subsubsection{Considerações Adicionais sobre os Resultados}

Em conjunto, os resultados das quatro hipóteses sugerem que o incentivo monetário promove o aumento do esforço, que por sua vez leva a melhoria no desempenho. No que tange especificamente ao esforço na realização da tarefa, confrontando os resultados dos modelos 1 e 2 com o modelo 4, observa-se que no grupo de tratamento vinculado ao lucro econômico houve aumento na sua intensidade, mesmo não havendo mudança significativa no tempo dedicado a tarefa depois da manipulação experimental. Esse achado sugere que o lucro econômico levou ao aumento na eficiência em função do processo de aprendizagem. Isso pode ter ocorrido porque, conforme explicam Bonner e Sprinkle (2002), o incentivo monetário motiva as pessoas a alocar mais esforço para adquirir as habilidades necessárias visando executar uma tarefa de modo que no futuro o desempenho e as recompensas sejam maiores. Esta forma de aumento do esforço (denominada estratégia de desenvolvimento) está relacionada com processo individual de aprendizado.

Como a medida da intensidade é o número de vezes que o participante fez a simulação em busca do nível de investimento ótimo, se existisse uma relação linear positiva entre o tempo e a intensidade, seria esperado que a intensidade do esforço também não alterasse significativamente depois do tratamento. Porém, os participantes aumentaram-na sem alterar significativamente o tempo de dedicado à realização da tarefa. Nesse caso, o lucro econômico pode ter motivado a melhoria no aprendizado dos participantes, levando-os a aprimorar suas 
estratégias na hora de tomar as decisões. Isso pode ter feito com que os indivíduos se tornassem mais eficientes, pois o grupo de tratamento subordinado ao lucro econômico aumentou o número de simulações por minuto, de 6,12 para 7,33 simulações.

Esse raciocínio não pode ser adotado para o grupo vinculado ao lucro contábil, tendo em vista que, mesmo tendo mantido o tempo de dedicação a tarefa estatisticamente igual antes e depois do tratamento, os indivíduos vinculados a este grupo diminuíram a intensidade do esforço (nesse caso, a razão entre o número de simulação e o tempo dedicado a tarefa variou de 7,54 para 5,71). Isso pode ter ocorrido em função do comportamento oportunista previsto pela teoria da agência, de modo que os participantes desse grupo não se sentiram motivados para um esforço adicional que levasse ao aprimoramento na estratégia de suas decisões de investimento e o consequente aumento da eficiência. Observe-se que esse mesmo fenômeno pode ter ocorrido com o grupo de controle, uma vez que o numero de simulações por minuto variou de 6,21 para 5,2 dentro deste grupo.

Para avaliar se, efetivamente, o contrato de incentivo teve efeito no numero de simulações por minuto, foi conduzida uma nova análise de regressão a partir da razão entre as variáveis $\mathbf{T e m p}$ e Simula (Simula/Temp). A tabela 15 mostra os resultados das estimativas e aponta que o efeito marginal do lucro econômico foi positivo e estatisticamente significativo, pois o beta da variável $\boldsymbol{E} \boldsymbol{c o} * \boldsymbol{D} \boldsymbol{t}$ foi de 2,38 com p-valor de 0,0014.

Tabela 15 - Modelo 6: Resultados da Regressão em Dados em Painel para a Variável Simula/Temp (número de simulações por minuto)

\begin{tabular}{|c|c|c|c|c|c|}
\hline & Coeficiente & Erro Padrão & razão-t & \multicolumn{2}{|c|}{$p$-valor } \\
\hline Const & 6,66763 & 0,435924 & 15,2954 & $<0,00001$ & $* * *$ \\
\hline Dt & $-0,806676$ & 0,742713 & $-1,0861$ & 0,27781 & \\
\hline Cont*Dt & $-0,627111$ & 0,581393 & $-1,0786$ & 0,28113 & \\
\hline $\mathrm{Eco}^{*} \mathrm{Dt}$ & 2,38186 & 0,743184 & 3,2049 & 0,00141 & $* * *$ \\
\hline
\end{tabular}

Nota: i) *** significativo a 1\%; ii) dados em Painel com Efeito Fixo e erros padrão robustos estimados pelo método PCSE (Panel-Corrected Standard Errors) de Beck e Katz; iii) valor da estatística F = 6,9156, com pvalor $=0,000$ e $\mathrm{R}^{2}=0,4420$; iv) o intercepto (constante) reflete a mensuração da variável em estudo para $\mathrm{o}$ grupo de controle antes do tratamento; v) $\boldsymbol{D} t$ é uma variável dummy que assume valor 1 quando os dados se referem ao período pós-tratamento e 0 para o período pré-tratamento. Representa o valor marginal da variável em estudo para o grupo de controle depois do tratamento; vi) Cont $* \boldsymbol{D} \boldsymbol{t}$ indica o efeito do tratamento quando o lucro contábil é a mensuração de desempenho; Eco*Dt indica o efeito do tratamento quando o lucro econômico é a mensuração de desempenho; vii) a variável dependente Simula/Temp corresponde ao número de vezes que o participante fez a simulação para identificar o nível ótimo de investimento em cada loja. Fonte: Elaborado pelo autor com base nos dados da pesquisa

Por outro lado, os resultados da tabela 15 sugerem que compensar com base no lucro contábil contemporâneo não teve efeito no comportamento dos indivíduos, pois o coeficiente da 
variável Cont*Dt, que mede o efeito margina do tratamento, não foi significativo $(-0,6271$, com p-valor de 0,2811$)$. Isso pode ter ocorrido porque ao recompensar com base no lucro contábil se impõe um tradeoff aos participantes, que se torna mais agudo na presença do problema do horizonte: investir menos para maximizar seus ganhos, ou se esforçar para identificar o nível ótimo de investimento e maximizar o retorno da empresa. Dado que o lucro contábil contemporâneo é uma medida incongruente, os sujeitos vinculados a essa mensuração de desempenho só poderiam maximizar seus ganhos minimizando o montante de recursos alocados nas atividades atuais que afetam o fluxo de caixa futuro. Para tanto, bastaria alocar o mínimo de recursos obrigatoriamente estabelecido sem a necessidade de pesquisar o nível ótimo de investimento. Esse comportamento naturalmente conduziria à diminuição na intensidade do esforço, mesmo que continuassem dedicando o mesmo tempo à tarefa.

Em relação à avaliação de desempenho na realização da tarefa, foi desenvolvida uma análise adicional com base no número de vezes que, em média, cada participante conseguiu identificar o valor ótimo dos investimentos nas atividades I e II antes e depois do tratamento. As tabelas 16, 17 e 18 mostram a mensuração dessa nova variável, os resultados dos testes não paramétricos ${ }^{13}$ de Mann-Whitney, relativo à comparação da diferença das diferenças entre os grupos (dentro de cada grupo de tratamento comparada com a diferença dentro do grupo de controle) e de Wilcoxon relativo à comparação antes e depois dentro de cada grupo. Apenas como informação adicional, foi realizado um teste $t$ para amostras independentes cuja síntese do resultado está na tabela 18.

Tabela 16 - Número de Vezes que o Valor do Investimento Ótimo foi Identificado

\begin{tabular}{l|c|c|c|c|c|c}
\hline \multicolumn{1}{c}{ Antes e Depois do Tratamento } \\
\hline \multirow{2}{*}{ VARIÁVEL } & \multicolumn{2}{|c|}{ CONTÁBIL } & \multicolumn{2}{c|}{ ECONÔMICO } & \multicolumn{2}{c}{ FIXO } \\
\cline { 2 - 8 } & Antes & Depois & Antes & Depois & Antes & Depois \\
\hline $\begin{array}{l}\text { N. }{ }^{\circ} \text { de vezes que o } \\
\text { valor do investimento } \\
\text { ótimo foi identificado }\end{array}$ & 1,92 & 1,04 & 1,52 & 2,60 & 1,19 & 1,50 \\
\hline
\end{tabular}

Nota: CONTÁBIL representa o grupo vinculado ao lucro contábil antes e depois do tratamento, ECONÔMICO representa o grupo vinculado ao lucro econômico antes e depois do tratamento e FIXO representa o grupo de controle.

Fonte: Elaborado pelo autor com base nos dados da pesquisa.

\footnotetext{
${ }^{13}$ Optou-se apenas pela realização do teste não paramétrico porque não foram apuradas medidas repetidas para essa mensuração de desempenho adicional. Existe apenas uma média antes e uma média depois do tratamento para cada participante.
} 
Tabela 17 - Resultado do Teste Mann-Whitney para Amostras

Independentes - Grupo de Controle x Grupo de Tratamento

\begin{tabular}{l|r|r}
\hline Estatísticas & Contábil x \\
Controle & $\begin{array}{r}\text { Econômico x } \\
\text { Controle }\end{array}$ \\
\hline Mann-Whitney U & 173,000 & 125,000 \\
Wilcoxon W & 498,000 & 450,000 \\
Z & $-2,968$ & $-3,709$ \\
P-valor (bicaudal) & 0,003 & 0,000 \\
\hline
\end{tabular}

Nota: O resultado trata da diferença das diferenças das médias entre o grupo de controle e o grupo de tratamento em relação à mensuração do n. ${ }^{\circ}$ de vezes que o participante conseguiu identificar o valor do investimento ótimo.

Fonte: Elaborado pelo autor com base nos dados da pesquisa.

Tabela 18 - Resultado do Teste Wilcoxon para Amostras Dependentes Dentro dos Grupos

\begin{tabular}{l|r|r|r}
\hline Estatísticas & CONTÁBIL & ECONÔMICO & FIXO \\
\hline Z & $-2,588$ & $-2,404$ & $-1,734$ \\
P-valor (bicaudal) & 0,01 & 0,02 & 0,08 \\
\hline
\end{tabular}

Nota: i) o teste foi feito comparando, dentro dos grupos, a situação antes e depois do tratamento; ii) a análise foi conduzida considerando um nível de significância de 5\%; iii) CONTÁBIL representa o grupo de tratamento vinculado ao lucro contábil antes e depois do tratamento, ECONÔMICO representa o grupo de tratamento vinculado ao lucro econômico antes e depois do tratamento e FIXO representa o grupo de controle antes e depois do tratamento.

Fonte: Elaborado pelo autor com base nos dados da pesquisa.

Tabela 19 - Teste-t: Duas Amostras Independentes Presumindo Variâncias Diferentes - Entre Grupos

\begin{tabular}{l|r|r}
\hline Estatísticas & $\begin{array}{r}\text { Grupo de Controle x } \\
\text { Grupo de Tratamento 1 } \\
\text { (lucro contábil) }\end{array}$ & $\begin{array}{r}\text { Grupo de Controle x } \\
\text { Grupo de Tratamento 2 } \\
\text { (lucro econômico) }\end{array}$ \\
\hline Stat t & $-3,56$ & 1,95 \\
P-valor unicaudal & 0,00 & 0,03 \\
$t$ crítico unicaudal & 1,68 & 1,69 \\
\hline
\end{tabular}

Nota: $\mathrm{O}$ resultado trata da diferença das diferenças das médias entre o grupo de controle e o grupo de tratamento em relação à mensuração do $n .^{\circ}$ de vezes que o participante conseguiu identificar o valor do investimento ótimo.

Fonte: Elaborado pelo autor com base nos dados da pesquisa

Os resultados mostram claramente o melhor desempenho do grupo de tratamento vinculado ao lucro econômico. A avaliação do efeito do tratamento (tabela 17) sugere que o incentivo teve influência no comportamento dos dois grupos, conforme já apontado. Note-se ainda que, considerando o nível de significância de 5\%, apenas o grupo de controle não apresentou diferença significativa entre o antes e depois (tabela 17; p-valor $=0,08$ ). Esses achados são consistentes com aqueles documentados na tabela 14 relativos ao modelo de análise de regressão múltipla com dados em painel. A tabela 19 registra os resultados do teste 
paramétrico de diferença de médias, e também indica haver diferenças nas diferenças entre o grupo de controle e os grupos de tratamento (p-valor unicaudal ${ }^{14}$ de 0,00 e 0,03 ).

A avaliação do número de vezes que o participante conseguiu identificar o nível ótimo de investimento mensura com mais exatidão a qualidade das decisões. A mensuração do desvio em relação ao fluxo de caixa ótimo é resultado da estratégia que o indivíduo adotou para tomar suas decisões de investimento e levar a cabo sua tarefa, mas não permite discriminar adequadamente as decisões de maior qualidade daquelas de menor qualidade. Por exemplo, é possível que algum participante tenha alocado recursos nas atividades de forma aleatória, com pouco empenho cognitivo, focando apenas cumprir a tarefa e receber a compensação ao final do experimento. Mesmo assim, ele poderia alocar um valor bem próximo do nível ótimo apresentando um bom desempenho pelo critério de desvio do fluxo de caixa ótimo.

Por outro lado, a mensuração da quantidade de vezes que o participante conseguiu identificar o nível ótimo de investimento discrimina melhor a qualidade da decisão tomada porque corresponde ao resultado da combinação entre intensidade do esforço e a estratégia utilizada no processo de tomada de decisão de investimento. Sendo assim, representa uma métrica mais acurada da qualidade das decisões.

Outro aspecto importante que merece ser observado é o fato dos resultados oferecerem, parcialmente, uma prova formal para às proposições feitas por Holmström e Milgrom (1991) em um dos trabalhos mais influentes da área. Os autores demonstram que num ambiente de múltiplas tarefas, onde existam duas ações substitutas igualmente importantes para o principal, o agente irá direcionar seu esforço para aquela que está sendo mensurada e incentivada. Isso implica que a direção do esforço só será congruente com os objetivos do principal se o desempenho na tarefa for recompensado com base em uma mensuração não distorcida. Caso o incentivo monetário seja provido com base em uma mensuração de desempenho distorcida, concluem os autores, é preferível compensar os agentes com base em uma remuneração fixa, pois, nesse caso, esse seria um contrato mais custo-efetivo do ponto de vista do principal e evitaria a distorção na alocação de esforço.

\footnotetext{
${ }^{14}$ Utilizou-se o p-valor unicaudal porque a hipótese a priori é que o grupo vinculado ao lucro econômico varia positivamente em relação ao grupo de controle enquanto que o grupo vinculado ao lucro contábil varia negativamente.
} 
No experimento, quando se comprara, nos modelos 1, 2, e 3, os resultados do grupo de controle com os do grupo de tratamento vinculado ao lucro contábil, o coeficiente da variável $D \boldsymbol{t}$ (que indica o efeito marginal sobre a variável em estudo em relação ao grupo de controle depois da manipulação experimental) contra o valor do coeficiente da variável $\boldsymbol{C o n t} * \boldsymbol{D} \boldsymbol{t}$ (que representa o efeito marginal do tratamento na variável em estudo para o grupo de tratamento vinculado ao lucro contábil), observa-se que o grupo de controle teve um melhor desempenho, pois: i) não alterou significativamente o tempo dedicado a tarefa em relação ao grupo de tratamento (beta $=-0,3224$, com p-valor de 0,2375 , contra um beta de $-0,0769$, com p-valor de 0,8309 do efeito marginal do tratamento no modelo 1 ); ii) diminuiu em menor proporção a intensidade do esforço em comparação ao grupo de tratamento (beta $=-3,1575$ com p-valor 0,0188 , contra um beta de $-4,8321$, com p-valor de 0,0109 do efeito marginal do tratamento no modelo 2); e iii) aumentou o investimento nas atividades de longo prazo enquanto que o grupo de tratamento diminuiu (beta $=1.858,87$ com de $\mathrm{p}$-valor 0,0939 , contra um beta de 3.959,42, com de p-valor 0,0176 do efeito marginal do tratamento no modelo 3).

Portanto, no contexto do experimento, o custo de agência foi menor quando os participantes receberam compensação fixa ao invés de compensação variável contingente ao desempenho, quando a mensuração do desempenho era o lucro contábil contemporâneo. Esse aspecto serve para reforçar a ideia de que o sucesso de sistema de incentivo contingente ao desempenho depende de como o este é medido e recompensando. Sendo assim, a principal característica a ser observada na escolha da mensuração de desempenho é sua congruência.

\subsection{Teste Não paramétrico das Hipóteses H1(a), H1(b), H1(c) e H2(a)}

Para checar a robustez das estimativas das regressões foi realizado um teste não paramétrico com base na diferença das diferenças. A ideia foi comparar a diferença de médias entre os grupos como pares de amostras independentes (grupo de controle $\mathrm{x}$ grupo de tratamento). Para esse intento, foi utilizado o teste Mann-Whitney. As tabelas 18 e 19 mostram os resultados das estatísticas dos testes para os seguintes pares, respectivamente: grupo de tratamento 1 (Lucro Contábil) x Grupo de Controle; e grupo de tratamento 2 (lucro econômico) x grupo de controle. Nessa análise também foram consideradas as variáveis representando o construto esforço (Esforc) e o número de simulações por minuto (Simula/Temp). 
Tabela 20 - Estatísticas do Teste Mann-Whitney para diferença de Médias Grupo de Controle x Grupo de Tratamento 1 (lucro contábil)

\begin{tabular}{l|c|c|c|c|c|c}
\hline \multirow{2}{*}{} & \multicolumn{7}{|c}{ VARIÁVEIS } \\
\cline { 2 - 7 } & Desv & Simula & Temp & Invest & Esforc & Simula/Temp \\
\hline Mann-Whitney U & $6.012,50$ & $6.536,00$ & $7.898,50$ & $6.660,00$ & $6.471,50$ & $7.261,50$ \\
Wilcoxon W & $13.887,50$ & $14.411,00$ & $15.773,50$ & $14.535,00$ & $14.346,50$ & $15.136,50$ \\
Z & $-3,59$ & $-2,70$ & $-0,39$ & $-2,49$ & $-2,81$ & $-1,467$ \\
P-valor. (bicaudal) & 0,00 & 0,01 & 0,70 & 0,01 & 0,01 & 0,142 \\
\hline
\end{tabular}

Nota: O resultado trata da diferença das diferenças das médias entre o grupo de controle e o grupo de tratamento vinculado ao lucro contábil.

Fonte: Elaborado pelo autor com base nos dados da pesquisa.

Tabela 21 - Estatísticas do Teste Mann-Whitney para diferença de Médias Grupo de Controle x Grupo de Tratamento 2 (lucro econômico)

\begin{tabular}{l|c|c|c|c|c|c}
\hline & \multicolumn{6}{|c}{ VARIÁVEIS } \\
\cline { 2 - 7 } & Desv & Simula & Temp & Invest & Esforc & Simula/Temp \\
\hline Mann-Whitney U & $3.936,00$ & $4.553,00$ & $7.033,00$ & $4.960,00$ & $5.982,50$ & $6.924,50$ \\
Wilcoxon W & $11.811,00$ & $12.428,00$ & $14.908,00$ & $12.835,00$ & 14497,50 & $15.439,50$ \\
Z & $-6,78$ & $-5,71$ & $-1,39$ & $-5,00$ & $-3,64$ & $-2,039$ \\
P-valor. (bicaudal) & 0,00 & 0,00 & 0,17 & 0,00 & 0,00 & 0,041 \\
\hline
\end{tabular}

Nota: $\mathrm{O}$ resultado trata da diferença das diferenças das médias entre o grupo de controle e o grupo de tratamento vinculado ao lucro econômico.

Fonte: Elaborado pelo autor com base nos dados da pesquisa.

Como se observa nas tabelas 19 e 20, avaliando as variáveis dependentes separadamente, apenas a variável Tempo não apresentou significância estatística para alfa igual 0.05 (pvalores de 0,70 e 0,17 para os grupos de tratamento 1 e 2, respectivamente). Esse resultado é compatível com o da regressão no modelo 1. Em conjunto, esses achados conferem robustez às estimativas das regressões, uma vez que, no geral, indicam que o incentivo monetário teve efeito no comportamento dos participantes no que diz respeito às decisões de alocação de esforço e desempenho na tarefa. Essa análise é reforçada quando se verifica que o construto esforço também apresentou significância estatística das diferenças (p-valor =0,01 e 0,00 para os grupos de tratamento 1 e 2, respectivamente). Os resultados sugerem que, em relação ao esforço, o tratamento teve o efeito esperado em ambos os grupos e que os participantes subordinados ao lucro econômico aumentou o numero de simulações por minuto (p-valor igual a 0,041$)$.

\subsection{Análise do Poder Estatístico dos Modelos de Regressão}

Para o estabelecimento do tamanho da amostra, havia sido fixado um poder estatístico de 0,8 para um efeito de tamanho grande. De acordo com o padrão definido por Cohen (1988), no caso da análise de regressão e outras estatísticas baseadas em análise de correlação, o tamanho 
de efeito grande deve ser uma medida a partir de 0,35 . Como pode ser observado na tabela 21 , a pesquisa alcançou o tamanho pretendido, pois todos os modelos atingiram um efeito acima 0,35. Adicionalmente, a tabela 22 registra ainda que todos os modelos apresentaram poder estatístico acima do definido a priori $(0,8)$, tendo em vista que alcançaram poder igual a 0,9999. Naturalmente, a probabilidade de cometer o erro do tipo II na pesquisa foi praticamente inexistente.

Tabela 22 - Poder Estatístico e Tamanho do Feito dos Modelos de Regressão

\begin{tabular}{l|c|c|c|c}
\hline REGRESSÕES & $\mathrm{R}^{2}$ & Tamanho do Efeito $\left(\mathrm{f}^{2}\right)$ & $\begin{array}{c}\text { Poder } \\
\text { Estatístico }\end{array}$ & $\begin{array}{c}\text { Variável } \\
\text { Dependente }\end{array}$ \\
\hline Modelo 1 & 0,3624 & 0,5684 & 0,9999 & Temp \\
Modelo 2 & 0,5993 & 1,4579 & 0,9999 & Simula \\
Modelo 3 & 0,5204 & 1,0851 & 0,9999 & Invest \\
Modelo 4 & 0,5698 & 1,3245 & 0,9999 & Esforc \\
Modelo 5 & 0,4065 & 0,6849 & 0,9999 & Desv \\
\hline
\end{tabular}

Fonte: Elaborado pelo autor com base nos dados da pesquisa

Sobre o tamanho do efeito encontrado, é interessante observar o comentário de Camerer e Hogarth (1999). Os autores chamam a atenção para o fato de que o experimento é uma atividade cognitiva na qual os sujeitos participam com conhecimento e objetivos. Ganhar dinheiro pode ser um deles, mas não o único. Nesse tipo de atividade os participantes podem estar intrinsecamente motivados para desempenhá-la bem, querer mostrar sua inteligência, cumprir exigências implícitas do experimento ou exibir um comportamento socialmente aceitável como generosidade, ou assumir riscos. Esses aspectos, ou alguns deles, podem moderar o peso que os participantes colocaram no objetivo de ganhar o máximo de dinheiro no experimento de modo a afetar a extensão do efeito do incentivo monetário. Neste contexto, poderia se esperar um tamanho do feito pequeno ou médio. Todavia, ter identificado um efeito de tamanho grande pode ser considerado um aspecto relevante da presente pesquisa.

Destaca-se ainda que, o tamanho do efeito e o poder estatístico tem relação com o tamanho da amostra do estudo. Amostras grandes tendem a produzir testes com muito poder e isso faz com que se identifique facilmente uma diferença estatisticamente significante entre o grupo de controle e de tratamento se o efeito do tratamento realmente existir. Com o número de observações (760) que foram coletadas entre os 76 participantes do experimento e o poder estatístico de 0,9999, já seria possível alcançar significância estatística com um efeito de apenas 0,0685. Note-se, portanto, que a opção por analisar os dados como painel 
(longitudinalmente) conferiu alta sensibilidade aos testes. Isso pode ser visto como um diferencial dessa pesquisa em relação a muitos dos trabalhos que foram revisados e constam nas referências. 


\section{CONCLUSÕES DA PESQUISA E RECOMENDAÇÕES}

O contrato de incentivo contingente ao desempenho é visto como um importante mecanismo no combate à miopia gerencial. No entanto, estudos anteriores têm feito um amplo registro de evidências sugerindo o efeito adverso da formulação de contratos ancorados em mensurações de desempenho incongruentes por causa da sua associação com o comportamento míope dos gestores quando o problema do horizonte se faz presente. Nesse cenário, o gestor tenderá a focar excessivamente nas ações de curto prazo comprometendo a capacidade criação de valor no longo prazo da empresa.

A teoria prediz que na situação onde o horizonte no emprego do agente é de curto prazo, se o seu desempenho for recompensado com base em métricas contemporâneas, haverá um problema de incongruência que levará a inadequação na alocação de esforço, pois ele atuará de forma oportunista, priorizando as ações que aumentem sua compensação no curto prazo em detrimento do desempenho de longo prazo da firma. No entanto, se a métrica de avaliação de desempenho for congruente no sentido de alinhar os interesses do agente aos objetivos do principal, mesmo que o agente tenha horizonte de curto prazo, ele terá motivação para escolher o nível de esforço que maximizará a utilidade do principal (valor presente do fluxo de caixa líquido futuro da empresa), desde que sua ação também maximize sua compensação.

As evidências empíricas sugerem que o lucro contábil contemporâneo é uma mensuração de desempenho incongruente. Seu uso em contratos de incentivo contingentes ao desempenho induz o agente a se comportar de forma míope, alocando menos esforço em ações que maximizam os resultados de longo prazo da empresa. Todavia, conforme foi discutido neste trabalho, uma alternativa para lidar com esse problema é a incorporação de informações de natureza forward-looking. Muitos estudos têm sugerido que mensurações de desempenho forward-looking influenciam a decisão de alocação de esforço dos empregados com problema de horizonte. Incorporá-la aos contratos de incentivo ajuda a alinhar os objetivos de curto prazo do agente com os interesses de longo prazo do principal, motivando-o a direcionar seus esforços para as ações que criam valor para a empresa.

Com base nessa ideia, esta pesquisa investigou se o uso do lucro econômico, em contraste ao lucro contábil contemporâneo, em contratos motiva os indivíduos a agir de forma mais consistente com os objetivos de longo prazo da empresa. Os resultados demonstraram que, no 
contexto do experimento realizado, os indivíduos incentivados com base no lucro econômico dedicaram mais esforço para alcançar os objetivos estabelecidos e tomaram decisões de investimentos mais eficientes do ponto de vista da maximização do VPL dos fluxos de caixa futuros da empresa. Documentou-se que o efeito marginal do incentivo monetário foi estatisticamente significante em duas das três dimensões do esforço, e três (dentre quatro) hipóteses levantadas foram suportadas. Dessa forma, em resposta à questão de pesquisa formulada, o principal resultado desta pesquisa sugere que, por ser congruente, o lucro econômico ajuda a mitigar o problema do foco acessivo nas ações de curto prazo, promovendo o aumento do esforço e a melhoria do desempenho na realização da tarefa. A implicação direta disso é que incorporá-lo aos contratos motiva os agentes a agir de forma mais consistente com os objetivos de longo prazo da empresa, mesmo na presença do problema do horizonte.

Ao focar o lucro econômico, a pesquisa também forneceu um teste direto para as proposições teóricas sobre o uso de mensurações forward-looking para mitigar problemas e, ao mesmo tempo, documentou novas evidências da inadequação da formulação de contratos de incentivo baseados em medidas de desempenho distorcidas, tal como o lucro contábil. Por isso, os resultados encontrados ajudam a entender como certas propriedades dos sistemas de incentivo afetam o esforço e o desempenho, e de que maneira eles podem ser utilizados para alinhar os interesses dos membros da organização com os objetivos da empresa.

No geral, os resultados dos testes de hipóteses documentam de forma consistente que o contrato de incentivo contingente ao desempenho, dependendo do contexto em que é estabelecido, tem importância no comportamento econômico dos indivíduos, exercendo o papel de influenciar a tomada de decisão no que tange a intensidade e a direção do esforço na realização das tarefas e promovendo a melhoria ou a piora no desempenho delas. No experimento, as ações dos participantes sugerem que eles agiram no sentido de maximizar seus ganhos. Entretanto, com efeito, os resultados mostram que motivar os agentes para os objetivos pretendidos depende da mensuração de desempenho.

Ao longo do experimento, os resultados do grupo de tratamento vinculados ao lucro econômico indicam que esses sujeitos tentaram cumprir o contrato conforme estabelecido. Eles se esforçaram mais, aumentando a intensidade do esforço e investindo mais visando otimizar o fluxo de caixa futuro. Todavia, é provável que tenham feito isso porque estavam 
agindo em seu autointeresse procurando maximizar suas compensações, e a única forma de fazê-lo seria se dedicando da melhor maneira possível à tarefa, mesmo que para isso tivessem que se esforçar mais. Considerando que o lucro econômico é uma mensuração de desempenho congruente, os sujeitos vinculados a esta mensuração de desempenho maximizariam seus ganhos maximizando o fluxo de caixa líquido futuro da firma, mesmo enfrentando o problema do horizonte. A pesquisa mostrou que fornecer incentivo contingente ao lucro econômico fez com que os participantes, ao agirem em interesse próprio, adotassem aquelas ações que maximizariam a riqueza da empresa. Com isso, era esperado que o esforço aumentasse juntamente com a mensuração de desempenho.

Por outro lado, no contrato vinculado ao lucro contábil, os participantes abriram mão de executar a tarefa conforme havia sido contratado (maximizar o fluxo de caixa futuro) e agiram em seu próprio interesse para aumentar suas compensações, pois deixaram de investir nas atividades, diminuindo a intensidade do esforço na realização da tarefa. A pesquisa mostrou que quando é fornecido incentivo com base no lucro contábil contemporâneo, mesmo sabendo que seu objetivo é maximizar o retorno de longo prazo, os agentes preferiram direcionar seu esforço para os resultados de curto prazo, dedicando-se menos aos objetivos estabelecidos.

De acordo com a da pesquisa, quando se compara os dois grupos de tratamento e o grupo de controle, fica evidenciado que os benefícios do incentivo monetário vinculados ao desempenho dependem do tipo de contrato, da mensuração de desempenho e das circunstâncias em que ele é estabelecido, reforçando a ideia de que as métricas contábeis tradicionais são inadequadas para motivar o comportamento congruente dos agentes. Com isso, os resultados da pesquisa apresentam uma implicação direta: é contraproducente incentivar com base lucro contábil contemporâneo se o agente não espera que irá usufruir dos benefícios futuros gerados pelo seu esforço. Conforme já apontado em estudos anteriores, esta mensuração de desempenho induz ao comportamento míope.

Esses resultados são previstos pela teoria da agência da agência, conforme discutido no capítulo 2, e sugerem que os participantes agiram de forma racional procurando maximizar suas compensações. Isso aconteceu porque o agente é maximizador de riqueza e tem desutilidade em relação ao esforço. Por isso, só se dispõe a trabalhar mais se o ganho marginal do seu esforço for maior que seu custo marginal. Como a empresa em geral não consegue observar perfeitamente as ações do agente, na ausência de um sistema de 
monitoramento, ele irá se esquivar das tarefas. Todavia, caso seja recompensado monetariamente com base no seu desempenho, agirá de forma racional visando maximizar sua riqueza. Como resultado, irá direcionar seu esforço para onde o desempenho é diferencialmente recompensado, sendo que essa ação só será compatível com os objetivos da empresa se a mensuração de desempenho for congruente.

Nesse contexto, a mensuração de desempenho irá influenciar a decisão de alocação ótima de esforço dos agentes e, como consequência, mitigar ou piorar o problema de agência relacionado à assimetria de informação, devido ao fato do agente estar mais bem informado que o principal sobre suas ações e as decisões que afetam a utilidade do principal. Se o objetivo é fazer com que o agente direcione seu esforço para as ações de longo prazo que criam valor para a empresa o lucro econômico é uma mensuração de desempenho congruente, porque ao ser recompensado com base nessa métrica os agentes passam a usufruir contemporaneamente dos benefícios futuros esperados de suas decisões atuais. Sendo assim, pouco importa se estarão ou não no emprego quando os resultados efetivamente se realizarem. Além disso, no caso específico da situação onde o agente tem esperança de curto prazo no cargo, o contrato não impõe risco algum a ele. O principal é quem o suportará na sua integridade e em troca tem o comprometimento do agente com as ações de longo prazo que criam valor para a empresa. Dado que o principal pode diversificar o seu risco com outras alternativas de investimentos, o lucro econômico pode ser uma solução ótima para o contrato estabelecido.

Os resultados deste estudo apresentam outras implicações que merecem ser observadas. O principal foco das pesquisas em contrato de incentivo envolvendo mensurações forwardlooking tem sido as medidas não financeiras de desempenho. No entanto, como lembram Ittner e Larcker (1998), muitas empresas acreditam que as mensurações de desempenho devem ser puramente financeiras porque elas permitem que seus administradores concentrem esforços nos objetivos finais da empresa. Além disso, segundo Debusk (2004), existem evidências de que as medidas financeiras são percebidas pelos gestores como mais importantes do que as medidas não financeiras e os usuários dos sistemas de mensuração de desempenho dependem fortemente delas para orientar suas decisões no dia a dia da empresa O lucro econômico pode ser interpretado como uma métrica financeira de desempenho. Sendo assim, ao registrar que seu emprego em contratos de incentivo funciona, a pesquisa fornece 
uma indicação que o lucro econômico pode ser usado para suplantar eventuais dificuldades relacionadas às medidas não financeiras forward-looking de desempenho.

De mais a mais, por suas propriedades, o lucro econômico pode ser um substituto em situações onde o preço das ações não se aplica ou se constitui numa mensuração de desempenho incongruente, tal como numa estrutura de descentralização e delegação de autoridade e responsabilidade onde as áreas de responsabilidades lidam com um conjunto de ações que afetam o desempenho da firma tanto no curto prazo quanto no longo prazo. Nesse caos, o lucro econômico pode ser utilizado para incentivar gestores de centros de investimentos e centros de resultados.

Finalmente, outra implicação importante desta pesquisa é o fato de que, ao fornecer uma prova empírica que o uso do lucro econômico em contratos influencia a tomada de decisão, ela aponta para a relevância de sistemas de controle gerencial que adotam essa métrica em seu modelo de mensuração.

\subsection{Recomendações para Futuros Trabalhos}

Este estudo avaliou o uso do lucro econômico em contratos apenas na situação onde o agente tem horizonte de curto prazo. Não foram abordadas questões quando o horizonte do agente é de longo prazo. Alguns estudos têm tratado desse tema avaliando se mensurações forwardlooking, além de influenciar, auxiliam a tomada de decisão intertemporal. Todavia, a maior parte desses estudos utiliza mensurações não financeiras de desempenho ou o preço das ações da empresa. Seria importante avaliar em futuros trabalhos o impacto de contratos de incentivo contingentes ao lucro econômico nesse cenário, pois assim seria possível tratar da questão do compartilhamento de risco uma vez que, nesse caso, o contrato também deveria considerar o lucro econômico ex-post num ambiente onde a incerteza é uma variável importante porque pode afetar o comportamento e as decisões dos indivíduos.

Muitos estudos têm demonstrado que o incentivo monetário nem sempre surte o efeito esperado e, consequentemente, não induz ao aumento do esforço e nem melhora o desempenho na realização da tarefa (JENKINS et al,1998; CAMERER e HOGARTH, 1999; BONNER et al, 2000), pois, conforme esclarecem Baker et al (1994) a efetividade desse mecanismo de controle gerencial depende de uma série de fatores sociais, psicológicos e 
econômicos. Por exemplo, algumas pesquisas têm sugerido que outros fatores tais como atratividade da tarefa (BONNER e SPRINKLE, 2002; FESSLER, 2003; BAILEY e FESSLER, 2011), complexidade da tarefa (BONNER et al, 2000; BONNER e SPRINKLE, 2002; FESSLER, 2003; BERGER, 2009; FESSLER, 2003; BAILEY e FESSLER, 2011), o comprometimento com metas (BERGER, 2009) e o incentivo social e preocupações éticas (ALEXANDER e FRANK, 2007) podem moderar o efeito do incentivo monetário ou mediar sua relação com o desempenho na tarefa.

Fessler (2003) comenta que muitos estudos e meta-análises indicam a existência de correlação positiva entre atratividade da tarefa e desempenho. Isso sugere que compensação baseada em incentivos pode afetar tanto a percepção da atratividade da tarefa quanto o desempenho nela. Como consequência, a percepção da atratividade pode interagir com o incentivo contingente ao desempenho e influenciar o desempenho na tarefa. De acordo com Bailey e Fessler (2011), quando uma tarefa é percebida como atraente, os indivíduos são mais propensos a ser intrinsecamente motivados para realizá-la e, nesse caso, o incentivo monetário pode ter pouco efeito positivo.

Além disso, Bonner et al (2000) identificaram que o efeito do incentivo monetário também pode ser afetado pela complexidade da tarefa. Muitos dos trabalhos analisados apontaram que quanto mais complexa era a tarefa menor era o efeito do incentivo. Isso indica que a percepção sobre a complexidade pode servir como mediador entre o incentivo monetário e o desempenho na tarefa. À medida que aumenta a complexidade da tarefa, as habilidades específicas para desempenhá-la e o conhecimento sobre ela aumentam. Como consequência, o desempenho na tarefa se torna menos sensível ao aumento de esforço e ao incentivo monetário (BONNER et al, 2000). Portanto, para tarefas percebidas como complexas, contratos de incentivo podem levar a níveis mais elevados de esforço individual, mas pode não estar associado com níveis mais elevados de desempenho (BAILEY e FESSLER, 2011).

Segundo Berger (2009), pesquisas mostram que altos níveis de comprometimento com as metas têm efeito positivo sobre o desempenho e a consecução delas. Logo, o comprometimento é um antecedente crítico para a realização das metas. Nesse caso, o resultado na realização da tarefa pode ser afetado pelo nível de comprometimento do indivíduo, independentemente do incentivo monetário. 
Por fim, de acordo com Alexander e Frank (2007), as normas e éticas sociais podem prover incentivos para os indivíduos seguirem certo curso de ação e afetar a efetividade do incentivo monetário. Por exemplo, preocupações éticas podem fazer com que as pessoas ajam de forma não oportunista porque consideram eticamente reprovável pensar em seus próprios interesses. Interações sociais com grupos ou pessoas podem criar ambientes com incentivos sociais. Esses autores fizeram uma investigação experimental e documentaram que a distorção na alocação de esforço, provocada por incentivo monetário vinculado a mensurações de desempenho incongruentes, é significativamente reduzida pelo uso de incentivos sociais congruentes.

Coletivamente, esses aspectos têm bastante relevância no experimento realizado porque eles podem afetar, moderando ou mediando, a identificação e a mensuração do efeito incentivo. Portanto, pode ser útil avaliar a influência e controlar os efeitos dessas variáveis em futuros trabalhos que envolvam o uso do lucro econômico em contratos. 


\section{REFERÊNCIAS}

ABERNETHY, M.; BOUWENS, J.; LENT, L. The Role of Performance Measures in the Intertemporal Decisions of Business Unit Managers. Working paper, Tilburg University, 2008.

AGGARWAL, R. K. Executive compensation and incentives. In ECKBO, Espen Handbook of Empirical Corporate Finance. Vol. 2 Elsevier, 2008.

ALEXANDER, B. and FRANK, M. The role of financial incentives and social incentives in multi-task settings. Journal of Management Accounting Research; 19, 2007.

ANTHONY, R. N. \& YOUNG, D. W. Management control in nonprofit organizations. 7. ed. Boston: McGraw-Hill/Irwin, 2003.

ANTHONY, R. N.; DEARDEN J.; GOVINDARAJAN, V. Management control systems. 7ed. Boston: Irwin, 1992.

ANTHONY, R.; GOVINDARAJAN, Vijay. Sistema de controle gerencial. Trad. Adalberto Ferreira das Neves. São Paulo: Atlas, 2001.

ANTIA, M. et al. CEO decision horizon and firm performance: an empirical investigation. Journal of Corporate Finance, n. 16, issue 3, p. 288-301, 2010.

ANTLE, R.; DEMSKI, J. S. The controllability principle in responsibility accounting. The Accounting Review, n. 62, p. 700-718, 10/1988.

ANTLE, R.; SMITH, A. An empirical investigation of the relative performance evaluation of corporate executives. Journal of Accounting Research, n. 24, p. 1-39, Spring/1986.

ARELlANO, M. Panel Data Econometrics. Oxford: Oxford University Press, 2003.

ATKINSON, Anthony A. et al. Contabilidade Gerencial. Trad. André Olímpio Mosselman Du Chenoy Castro ; revisão técnica Rubens Fama. São Paulo: Atlas, 2000.

ATTMORE, Rober H. Forward-looking information: what it is and why it matters. Journal of Government Financial Management, Vol. 59, n. 4, pp 8-9, Winter/2010.

BABER, William R. et al. Accounting earnings and executive compensation: the role of earnings persistence. Journal of Accounting and Economics, n. 25, issue 2, p. 169-193, 05/1998. 
BAILEY, Charles D. and FESSLER, Nicholas J. The moderating effects of task complexity and task attractiveness on the impact of monetary incentives in repeated tasks. Journal of Management Accounting Research, n. 23, issue 1, p.189-210, Dec/2011.

BAIMAN, S.; NOEL J. Noncontrollable costs and responsibility accounting. Journal of Accounting Research, 23, p. 486-501, Autumn)/1985.

BAKER, G. P. Discussion of an analysis of the use of accounting and market measures of performance in executive compensation contracts. Journal of Accounting Research, v. 25, issue 3, p. 126-129, 1987.

BAKER, G. P. Distortion and risk in optimal incentive contracts. The Journal of Human Resources, n.4, p. 728-751, Autumn/2002.

BAKER, G. P. Incentive contracts and performance measurement. Journal of Political Economy, n.100, issue 3, p. 598-614, June/1992.

BAKER, George P. et. al. Subjective performance measures in optimal incentive contracts. Quarterly Journal of Economics, n. 109, issue 4, p. 1125-1156, 1994.

REICHELSTEIN, S. Providing managerial incentives: cash flows versus accrual accounting. Journal of Accounting Research, n. 38, issue 2, p. 243-269, 2000.

BAKER, George P. et. al. Compensation and incentives: practice vs. theory. Journal of Finance, n. XLIII, issue 3, p. 593-616, jul/1988.

BANKER, R. D.; DATAR, S. M. Sensitivity, precision, and linear aggregation of signals for performance evaluation. Journal of Accounting Research, 27, p.21-39, Spring/1989.

BANKER, R. D.; THEVARANJAN, A. Goal congruence and evaluation of performance measures. Working Paper, University of Texas at Dallas, 2000.

BAREKET, Moshe. Providing investment incentives: the role of revenue recognition in performance measurement. Ph.D. dissertation, Columbia University, United States - New York, 2002.

BAR-GILL, O.; BEBCHUK, L. A. Misreporting corporate performance. Working paper. Harvard Law School, 2003.

BARIL, C. P. Long-term incentive compensation plan adoption and the capital spending decisions of managers. Ph.D. dissertation. United States - Florida: University of Florida; 1986. Disponível em: http://www.proquest.com/; Publication Number: AAT 8715966.

BARKER, V. B. and MUELLER, G. C. CEO characteristics and firm $R \& D$ spending. Management Science, n. 48, p. 782-801, 2002. 
BASTIAN, N. M. Essays on managerial incentives and performance measurement. $\mathrm{Ph} . \mathrm{D}$. Dissertation. United States - California: Stanford University, 2005. Disponível em: http://www.proquest.com/;PublicationNumber:AAT 3186325.

BAUSELL R. Barker e LI, Yu-Fang. Power analysis for experimental research: a practical guide for the biological, medical and Social Sciences. Cambridge University Press, 2002.

BEBCHUK, L.; STOLE, L. Do short-term managerial objectives lead to under-or over investment in long-term projects? Journal of Finance, n. XLVIII, p. 719-30, 1993.

BEBCHUK, Lucian A. and FRIED, Jesse M. Paying for Long-Term Performance. University of Pennsylvania Law Review, Vol. 158, pp. 1915-1959, 2010; Harvard Law and Economics Discussion Paper No. 658. Available at SSRN: http://ssrn.com/abstract=1535355

BECK, N.; KATZ, J. What to do (and not to do) with time-series cross-section data. American Political Science Review, n.89, issue.3, p. 634-647, 1995.

BERGER, L. A. How incentive contracts and task complexity influence and facilitate longterm performance. Ph.D. dissertation. Canada: University of Waterloo (Canada); 2009.

BESANKO, D. et al. Economics of Strategy. 5 ed. Wiley, 2009.

BHOJRAJ, S.; LIBBY, R. Capital market pressure, disclosure frequency-induced earnings/cash flow conflict, and managerial myopia. Accounting Review, n. 80, issue 1, p. 1$20,2005$.

BONNER, Sarah E. et al. A review of the effects of financial incentives on performance in laboratory tasks: implications for management accounting. Journal of Management Accounting Research, n. 12, Issue 1, p. 19-64, 2000.

The effects of monetary incentives on effort and task performance: theories, evidence, and a framework for research. Accounting, Organizations and Society, n. 27, issues 4-5, p. 303-345, 2002.

BOUWENS, J.; LAURENCE V. L. Managerial investment horizon and the role of performance measures. Artigo não publicado, 2007. Disponível em: http://www.tilburguniversity.edu/research/institutes-

and;researchgroups/center/staff/lent/horizon.pdf.

BRICKLEY, J. A. et al. The impact of long-range managerial compensation plans on shareholder wealth. Journal of Accounting and Economics, n. 7, issue 1-3, p. 115-129, 1985 .

BUDDE, J. Performance Measure Congruity and the Balanced Scorecard. Journal of Accounting Research. n. 45, issue 3, p. 515-539, 2007. 
BUDDE, J. Performance measure congruity in linear agency models with interactive tasks. Discussion Paper No. 204, 2006. Disponível em: http://www.sfbtr15.de/uploads/media/204.pdf

Performance measure congruity and the balance scorecard. Journal of Accounting Research, n.45, issue 3, p. 515-539, june/2007.

BUSHEE, B. J. The influence of institutional investors in myopic $R \& D$ investment behavior. Accounting Review, n. 73, issue 3, p. 305-333, 1998.

BUSHMAN, R. M. et al. Private predecision information, performance measure congruity, and the value of delegation. Contemporary Accounting Research, n. 17, issue 4, p. 561$587,2000$.

CEO compensation: the role of individual performance evaluation.

Journal of Accounting \& Economics, n. 21, p. 161-193, 1996.

; INDJEJIKIAN, R. J.Accounting income, stock price and managerial compensation. Journal of Accounting and Economics, n. 16, p.3-23, January/April/July /1993.

CAMERER, Colin F. and HOGARTH, Robin M. The effects of financial incentives in experiments: a review and capital-labor-production framework. Journal of Risk and Uncertainty, n. 19, p. 7-42, 1999.

CAMERON, A. C.; TRIVEDI, P. K. Microeconometrics, Methods and Applications. Cambridge: Cambridge University Press, 2005.

CAZIER, R.A. R\&D spending among short-horizon CEOs: a reexamination. Phd Dissertation, The University of Iowa, United States - Iowa, 2009.

CHAN, L.; LAKONISHOK, J.; SOUGIANNIS, T. The stock market valuation of research and development expenditures. The Journal of Finance, n. 56, p. 2431-2456, 2001.

CHAN, S.; MARTIN, J; KENSINGER, J. Corporate research and development expenditures and share value. Journal of Financial Economics, n. 26, p. 255-276, 1990.

CHENG, et al. Yesterday's Heroes: Compensation and Creative Risk-Taking. ECGI Finance Working Paper No. 285/2010; AFA 2011 Denver Meetings Paper. Disponível em: http://ssrn.com/abstract=1502762

CHENG, S. R\&D expenditures and CEO compensation. The Accounting Review, n. 79, p. 305-328, 2004. 
R\&D expenditures and CEO compensation. Ph.D. dissertation. United States

- Pennsylvania: University of Pittsburgh; 2001. Disponível em: http://www.proquest.com/; Publication Number: AAT 3013251.

CHOW, C. W. The effects of job standard tightness and compensation scheme on performance: An exploration of linkages. The Accounting Review, n. 58, issue 4, p. 667-667, 1983.

CHOWDHURY, Jaideep. Managerial Myopia: A new look. 2012. Available at SSRN: http://ssrn.com/abstract=1991429 or http://dx.doi.org/10.2139/ssrn.1991429

CHURCHILL, G. A. Marketing research: methodological foundations. 3 ed. Fort Worth: The Dryden Press, 1987.

COHEN, J. Statistical power analysis for the behavioral sciences, 2nd. New York: Academic Press, 1988.

DATAR, et al. Balancing performance measures. Journal of Accounting Research, n. 39, p. 75-92, 2001.

DEBUSK, G. K. An examination of organizational performance measurement system utilization. Ph.D. dissertation. United States - Virginia: Virginia Polytechnic Institute and State University; 2004.

DECHOW, P. M.; SLOAN, R. G. Executive incentives and the horizon problem: an empirical investigation. Journal of Accounting \& Economics. n. 14, issue 1, p. 51-89, 1991.

DECHOW, et al. Economic consequences of accounting for stock based compensation. Journal of Accounting Research, n. 34, p.1-20, 1996.

DEMSKI, Joel S. Managerial Uses of Accounting Information, 2ed. Springer Science+Business Media, LLC, 2008.

DENISON, C. A. et al. Managers' incorporation of the value of real options into their longterm investment decisions: an experimental investigation. Contemporary Accounting Research: no-no. Accepted Articles (Accepted, unedited articles published online for future issues), 2011.

DIKOLLI, S. S. Agent employment horizons and contracting demand for forward-looking performance measures. Journal of Accounting Research, n. 39, issue 3, p. 481-494, 2001.

.; VAYSMAN, I. Contracting on the Stock Price and Forward-Looking Performance Measures. European Accounting Review, n. 15, issue 4, p. 445-464, 2006.

DON EGGINTON. Divisional performance measurement: residual income and the asset base. Management Accounting Research, n. 6, Issue 3, p. 201-222, September/1995. 
DUTTA, S., and REICHELSTEIN S. Asset valuation and performance measurement in a dynamic agency setting. Review of Accounting Studies, n. 4, p. 235-258, 1999.

Controlling investment decisions: depreciation and capital charges. Review of Accounting Studies, n.7, p. 253-281, 2002.

Accrual accounting for performance evaluation. Review of Accounting Studies, n. 10, p. 527-552, 2005.

Leading indicator variables, performance measurement, and long-term versus short-term contracts. Journal of Accounting Research, n. 41, issue 5, p. 837-866, 2003.

EDWARDS, E. O.; BELL, P W. The theory and measurement of business income. Econometrica, n. 30. University of California Press, 1961.

ELliOTT, B. and ELLIOTT, J. Financial Accounting and Reporting 14th ed. Pearson, 2011.

ENG, L.; MARGARET, S. The implications of long-term performance plans and institutional ownership for firms' research and development $(R \& D)$ investments. Journal of Accounting, Auditing and Finance, n. 16, p. 117-139, 2001.

EZZAMEL, Mahmoud A. Divisional cost of capital and the measurement of divisional performance. Journal of Business Finance \& Accounting, n. 6, issue 3, p. 307-320, 1979.

FELTHAM, G. A.; XIE, J. Performance measure congruity and diversity in multi-task principal/agent relations. The Accounting Review, n. 69, issue 3, p. 429-453, Jul/1994.

; WU, M. G. H. Public reports, information acquisition by investors, and management incentives. Review of Accounting Studies, 5: 155-90, 2000.

FESSLER, Nicholas J. Experimental evidence on the links among monetary incentives, task attractiveness, and task performance. Journal of Management Accounting Research, n. 15, p. 161-176, 2003.

FIELD, Andy. Descobrindo a estatística usando o SPSS. Tradução de Lori Viali. 2. ed. Porto Alegre: Artemed, 2009.

FISHER, Irving. A teoria do juro: determinada pela impaciência por gastar renda e pela oportunidade de investi-la. Tradução de Wanda Nogueira Caldeira Brant, Rosely Rodrigues e Ana Maria Busch Iverson. 2. ed. São Paulo: Nova Cultural, 1986.

FISHER, et al. Incentive compensation: bridging theory and practice. The Journal of Corporate Accounting \& Finance, n. 19, issue 3, p.35-40, March/April/2008. 
FLAMHOLTZ, Eric G. Effective Organizational Control: a framework, applications, and implications. European Management Journal, n. 14, issue 6, p. 596-611, 1996.

FREDERICKSON, et al. Performance evaluation judgments: effects of prior experience under different performance evaluation schemes and feedback frequencies. Journal of Accounting Research, n. 37, issue 1, p. 151-165, 1999.

FUDENBERG, et al. Short-term contracts in long-term agency relations. Journal of Economic Theory, n. 51, p. 1-31, 1990.

GAVER, J. J.; GAVER K. M. Compensation policy and the investment opportunity set. The Journal of the Financial Management Association, n. 24, issue 1, p. 19-32, 1995.

GHOSH, et al. Contemporaneous and forward-looking measures: implicationsfor incentive structure for long-horizon employees. AAA 2009 Management Accounting Section (MAS) Meeting Paper, 2009. Disponível em SSRN: http://ssrn.com/abstract=1194143

GIBBONS, R.; MURPHY, K. J. Does executive compensation affect investment? Journal of Applied Corporate Finance, n. 5, p. 99-109, 1992.

GJESDAL, F. Accounting for stewardship. Journal of Accounting Research, n. 19, p. 208231, Spring/1981.

GJESDAL, F. Information and incentives: the agency information problem. Review of Economic Studies, n. 19, issue 3, p. 373-390, July/1982.

GRAHAM, et al. The economic implications of corporate financial reporting. Journal of Accounting \& Economics, n. 40, issue 1-3, p. 3-73, 2005.

GREENE, Willian H. Econometric analysis. 5 ed. New Jersey: Prentice Hall, 2003.

GROSSMAN, S.; HART; O. D. An analysis of the principal-agent problem. Econometrica, n. 51, p. 7-45, January/1983.

GUERREIRO, Reinaldo. Modelo Conceitual de sistemas de informação de gestão econômica: uma contribuição à teoria da comunicação da contabilidade. Tese de Doutorado apresentada à FEA-USP. São Paulo. USP, 1989.

HAIR, Jr., Joseph F. Análise multivariada de dados. Traduação de Adonai S. Sant'Anna e Anselmo C. Neto. 5.ed. Porto Alegre: Bookman.

HOGAN, C. E.; LEWIS, C. M. Long-run investment decisions, operating performance, and shareholder value creation of firms adopting compensation plans based on economic profits. Journal of Financial and Quantitative Analysis, n. 40, p. 721-745, 2005. 
HOGAN, C. E.; LEWIS, C. M. The long-run performance of firms adopting compensation plans based on economic profits. Work-Paper, 2000. Disponível em http://ssrn.com/abstract=191551

HOLMSTRÖM, B. Moral hazard in teams. Bell Journal of Economics, n. 13, p. 324-340, Autumn/1982.

91, Spring/1979

Moral hazard and Observability. Bell Journal of Economics, n.10, p. 74-

; MILGROM, P. Multitask principal-agent analyses: incentive contracts, asset ownership, and job design. Journal of Law, Economics and Organizations, n. 7, p. 24-52, 1991.

Aggregation and linearity in the provision of intertemporal incentives. Econometrica, n. 55, p. 303-328, 1987.

HORNGREN, et al. Contabilidade de custos. Trad. Robert Brian Taylor; revisão técnica Arthur Ridolfo Neto, Antonieta Magalhães, Fabio Gallo Garcia. 11 ed. São Paulo: Prentice Hall, 2004.

HOSKISSON, R. E. et al. Managerial incentives and investment in $R \& D$ in large multiproduct firms. Organization Science, n. 4, issue 2, p. 325-341, 1993.

INDJEJLKLAN, Raffi J. Performance evaluation and compensation research: an agency perspective. Accounting Horizons, n. 13, issue 2, p. 147-157, 1999.

ITTNER, C; LARCKER, D. Innovations in performance measurement: trends and research implications. Journal of Management Accounting Research, n. 6, p. 205-238, 1998.

JASMIJN C. B. Empirical Research on Performance-based Compensation Contracts. In: Performance Measurement and Management Control: Improving Organizations and Society Studies in Managerial and Financial Accounting, n. 16, p.405-433, Elsevier Ltd., 2006.

JENKINS, et al. Are financial incentives related to performance? A meta-analytic review of empirical research. Journal of Applied Psychology, n.83, issue 5, p. 777-787, 1998.

JIA et al. Evidence Regarding the Usefulness of Accounting in Managers' Bonus Contracts. SSRN eLibrary, 2010. Disponível em: http://ssrn.com/abstract=1485058.

KALYTA, Paul. Accounting discretion, horizon problem, and CEO retirement benefits. The Accounting Review, n. 84, issue 5, p. 1553-1573, 2009.

KELLY, K. Feedback and incentives on non-financial value drivers: effects on managerial decision making. Contemporary Accounting Research, n. 24, issue 2, p. 523-556, 2007. 
Rewarding multiple leading measures of financial performance: does accuracy of relative incentive weights matter? Unpublished Working Paper, University of Waterloo, 2009.

KIM, Y. Three essays about the financial impact of top managers on firm. Ph.D. dissertation. United States - Minnesota: University of Minnesota; 2009.

KREITZMAN, Kevin; WILLIAMS, Michael A. Estimating Market Power with Economic Profits, SSRN eLibrary, 2008. Disponível em: http://ssrn.com/abstract=1167823.

LAFFONT, J. J.; TIROLE, J. Managerial switching and myopia. Unpublished manuscript, MIT, 1987.

LAMBERT, R.A. Contracting theory and accounting. Journal of Accounting and Economics, n. 32, issue 1-3, p. 3-87, 2001.

LAMBERT, Richard A., Agency Theory and Management Accounting. In: CHAPMAN et al. Handbooks of Management Accounting Research, n. 1, p. 247-268, Elsevier, 2006.

; LARCKER, D. F. An analysis of the use of accounting and market measures of performance in executive compensation contracts. Journal of Accounting Research, n. 25, p. 85-125, 1987.

LARCKER, D. F. The association between performance plan adoption and corporate capital investment. Journal of Accounting \& Economics, n.5, issue 1, p. 3-30, 1983.

LIBBY, R.; LIPE, M. G. Incentives, effort, and the cognitive processes involved in accounting related judgments. Journal of Accounting Research, n. 30, p. 249-273, Autumn/1992.

LIPSEY, M. W.; HURLEY, S. M. Design sensitivity: statistical power for applied experimental research. In: BICKMAN, L.; ROG, D. J. (Org.). Handbook of applied social research methods, 2 Ed. p. 44-76, Los Angeles: Sage. 2009.

MAEDLER, M. Essays on Task Assignment and Performance Measurement. Ph.D. Dissertation, Columbia University, 2008.

MAGEE, R. P. Accounting measurement and employment contracts: current value reporting. Bell Journal of Economics, n. 9, p. 145-158, Spring/1978.

MAGNI, Carlo Alberto. Economic profit, NPV, and CAPM: biases and violations of Modigliani and Miller's proposition I. The ICFAI Journal of Applied Finance, n. 14, issue 10, p. 59-72, October/2008. Disponível em: http://ssrn.com/abstract=1075462

MAHER et al. Managerial Accounting: an introduction to concepts, methods and uses. Tomson South-Western USA: Manson, Ohio, 2008. 
MALHOTRA, Naresh K. Pesquisa de marketing: uma orientação aplicada. 3ed. PA, RS: Bookman, 2001.

MATEJKA, M. et al. Employment horizon and the choice of performance measures: empirical evidence from annual bonus plans of loss-making entities. Management Science, n. 55, issue 6, p. 890-905, 2009.

MAULDIN, E. G. Decision aids and the design of incentive compensation contracts: An experimental study of self-selection and effort effects. Ph.D. Dissertations, The University of Nebraska - Lincoln. 1997.

MILGROM, Paul \& ROBERTS, John. Economics, Organization and Management. Prentice Hall, 1992.

NARAYANAN, M. Managerial incentives for short-term results. Journal of Finance, n. 40, p. 69-84, 1985.

NAVEEN, L. Organizational Complexity and Succession Planning. The Journal of Financial and Quantitative Analysis, n. 41, issue 3, p. 661-683, 2006.

NOLAN, D. Capital structure and short-term decision. Oxford Economic Papers. n. 54, issue 3, p. 470, 2002.

PAUL, J. M. On the efficiency of stock-based compensation. Review of Financial Studies, n. 5, p. 471-502, 1992.

PFEIFFER, T.; G. SCHNEIDER. Residual income-based compensation plans for controlling investment decisions. Management Science, n. 53, p. 495-507, 2007.

PRENDERGAST, C. The provision of incentives in firms. Journal of Economic Literature, n. XXXVII, p. 7-63, March/1999.

What tradeoff of risk and incentives? American Economic Review, n. 90, issue 2, p421-425, May/2000.

RAPPAPORT, A. How to design value-contributing executive incentives. Journal of Business Strategy, n. 4, Fall/1983.

- Perspectives: the economics of short-term performance obsession. Financial Analysts Journal, n. 61, issue 3, p. 65-79, May/June/2005. Disponível em: http://ssrn.com/abstract=74656.

REICHELSTEIN, S. Investment decisions and managerial performance evaluation. Review of Accounting Studies, n. 2, p. 157-180, 1997. 
Providing managerial incentives: cash flows versus accrual accounting. Journal of Accounting Research, n. 38, p. 243-269, 2000.

.; DUTTA, S. Accrual accounting for performance evaluation. Review of Accounting Studies, n. 10, p. 527-552, 2005.

ROGERSON, W. P. Intertemporal cost allocation and managerial investment incentives: a theory explaining the use. Journal of Political Economy. n. 105, issue 4, p. 770-795, 1997.

Intertemporal cost allocation and investment decisions. Journal of Political Economy, n. 116, issue 5, p. 931-950, 2008.

SCAPENS, R. W. A neoclassical measure of profit. Accounting Review, n. 53, issue 2, p. 448-469, 1978.

SCHOTTER, A.; WEIGELT, K. Behavioral consequences of corporate incentives and longterm bonuses: an experimental study. Management Science, n. 38. issue 9, 1992.

SCHULTZE, Wolfgang; WEILER, Andreas. Performance measurement, value-creation and managerial compensation: the missing link. SSRN, 2008. Disponível em: http://ssrn.com/abstract=1088702 SCOTT,

SEDATOLE, K. L. The effect of measurement alternatives on a nonfinancial quality measure's forward looking properties. The Accounting Review, n. 78, issue 2, p. 555-580, 2003.

et al., The role of CEO and investor horizons in the contracting use of forwardlooking performance measures. Harvard NOM Working Paper, n. 03-35, 2003. Disponível me: http://ssrn.com/abstract=418261.

SLIWKA, D. 2002. On the use of nonfinancial performance measures in management compensation. Journal of Economics \& Management Strategy, n. 11, issue 3, p. 487-511, 2002.

SMITH, C.; WATTS, R. Incentive and tax effects of executive compensation plans. Australian Journal of Management, n. 7, p. 139-157, issue 2, 1982.

SMITH, Michael J. Gaming nonfinancial performance measures. Journal of Management Accounting Research, n. 14, p. 119-133, 2002.

SOLOMONS, David. Economic and Accounting Concepts of Income. The Accounting Review, n. 36, issue 3, p.374-383, 1961.

SPRINKLE, G.B. The effect of incentive contracts on learning and performance. The Accounting Review, n. 75, issue 3, p. 299-326, 2000. 
; WILLIAMSON, M. G. Experimental Research in Managerial Accounting.

In: Chapman et al. Handbook of Management Accounting Research. Elsevier Ltd., 2007

STEIN, J. C. Takeover threats and managerial myopia. Journal of Political Economy, n. 96, issue 1, p. 61, 1988.

Efficient capital markets, inefficient firms: a model of myopic corporate behavior.

Quarterly Journal of Economics, n. 104, p. 655-69, 1989.

TEHRANIAN, H.; WAEGELEIN, J. F. Market reaction to short-term executive compensation plan adoption. Journal of Accounting and Economics, n. 7, p. 131-144, 1985.

TULL, S. D.; HAWKINS, L. D. Marketing research: meaning, measurement and method. New York: Macmillan Publishing Co. Inc, 1990.

TYLER, M. L. The impact of CEO compensation and CEO horizon on a firm's discretionary research and development expenditures. Ph.D. dissertation. United States Florida: Florida International University; 1995. Disponível em: http://www.proquest.com/; Publication Number: AAT 9610900.

UBELHART, M. A new look at executive compensation plans. Compensation Review, n. 14, issue $2,1982$.

VERBEEK, M. A guide to modern econometrics. Londres: John Wiley and Sons, 2000.

WALLACE, J. S. Adopting residual income-based compensation plans- Evidence of effects on management actions. Ph.D. Dissertation. USA: University Of Washington, 1996.

. Adopting residual income-based compensation plans: Do you get what you pay for? Journal of Accounting \& Economics, n. 24, issue 3, p. 275-300, 1997.

WALLER, W. S.; CHOW, C. W. The self-selection and effort effects of standard-based employment contracts: A framework and some empirical evidence. The Accounting Review, n. 60, issue 3, 458-458, p. 1985.

WILLIAM R. Financial accounting theory. 5 ed. Toronto, Canada: Pearson Education, 2009.

WUNSCH, A. The effect of executive compensation policy on long-term investment expenditures of large corporations. Ph.D. Dissertation. United States - Georgia: University of Georgia; 1992. Disponível em: http://www.proquest.com/; Publication Number: AAT 9301240 .

XI, K. K. The Use of Balanced Scorecard Measures in Executive Incentives and Organizational Performance. Ph.D. Dissertation. Canada: Carleton University, 2010. 
XU J. R\&D investment around CEO turnover. D.B.A. Dissertation. United States Massachusetts: Boston University; 2009.

YAMANE, Taro. Elementary sampling theory. Englewood Cliffs, London: Prentice-Hall, 1967.

YUAN, G.; YU, Z. Congruity of multiple performance measures. Journal of Modern Accounting and Auditing, n.1, issue 2, 2005.

ZHOU, Y. Earnings distortion and CEO compensation. Ph.D. Dissertation, University of Toronto, Canada, 2006. 


\section{APÊNDICES}

APÊNDICE 1 - TELAS DO SIMULADOR DO EXPERIMENTO E INFORMAÇÕES QUE CONSTAM NO SISTEMA

APÊNDICE 2 - CONVITE ENVIADO PARA OS ESTUDANTES

APÊNDICE 3 - MODELO DO RECIBO UTILIZADO PARA PAGAMENTO DOS PARTICIPANTES

APÊNDICE 4 - QUESTIONÁRIOS DA WEB: AVALIAÇÃO SOBRE O ENTENDIMENTO DA SIMULAÇÃO E INFORMAÇÕES DEMOGRÁFICAS E DE CONTROLE

APÊNDICE 5 - INFORMAÇÕES SOBRE OS CONTRATOS DE INCENTIVO

APÊNDICE 6 - RESULTADO DOS DIAGNÓSTICOS DAS REGRESSÕES EM DADOS EM PAINEL (OUTPUTS DO SOFTWARE GRETL 1.9.9)

APÊNDICE 7 - TESTE DE NORMALIDADE E HOMOGENEIDADE DE VARIÂNCIA DAS VARIÁVEIS DEPENDENTES 
APÊNDICE 1 - TELAS DO SIMULADOR DO EXPERIMENTO E INFORMAÇÕES QUE CONSTAM NO SISTEMA
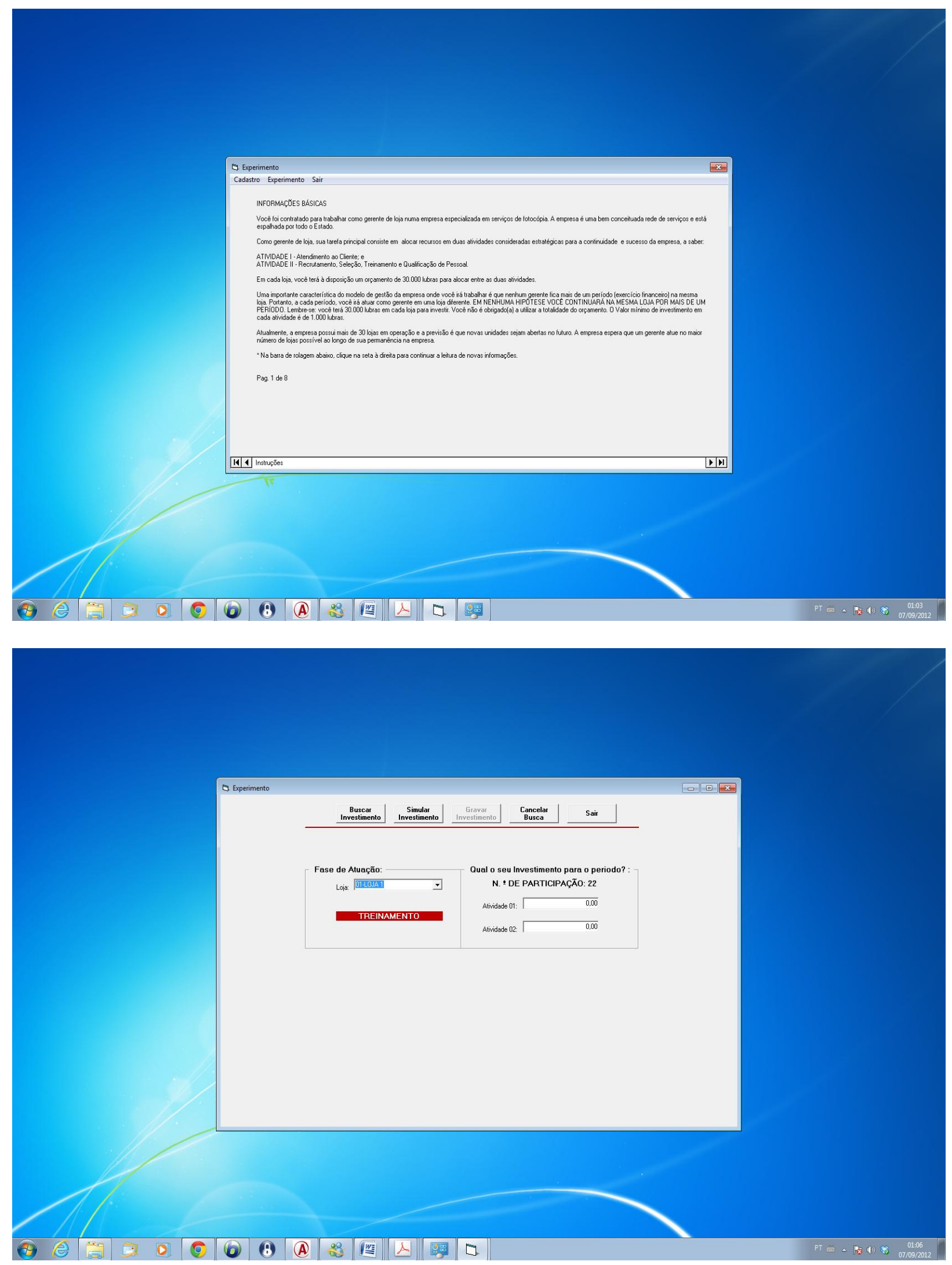


\section{INFORMAÇÕES DO SISTEMA}

\section{TELA 1: Informações básicas}

Você foi contratado para trabalhar como gerente de loja numa empresa especializada em serviços de fotocópia. A empresa é uma bem conceituada rede de serviços e está espalhada por todo o Estado.

Como gerente de loja, sua tarefa principal consiste em alocar recursos em duas atividades consideradas estratégicas para a continuidade e sucesso da empresa, a saber:

ATIVIDADE I - Atendimento ao Cliente; e

ATIVIDADE II - Recrutamento, Seleção, Treinamento e Qualificação de Pessoal.

Em cada loja, você terá à disposição um orçamento de 30.000 lubras para alocar entre as duas atividades.

Uma importante característica do modelo de gestão da empresa onde você irá trabalhar é que nenhum gerente fica mais de um período (exercício financeiro) na mesma loja. Portanto, a cada período, você irá atuar como gerente em uma loja diferente. EM NENHUMA HIPÓTESE VOCÊ CONTINUARÁ NA MESMA LOJA POR MAIS DE UM PERÍODO. Lembre-se: você terá 30.000 lubras em cada loja para investir. Você não é obrigado(a) a utilizar a totalidade do orçamento. O Valor mínimo de investimento em cada atividade é de 1.000 lubras.

Atualmente, a empresa possui mais de 30 lojas em operação e a previsão é que novas unidades sejam abertas no futuro. A empresa espera que um gerente atue no maior número de lojas possível ao longo de sua permanência na empresa.

\section{TELA 2: Descrição das atividades}

\section{I - SERVIÇO DE ATENDIMENTO AO CLIENTE}

Essa atividade é descrita como as ações que a LOJA desenvolve para prestar o melhor serviço possível ao cliente. Essas ações estão relacionadas às características básicas que o empreendimento exige, a saber:

- Estrutura eficiente;

- Bom atendimento;

- Qualidade dos serviços;

- Melhorias na loja para tornar sua atmosfera mais atrativa e confortável.

ALOCAR RECURSOS NESSA ATIVIDADE TERÁ EFEITO POSITIVO NO LUCRO FUTURO DA LOJA. Estudos especializados contratados pela empresa indicam que o investimento ótimo de recursos no exercício financeiro corrente (atual) irá aumentar o lucro da loja (e fluxo de caixa líquido) nos exercícios financeiros subsequentes. Por isso, você deve alocar, no mínimo, 1.000 de lubras em cada período, até o limite de 29.000 lubras.

\section{II - RECRUTAMENTO, SELEÇÃO, TREINAMENTO E QUALIFICAÇÃO DE PESSOAL}

Essa atividade é descrita como as ações que a empresa desenvolve para recrutar, selecionar e fornecer treinamento adicional aos funcionários da loja.

Nesse tipo de empreendimento, é importante que os funcionários passem pelo treinamento oferecido, geralmente, pelo fabricante das máquinas, para diminuir as perdas, e também, se possível, treinar os funcionários que não utilizam diretamente a máquina, para que eventualmente possam operá-la.

Todas as pessoas que trabalham na sua loja devem ter algumas características para saber atender bem. É por essas características e alguns atributos (como a habilidade em ouvir e atender os clientes, boa vontade, persistência e paciência, naturalidade na orientação dos clientes, poder de negociação, equilíbrio emocional, capacidade de identificar as necessidades e o perfil dos clientes, iniciativa, agilidade e presteza no atendimento) que a loja deve orientar-se ao recrutar e selecionar seus funcionários. 
financeiro corrente irá aumentar o lucro da loja (e fluxo de caixa líquido) nos exercícios financeiros subsequentes. Por isso, você deve alocar, no mínimo, 1.000 lubras em cada período, até o limite de 29.000 lubras.

\section{TELA 3: Descrição da tarefa}

Nessa simulação, sua única tarefa é alocar um orçamento de 30.000 lubras entre as duas atividades descritas previamente de modo que maximize O FLUXO DE CAIXA LÍQUIDO FUTURO da loja. A maximização do fluxo de caixa irá maximizar o lucro futuro. Então, você deverá decidir qual o melhor investimento em cada uma das atividades. O investimento no período atual afetará o lucro e o fluxo de caixa nos períodos futuros. Existe um nível de investimento ótimo em cada atividade. No entanto, a empresa não está certa de qual é esse nível de investimento.

\section{OBSERVAÇÕES:}

- Os montantes dos investimentos devem ser múltiplos de 1.000 (Por exemplo: 1.000, 2.000, 3.000, ..., 29.000).

- Você poderá alocar qualquer valor entre 1.000 e 29.000 lubras em cada atividade.

\section{QUANTO VOCÊ RECEBERÁ POR PARTICIPAR DA SIMULAÇÃO}

Para realizar esta tarefa, você receberá 1.500 lubras por período em que você atuar como gerente. Cada 1.500 lubras equivalem a $\mathrm{R} \$ 1,00$ (um real). Portanto, quanto mais loja você gerenciar maior será o valor que você receberá ao final da simulação. Por exemplo, se você gerenciar cinco lojas, irá receber: 5 lojas x 1.500 lubras = 7.500 lubras. Logo, em reais você irá receber: $7.500 / 1.500=\mathrm{R} \$ 5$ reais

\section{TELA 4: Definição do objetivo do participante}

Na condição de gerente, seu principal objetivo é maximizar o FLUXO DE CAIXA LÍQUIDO FUTURO ou o FLUXO DE CAIXA LÍQUIDO PARA OS PRÓXIMOS PERÍODOS da loja. Isso significa que seu objetivo nessa simulação é tentar descobrir qual a combinação ótima de lubras em cada atividade que maximiza o fluxo de caixa líquido futuro.

\section{TELA 5: Indicação das informações que podem ser acessadas durante a simulação}

Em cada período, você terá acesso as seguintes informações:

- Os investimentos que você fez nas lojas em que já foi gerente (através da função BUSCAR INVESTIMENTOS).

- Simulação do Lucro Líquido do Exercício (previsão).

- Simulação do Fluxo de Caixa Líquido para os próximos períodos.

A previsão do Fluxo de Caixa Líquido para os próximos períodos é função dos gastos feitos no período corrente (atual). O gasto que você realizar em sua loja não afetará o lucro das outras lojas.

A previsão do Lucro Líquido do período é feita com base nos gastos realizados pelo gerente anterior e os gastos que você realiza na loja nas duas atividades. ENTÃO, quanto maior for o investimento que você fizer nas atividades I e II, MENOR será o lucro líquido da loja quando você for o gerente. POR OUTRO LADO, quanto maior for a previsão de fluxo de caixa líquido para os próximos períodos, MAIOR será o lucro líquido nos próximos períodos.

O LUCRO LÍQUIDO DO PERÍODO É CALCULADO DA SEGUINTE FORMA:

(+) Lucro Operacional antes dos gastos com as atividades I e II

(-) Total dos gastos nas duas atividades no período

(=) Lucro Líquido da LOJA

Por exemplo:

(+) Lucro Operacional antes dos gastos com as atividades I e II $=\quad 100.000$

(-) Total dos gastos nas duas atividades no período $=\quad(15.000)$

$\begin{array}{ll}(=) \text { Lucro Líquido da LOJA } & =85.000\end{array}$

TELA 6: Informação sobre o período de treinamento 
Antes de iniciar sua simulação, você terá um tempo para praticar. O objetivo dessa prática é fazer você se familiarizar com o software da simulação. Na parte superior desse software você deverá clicar na função EXPERIMENTO. Em seguida irá aparecer uma tela indicando o seu número de participação e os campos onde você deverá indicar qual o montante de recursos que você pretende alocar em cada uma das atividades. Após definir o montante a ser aplicado nas atividades, você poderá clicar no botão SIMULAR INVESTIMENTOS para saber qual será a PREVISÃO do Lucro Líquido para o período em que você está gerenciando a loja e a PREVISÃO do Fluxo de Caixa Líquido para o próximo período. Você poderá fazer quantas simulações desejar antes de tomar sua decisão de investimento. Note que depois de definidos os montantes de recursos a serem alocados, você deverá validar sua decisão clicando no botão GRAVAR INVESTIMENTOS. Depois de gravado, você não poderá alterar o valor alocado e passará imediatamente para um próximo período em uma nova loja.

As decisões que você tomar nesse período de treinamento não irá afetar o seu desempenho nos próximos períodos (outras lojas).

TELA 7: Aviso final

\section{ATENÇÃO:}

Ao longo da simulação você poderá ser solicitado a responder a algumas perguntas na internet. Por isso, é possível que surjam algumas páginas para você acessar. Caso isso ocorra, você só poderá continuar na simulação após preencher as informações solicitadas na internet.

A QUALQUER MOMENTO VOCÊ PODERÁ VOLTAR A ESTA TELA DE INFORMAÇÕES. PORTANTO, NUNCA FECHE ESSA TELA.

Você será informando quando o experimento acabar.

\section{MUITO OBRIGADO PELA SUA PARTICIPAÇÃO!}

AGORA: Na barra de ferramenta clique em EXPERIMENTO para iniciar a simulação. 


\section{APÊNDICE 2 - CONVITE ENVIADO PARA OS ESTUDANTES}

Caro aluno,

Eu sou estudante do programa de pós-graduação em Controladoria e Contabilidade do EAC/FEA/USP e gostaria de convidá-lo a participar do experimento vinculado a minha tese de doutorado que está sendo orientada pelo Prof. Dr. Edgard B. Cornachione Jr.

O experimento consiste na realização de uma tarefa simples, não exige nenhum tipo de habilidade técnica ou conhecimento específico e poderá durar entre 30 e 60 minutos. Sua participação será remunerada. É garantido que você receberá, pelo menos, R $\$ 10,00$. Todavia, sua compensação total poderá chegar a $\mathrm{R} \$ 20,00$.

As sessões experimentais acontecerão no dia 21/06/12 (quinta-feira) na sala 307 do FEA5, em duas opções de horário: das $14 \mathrm{~h} 00 \mathrm{~min}$ às $16 \mathrm{~h} 00 \mathrm{~min}$ ou das $16 \mathrm{~h} 00 \mathrm{~min}$ às $18 \mathrm{~h} 00 \mathrm{~min}$. As vagas são limitadas. Para participar, você deve fazer sua inscrição até o dia 20/06/12 (quarta-feira) no seguinte link: https://pt.surveymonkey.com/s/participar

Todos os participantes receberão um e-mail de confirmação de inscrição.

Certo de poder contar com sua colaboração, agradeço desde já.

Atenciosamente,

Luis Paulo Guimarães dos Santos

N. ${ }^{\circ}$ USP 3168667 


\section{APÊNDICE 3 - MODELO DO RECIBO UTILIZADO PARA PAGAMENTO DOS PARTICIPANTES}

\section{DECLARAÇÃO}

$\mathrm{Eu}$, com matrícula n. ${ }^{\circ}$ declaro que aluno(a) da FEA-USP recebi $\mathrm{R} \$$ ) em função da minha participação no experimento vinculado à tese de doutorado de LUIS PAULO GUIMARÃES DOS SANTOS, sob a orientação do professor Doutor EDGARD BRUNO CORNACCHIONE JUNIOR.

ASSINATURA

São Paulo, 21 de junho de 2012 
APÊNDICE 4 - QUESTIONÁRIOS DA WEB: AVALIAÇÃO SOBRE O ENTENDIMENTO DA SIMULAÇÃO E INFORMAÇÕES DEMOGRÁFICAS E DE CONTROLE

\section{Conhecimento}

*1. POR FAVOR, INDIQUE O SEU NÚMERO DE PARTICIPAÇÃO:

N.` de participaçăo -

POR FAVOR, RESPONDA AS SEGUINTES PERGUNTAS (woce pode consultar a tela de informaçbes do experimento antes de responder):

*2. Quantos períodos consecutivos você pode ficar como gerente na mesma loja?

$C$ um periodo

C dols perbodos

C. tres perbodos

C quatro periodos

C por tempo indeterminado

*3. Qual é sua tarefa como gerente de loja?

C Comprar e vender mercadorias

C. Alocar um orçamento de 20.000 lubras nas attvidades I e l| da loja

C. Contactar fornecedores

C. Desenvolver novos produtos

* 4. Qual é o seu principal objetivo na função de gerente de loja?

C. Vistar as outras lojas do grupo

C. Maximlzar o fluxo de calxa llquido futuro da loja

C. Maximizar o lucro liquldo da loja

C. Investir o maximo de recursos nas duas attudades da loja

*5. Se o lucro operacional da loja é de $\mathbf{8 0 . 0 0 0 ~ l u b r a s , ~ c a s o ~ v o c e ̂ ~ a l o q u e ~} \mathbf{1 0 . 0 0 0}$ lubras na atividade I e $\mathbf{5 . 0 0 0}$ lubras na atividade II qual será o lucro líquido?
C 95.000 lubras
C 80.000 lubras
C 70.000 lubras
C 65.000 luaras 


\section{Demografico}

*1. Por FAVOR, INDIQUe o SEU NúMERO de participação:

N.o de participaçăo -

*2. Eu achei essa simulação bastante realista.

$\begin{array}{ccccc}\begin{array}{c}\text { Discordo } \\ \text { totalmente Discordo Discordo um Ná concordo, Concordo um } \\ \text { pouco }\end{array} & \begin{array}{c}\text { nem discordo } \\ \text { pouco }\end{array} & \text { Concordo } & \begin{array}{c}\text { concordo } \\ \text { totalmente }\end{array}\end{array}$

* 3. Quão difícil você acha que é cumprir a tarefa de investir nas duas atividades?

Multo dificll Dificll Umpouco Nem facil, nem Um pouco facll Fack $\begin{gathered}\text { dificll } \\ \text { diflicll }\end{gathered}$ Multo facill
c
C
$c$
c
c
c

\section{Agora que estamos encerrando a simulaçäo, por favor responda as S...}

*4. Qual o seu gênero?
C Feminino
C Mascullno

*5. Qual sua idade?

Responda no quadro

ao lado

*6. Em qual semestre do curso de graduação você está matriculado? Se você já é formado, indique a opção $12^{\circ}$

* 7. Você está trabalhando em alguma empresa ou fazendo estágio?
C sim
C Nă

* 8. Qual o seu curso de graduação?
C Administraçăo
C Atuarla
C Contablildade
C. Economla
C Outro (especinque o nome)

Por favor, procure o instrutor para saber sobre o seu pagamento. 


\section{APÊNDICE 5 - INFORMAÇÕES SOBRE OS CONTRATOS DE INCENTIVO}

\section{NOVO SISTEMA DE INCENTIVO (BÔNUS COM BASE NO LUCRO ECONÔMICO)}

A partir do próximo período, a empresa adotará um novo mecanismo de incentivo. Na condição de gerente de loja, você receberá um bônus de 4,5\% sobre o LUCRO ECONÔMICO. Cada 1.500 lubras valem R \$1,00. Desse modo, a partir de agora você receberá 1.500 lubras de salário fixo por período mais o bônus em função do lucro econômico alcançado. Quanto maior o Lucro econômico maior será a sua compensação ao final de cada período.

O LUCRO ECONÔMICO representa o cálculo periódico do valor presente do fluxo de caixa líquido futuro esperado pela loja, descontado pelo custo de oportunidade definido pelos donos da empresa.

Agora, o sistema de informação também irá lhe informar o LUCRO ECONÔMICO.

EXEMPLO DE CÁLCULO DO BÔNUS A RECEBER NO FINAL DO PERÍODO:

Lucro Líquido do período $=100.000$

Total de bônus no período $=100.000 \times 4,5 \%=4.500$ lubras

Valor do bônus em reais $=4.500 / 1.500=\mathrm{R} \$ 3$

Valor total da compensação a receber em reais no final do período $=1,00+3=\mathrm{R} \$ 4$ (SALÁRIO TOTAL)

Por favor, agora volte ao simulador e continue sua atuação como gerente de loja.

LEMBRE-SE: Seu objetivo como gerente é maximizar o fluxo de caixa líquido para os próximos períodos.

Em algum momento lhe será solicitada a seguinte senha para prosseguir na simulação:

SENHA: XX (favor anotar para não esquecer)

\section{NOVO SISTEMA DE INCENTIVO (BÔNUS COM BASE NO LUCRO LÍQUIDO DO EXERCÍCIO)}

A partir do próximo período, a empresa adotará um novo mecanismo de incentivo. Na condição de gerente de loja, você receberá um bônus de 5,85\% sobre o LUCRO LÍQUIDO DO PERÍODO. Cada 1.500 lubras valem $\mathrm{R} \$ 1,00$. Desse modo, a partir de agora você receberá 1.500 lubras de salário fixo por período mais o bônus em função do lucro líquido alcançado. Quanto maior o Lucro Líquido maior será a sua compensação ao final de cada período.

\section{EXEMPLO DE CÁLCULO DO BÔNUS A RECEBER NO FINAL DO PERÍODO:}

Lucro Líquido do período $=100.000$

Total de bônus no período $=100.000 \times 5,85 \%=5.850$ lubras

Valor do bônus em reais $=5.850 / 1.500=\mathrm{R} \$ 3,90$

Valor total da compensação a receber em reais no final do período $=1,00+3,90=\mathrm{R} \$ 4,90$ (SALÁRIO

TOTAL)

LEMBRE-SE: Seu objetivo como gerente é maximizar o fluxo de caixa líquido para os próximos períodos.

Por favor, agora volte ao simulador e continue sua atuação como gerente de loja.

Em algum momento lhe será solicitada a seguinte senha para prosseguir na simulação:

SENHA: XX (favor anotar para não esquecer) 


\section{APÊNDICE 6 - RESULTADO DOS DIAGNÓSTICOS DAS REGRESSÕES EM DADOS EM PAINEL (OUTPUTS DO SOFTWARE GRETL 1.9.9)}

\section{Modelo 1: MQO agrupado, usando 760 observações Incluídas 76 unidades de corte transversal \\ Comprimento da série temporal $=\mathbf{1 0}$ Variável dependente: TEMP Erros padrão de Beck-Katz}

$\begin{array}{lccccc} & \text { Coeficiente } & \text { Erro Padrão } & \text { razão- } t & p \text {-valor } & \\ \text { const } & 2,36923 & 0,329443 & 7,1916 & <0,00001 & * * * \\ \text { Dt } & -0,238462 & 0,465902 & -0,5118 & 0,60892 & \\ \text { Cont } & 0,606769 & 0,104158 & 5,8255 & <0,00001 & * * * \\ \text { Eco } & 0,462769 & 0,123611 & 3,7438 & 0,00020 & * * * \\ \text { Cont_Dt } & -0,0895385 & 0,147301 & -0,6079 & 0,54346 & \\ \text { Eco_Dt } & 0,262462 & 0,174812 & 1,5014 & 0,13367 & \end{array}$

$\begin{array}{lrlr}\text { Média var. dependente } & 2,630263 & \text { D.P. var. dependente } & 1,604959 \\ \text { Soma resíd. quadrados } & 1887,374 & \text { E.P. da regressão } & 1,582134 \\ \text { R-quadrado } & 0,034643 & \text { R-quadrado ajustado } & 0,028241 \\ \text { F(5, 754) } & 5,411593 & \text { P-valor(F) } & 0,000067 \\ \text { Log da verossimilhança } & -1424,050 & \text { Critério de Akaike } & 2860,100 \\ \text { Critério de Schwarz } & 2887,900 & \text { Critério Hannan-Quinn } & 2870,805 \\ \text { Rô } & 0,327419 & \text { Durbin-Watson } & 1,250810\end{array}$

Diagnósticos: assumindo um painel equilibrado com 76 cortes transversais observados durante 10 períodos

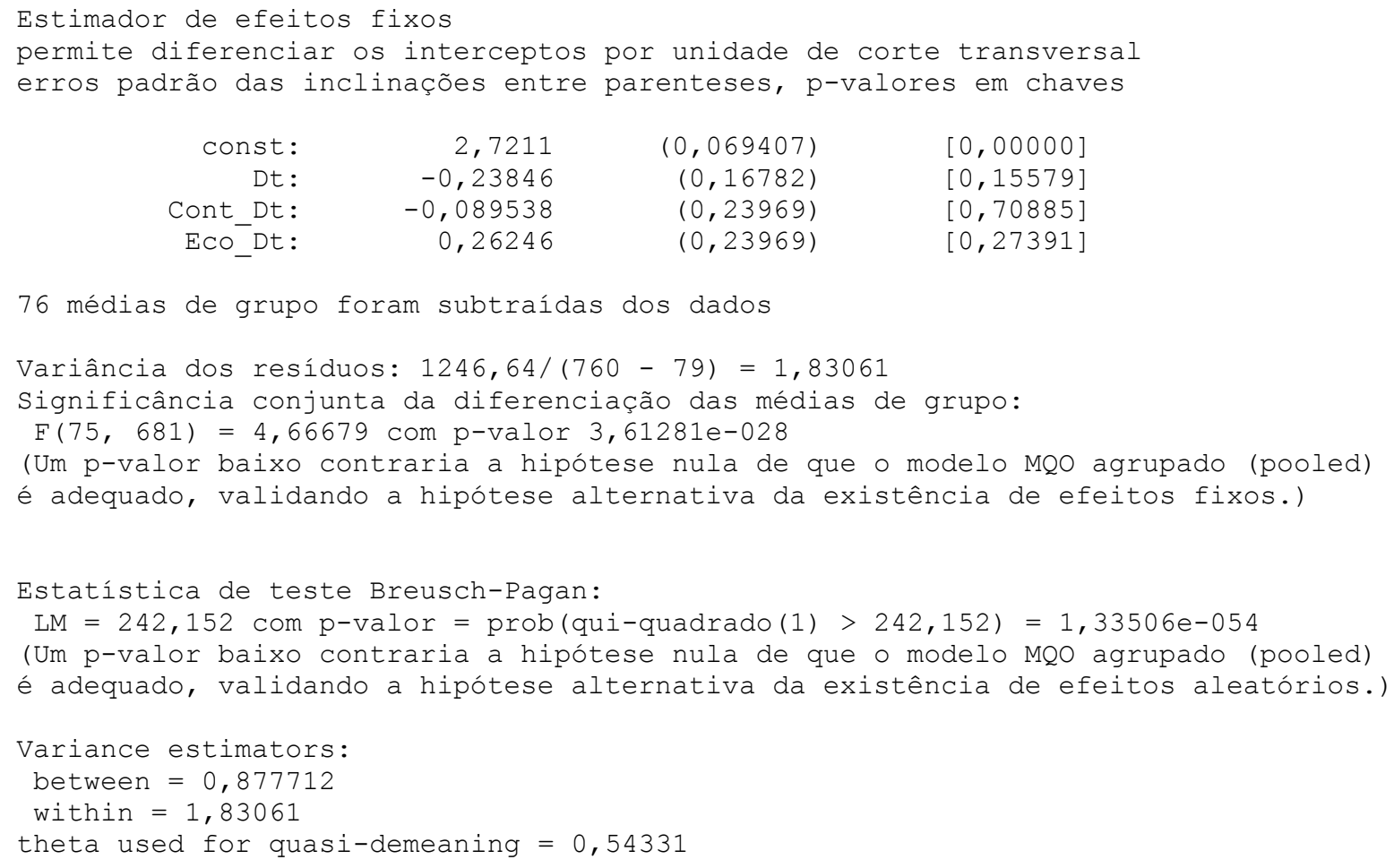




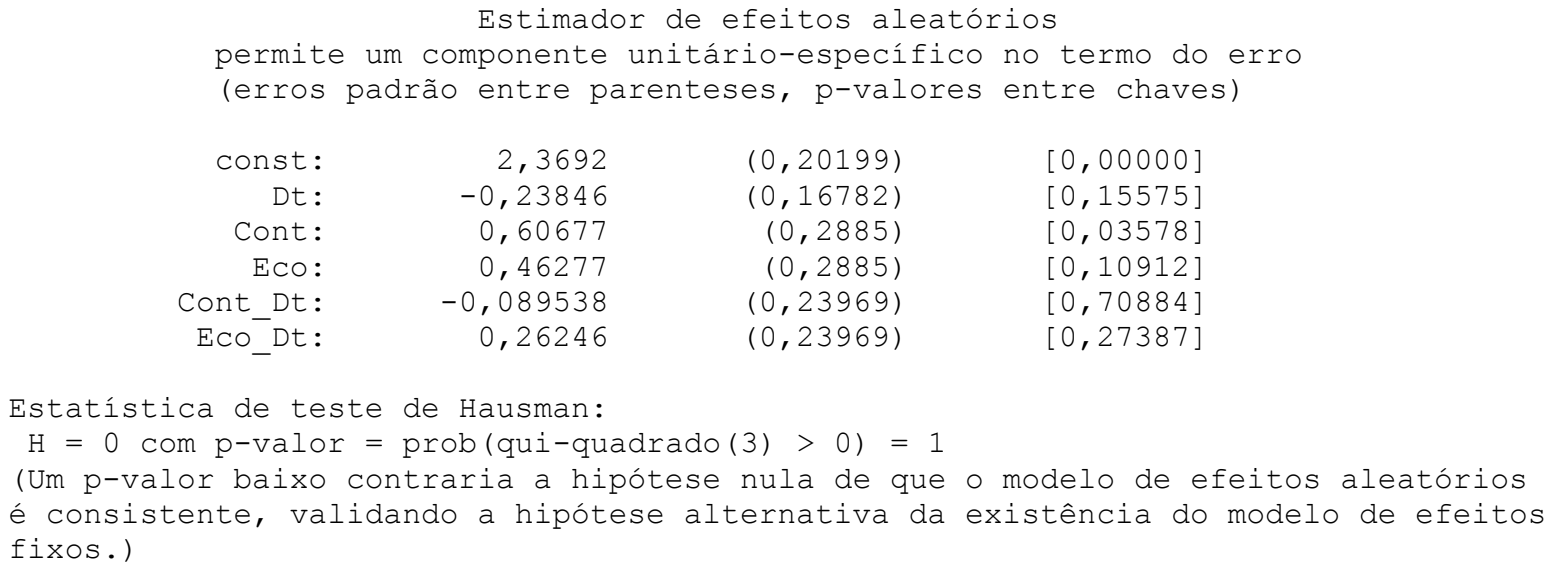

\section{Modelo 2: Efeitos-fixos, usando 760 observações \\ Incluídas 76 unidades de corte transversal Comprimento da série temporal $=\mathbf{1 0}$ Variável dependente: TEMP Erros padrão de Beck-Katz}

$\begin{array}{lccccc} & \text { Coeficiente } & \text { Erro Padrão } & \text { razão- } t & p \text {-valor } & \\ \text { const } & 2,72105 & 0,32564 & 8,3560 & <0,00001\end{array} * * * *$

$\begin{array}{lrlr}\text { Média var. dependente } & 2,630263 & \text { D.P. var. dependente } & 1,604959 \\ \text { Soma resíd. quadrados } & 1246,644 & \text { E.P. da regressão } & 1,353000 \\ \text { R-quadrado } & 0,362364 & \text { R-quadrado ajustado } & 0,289331 \\ \text { F(78, 681) } & 4,961643 & \text { P-valor(F) } & 1,63 \mathrm{e}-31 \\ \text { Log da verossimilhança } & -1266,452 & \text { Critério de Akaike } & 2690,904 \\ \text { Critério de Schwarz } & 3056,937 & \text { Critério Hannan-Quinn } & 2831,857 \\ \text { rô } & -0,017196 & \text { Durbin-Watson } & 1,893681\end{array}$

Teste para diferenciar interceptos de grupos Hipótese nula: Os grupos têm um intercepto comum Estatística de teste: $\mathrm{F}(75,681)=4,66679$ com $\mathrm{p}$-valor $=\mathrm{P}(\mathrm{F}(75,681)>4,66679)=3,61281 \mathrm{e}-028$

Teste de Wald independente da distribuição para heteroscedasticidade Hipótese nula: as unidades têm a mesma variância de erro Estatística de teste assintótica: Qui-quadrado(76) = 711,428 com $\mathrm{p}$-valor $=6,5297 \mathrm{e}-104$ 
Modelo 3: Efeitos-aleatórios (GLS), usando 760 observações Incluídas 76 unidades de corte transversal Comprimento da série temporal $=10$

Variável dependente: $\boldsymbol{T E M P}$

$\begin{array}{lccccc} & \text { Coeficiente } & \text { Erro Padrão } & \text { razão-t } & p \text {-valor } & \\ \text { const } & 2,36923 & 0,201988 & 11,7296 & <0,00001 & * * * \\ \text { Dt } & -0,238462 & 0,167819 & -1,4209 & 0,15575 & \\ \text { Cont } & 0,606769 & 0,288496 & 2,1032 & 0,03578 & * * \\ \text { Eco } & 0,462769 & 0,288496 & 1,6041 & 0,10912 & \\ \text { Cont_Dt } & -0,0895385 & 0,239693 & -0,3736 & 0,70884 & \\ \text { Eco_Dt } & 0,262462 & 0,239693 & 1,0950 & 0,27387 & \end{array}$

$\begin{array}{lrll}\text { Média var. dependente } & 2,630263 & \text { D.P. var. dependente } & 1,604959 \\ \text { Soma resíd. quadrados } & 1887,374 & \text { E.P. da regressão } & 1,581086 \\ \text { Log da verossimilhança } & -1424,050 & \text { Critério de Akaike } & 2860,100 \\ \text { Critério de Schwarz } & 2887,900 & \text { Critério Hannan-Quinn } & 2870,805\end{array}$

'Por dentro' da variância $=1,83061$

'Por entre' a variância $=0,877712$

teta utilizado para quasi-desmediação $=0,54331$

Teste de Breusch-Pagan -

Hipótese nula: Variância do erro de unidade-específica $=0$

Estatística de teste assintótica: Qui-quadrado $(1)=242,152$

com $\mathrm{p}$-valor $=1,33506 \mathrm{e}-054$

Teste de Hausman -

Hipótese nula: As estimativas GLS são consistentes

Estatística de teste assintótica: Qui-quadrado(3) $=0$

com $\mathrm{p}$-valor $=1$

Modelo 4: MQO agrupado, usando 760 observações

Incluídas 76 unidades de corte transversal

Comprimento da série temporal $=\mathbf{1 0}$

Variável dependente: SIMULA

Erros padrão de Beck-Katz

$\begin{array}{lccccc} & \text { Coeficiente } & \text { Erro Padrão } & \text { razão-t } & p \text {-valor } & \\ \text { const } & 14,8154 & 0,644779 & 22,9775 & <0,00001 & * * * \\ \text { Dt } & -2,87692 & 0,911855 & -3,1550 & 0,00167 & * * * \\ \text { Cont } & 7,62462 & 0,94088 & 8,1037 & <0,00001 & * * * \\ \text { Eco } & 3,13662 & 0,865212 & 3,6253 & 0,00031 & * * * \\ \text { Cont_Dt } & -4,81108 & 1,3306 & -3,6157 & 0,00032 & * * * \\ \text { Eco_Dt } & 4,60492 & 1,22359 & 3,7634 & 0,00018 & * * *\end{array}$

Média var. dependente

16,88289

D.P. var. dependente

11,79181

Soma resíd. quadrados

96254,10

E.P. da regressão

11,29858 


$\begin{array}{lrlr}\text { R-quadrado } & 0,087955 & \text { R-quadrado ajustado } & 0,081907 \\ \text { F(5, 754) } & 14,54273 & \text { P-valor(F) } & 1,27 \mathrm{e}-13 \\ \text { Log da verossimilhança } & -2918,136 & \text { Critério de Akaike } & 5848,272 \\ \text { Critério de Schwarz } & 5876,072 & \text { Critério Hannan-Quinn } & 5858,977 \\ \text { rô } & 0,533662 & \text { Durbin-Watson } & 0,801443\end{array}$

Teste de White para a heteroscedasticidade Hipótese nula: sem heteroscedasticidade Estatística de teste: $\mathrm{LM}=13,469$ com $\mathrm{p}$-valor $=\mathrm{P}($ Qui-quadrado $(5)>13,469)=0,0193583$

Diagnósticos: assumindo um painel equilibrado com 76 cortes transversais observados durante 10 períodos

Estimador de efeitos fixos

permite diferenciar os interceptos por unidade de corte transversal

erros padrão das inclinações entre parenteses, p-valores em chaves

$\begin{array}{rrrr}\text { Const: } & 18,355 & (0,40733) & {[0,00000]} \\ \text { Dt: } & -2,8769 & (0,98489) & {[0,00360]} \\ \text { Cont_Dt: } & -4,8111 & (1,4067) & {[0,00066]} \\ \text { Eco_Dt: } & 4,6049 & (1,4067) & {[0,00112]}\end{array}$

76 médias de grupo foram subtraídas dos dados

Variância dos resíduos: 42937/(760 - 79) = 63,0499

Significância conjunta da diferenciação das médias de grupo:

$\mathrm{F}(75,681)=11,2751$ com p-valor $1,62839 e-078$

(Um p-valor baixo contraria a hipótese nula de que o modelo Moo agrupado (pooled)

é adequado, validando a hipótese alternativa da existência de efeitos fixos.)

Estatística de teste Breusch-Pagan:

$\mathrm{LM}=869,962 \mathrm{com}$ p-valor $=$ prob(qui-quadrado(1) > 869,962) = 3,32581e-191

(Um p-valor baixo contraria a hipótese nula de que o modelo MQo agrupado (pooled)

é adequado, validando a hipótese alternativa da existência de efeitos aleatórios.)

Variance estimators:

between $=73,0371$

within $=63,0499$

theta used for quasi-demeaning $=0,706187$

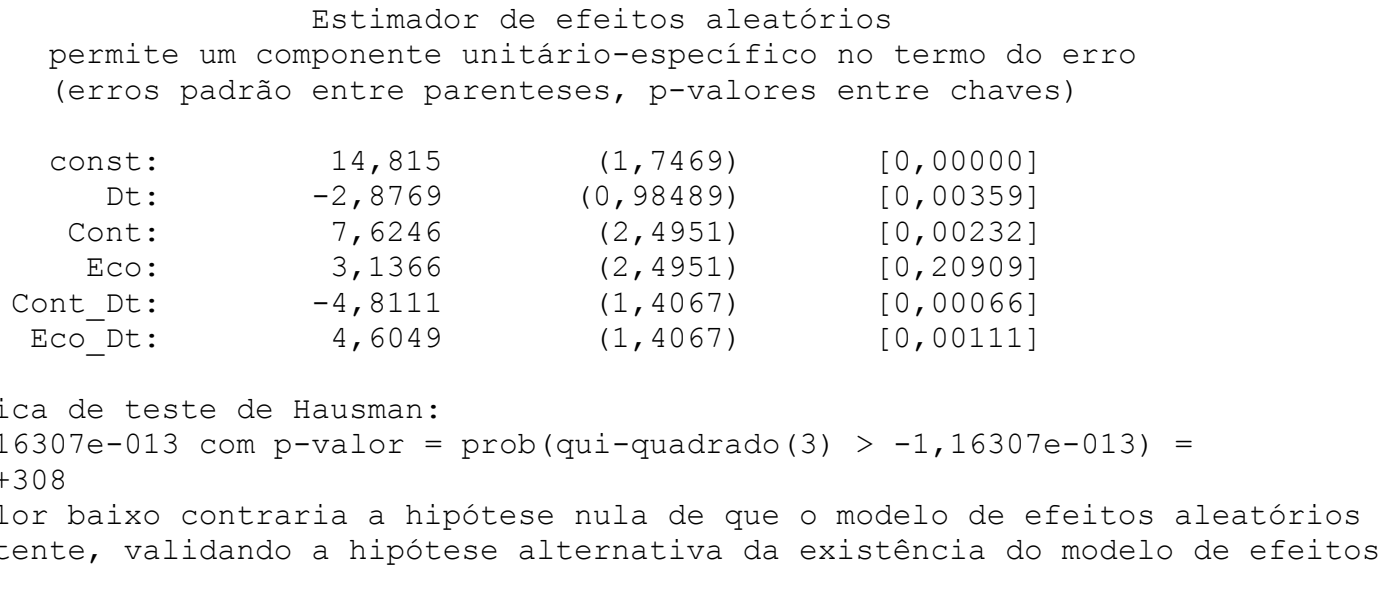

Estatística de teste de Hausman:

$\mathrm{H}=-1,16307 e-013 \mathrm{com}$-valor = prob (qui-quadrado(3) > -1,16307e-013) =

$1,79769 e+308$

(Um p-valor baixo contraria a hipótese nula de que o modelo de efeitos aleatórios

é consistente, validando a hipótese alternativa da existência do modelo de efeitos

fixos.) 
Modelo 5: Efeitos-fixos, usando 760 observações

Incluídas 76 unidades de corte transversal

Comprimento da série temporal $=\mathbf{1 0}$

Variável dependente: SIMULA

Erros padrão de Beck-Katz

$\begin{array}{lccccc} & \text { Coeficiente } & \text { Erro Padrão } & \text { razão-t } & p \text {-valor } & \\ \text { Const } & 18,3553 & 0,820375 & 22,3742 & <0,00001 & * * * \\ \text { Dt } & -2,87692 & 0,911855 & -3,1550 & 0,00168 & * * * \\ \text { Cont_Dt } & -4,81108 & 1,3306 & -3,6157 & 0,00032 & * * * \\ \text { Eco_Dt } & 4,60492 & 1,22359 & 3,7634 & 0,00018 & * * *\end{array}$

$\begin{array}{lrlr}\text { Média var. dependente } & 16,88289 & \text { D.P. var. dependente } & 11,79181 \\ \text { Soma resíd. quadrados } & 42937,01 & \text { E.P. da regressão } & 7,940399 \\ \text { R-quadrado } & 0,593155 & \text { R-quadrado ajustado } & 0,546556 \\ \text { F(78, 681) } & 12,72894 & \text { P-valor(F) } & 6,90 \mathrm{e}-90 \\ \text { Log da verossimilhança } & -2611,378 & \text { Critério de Akaike } & 5380,756 \\ \text { Critério de Schwarz } & 5746,789 & \text { Critério Hannan-Quinn } & 5521,709 \\ \text { Rô } & -0,004997 & \text { Durbin-Watson } & 1,796637\end{array}$

Teste para diferenciar interceptos de grupos -

Hipótese nula: Os grupos têm um intercepto comum

Estatística de teste: $\mathrm{F}(75,681)=11,2751$

com $\mathrm{p}$-valor $=\mathrm{P}(\mathrm{F}(75,681)>11,2751)=1,62839 \mathrm{e}-078$

Teste de Wald independente da distribuição para heteroscedasticidade -

Hipótese nula: as unidades têm a mesma variância de erro

Estatística de teste assintótica: Qui-quadrado(76) = 9,36794e+036

com $\mathrm{p}$-valor $=0$

\section{Modelo 6: Efeitos-aleatórios (GLS), usando 760 observações \\ Incluídas 76 unidades de corte transversal \\ Comprimento da série temporal $=\mathbf{1 0}$ Variável dependente: SIMULA}

$\begin{array}{lccccc} & \text { Coeficiente } & \text { Erro Padrão } & \text { razão-t } & p \text {-valor } & \\ \text { Const } & 14,8154 & 1,74689 & 8,4810 & <0,00001 & * * * \\ \text { Dt } & -2,87692 & 0,984885 & -2,9211 & 0,00359 & * * * \\ \text { Cont } & 7,62462 & 2,49506 & 3,0559 & 0,00232 & * * * \\ \text { Eco } & 3,13662 & 2,49506 & 1,2571 & 0,20909 & \\ \text { Cont_Dt } & -4,81108 & 1,4067 & -3,4201 & 0,00066 & * * * \\ \text { Eco_Dt } & 4,60492 & 1,4067 & 3,2736 & 0,00111 & * * *\end{array}$

Média var. dependente

16,88289

D.P. var. dependente

11,79181

Soma resíd. quadrados

96254,10

E.P. da regressão

11,29110

Log da verossimilhança

$-2918,136$

Critério de Akaike

5848,272

Critério de Schwarz

5876,072

Critério Hannan-Quinn

5858,977

'Por dentro' da variância $=63,0499$

'Por entre' a variância $=73,0371$ 
teta utilizado para quasi-desmediação $=0,706187$

Teste de Breusch-Pagan -

Hipótese nula: Variância do erro de unidade-específica $=0$

Estatística de teste assintótica: Qui-quadrado(1) = 869,962

com p-valor $=3,32581 \mathrm{e}-191$

Teste de Hausman -

Hipótese nula: As estimativas GLS são consistentes

Estatística de teste assintótica: Qui-quadrado(3) = -1,16307e-013

com $\mathrm{p}$-valor $=\mathrm{NA}$

\section{Modelo 7: MQO agrupado, usando 760 observações \\ Incluídas 76 unidades de corte transversal \\ Comprimento da série temporal $=\mathbf{1 0}$ \\ Variável dependente: INVEST \\ Erros padrão de Beck-Katz}

$\begin{array}{lccccl} & \text { Coeficiente } & \text { Erro Padrão } & \text { razão-t } & p \text {-valor } & \\ \text { Const } & 22230,8 & 868,638 & 25,5927 & <0,00001 & * * * \\ \text { Dt } & 1369,23 & 1228,44 & 1,1146 & 0,26537 & \\ \text { Cont } & 2313,23 & 353,221 & 6,5490 & <0,00001 & * * * \\ \text { Eco } & 737,231 & 346,583 & 2,1271 & 0,03373 & * * \\ \text { Cont_Dt } & -4121,23 & 499,53 & -8,2502 & <0,00001 & * * * \\ \text { Eco_Dt } & 3310,77 & 490,142 & 6,7547 & <0,00001 & * * *\end{array}$

Média var. dependente

23785,53

D.P. var. dependente

7347,935

Soma resíd. quadrados

$3,81 \mathrm{e}+10$

E.P. da regressão

7112,609

R-quadrado

0,069199

R-quadrado ajustado

0,063027

$\mathrm{F}(5,754)$

11,21101

P-valor(F)

$1,93 \mathrm{e}-10$

Log da verossimilhança

$-7816,296$

Critério de Akaike

15644,59

Critério de Schwarz

15672,39

Critério Hannan-Quinn

15655,30

Rô

0,582091

Durbin-Watson

0,762450

Teste de White para a heteroscedasticidade -

Hipótese nula: sem heteroscedasticidade

Estatística de teste: $\mathrm{LM}=59,5219$

com $\mathrm{p}$-valor $=\mathrm{P}(\mathrm{Qui}$-quadrado $(5)>59,5219)=1,52588 \mathrm{e}-011$

Diagnósticos: assumindo um painel equilibrado com 76 cortes transversais observados durante 10 períodos

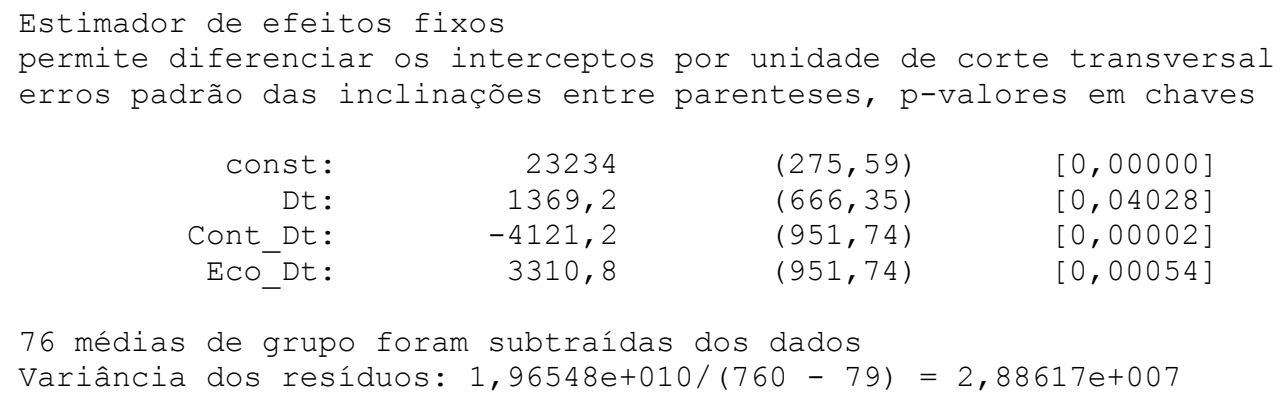




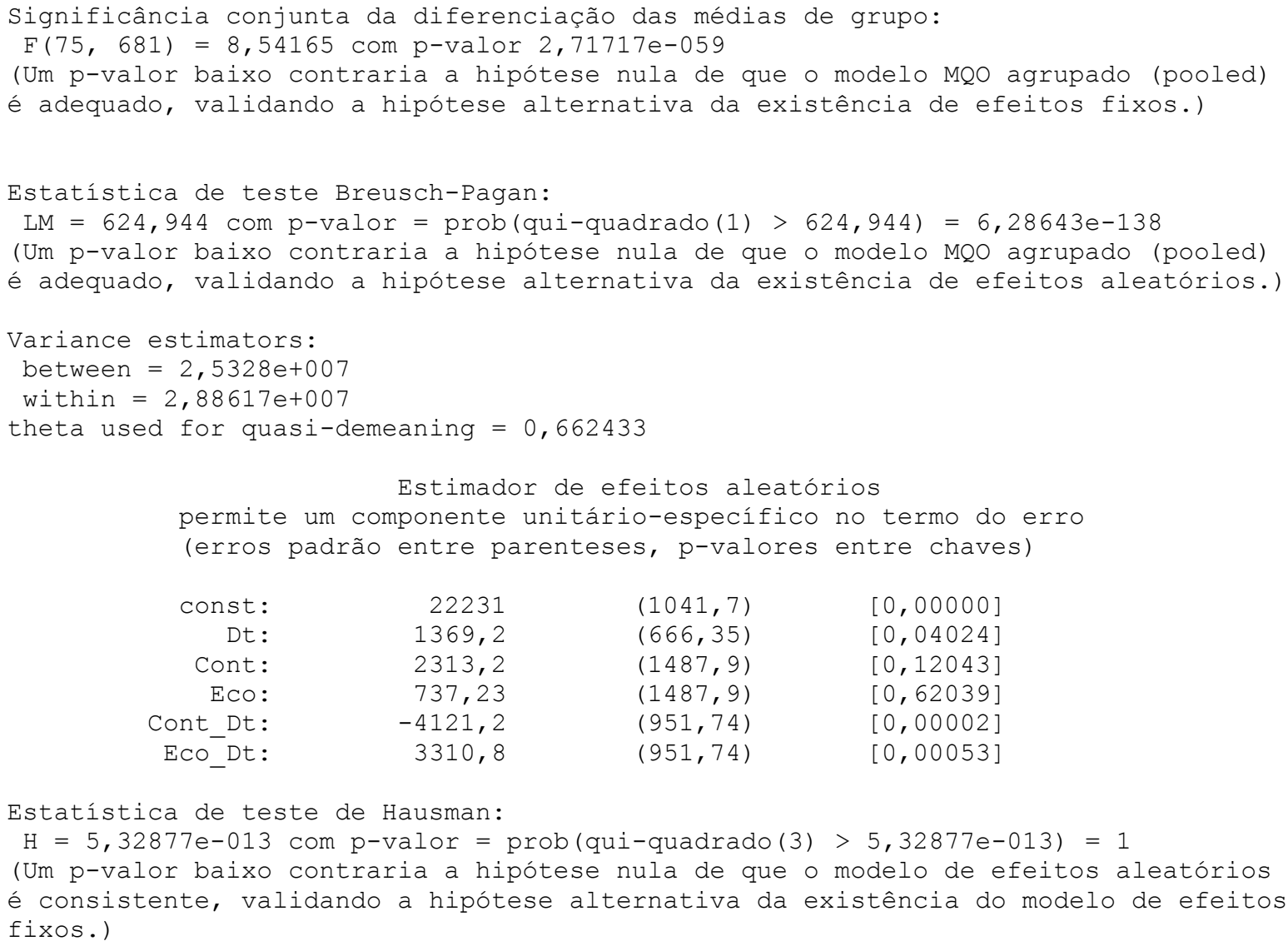

\section{Modelo 8: Efeitos-fixos, usando 760 observações Incluídas 76 unidades de corte transversal Comprimento da série temporal $=10$ Variável dependente: INVEST Erros padrão de Beck-Katz}

$\begin{array}{lccccc} & \text { Coeficiente } & \text { Erro Padrão } & \text { razão-t } & p \text {-valor } & \\ \text { const } & 23234,2 & 838,933 & 27,6949 & <0,00001 & * * * \\ \text { Dt } & 1369,23 & 1228,44 & 1,1146 & 0,26541 & \\ \text { Cont_Dt } & -4121,23 & 499,53 & -8,2502 & <0,00001 & * * * \\ \text { Eco_Dt } & 3310,77 & 490,142 & 6,7547 & <0,00001 & * * *\end{array}$

$\begin{array}{lrlr}\text { Média var. dependente } & 23785,53 & \text { D.P. var. dependente } & 7347,935 \\ \text { Soma resíd. quadrados } & 1,97 \mathrm{e}+10 & \text { E.P. da regressão } & 5372,305 \\ \text { R-quadrado } & 0,520381 & \text { R-quadrado ajustado } & 0,465447 \\ \text { F(78, 681) } & 9,472793 & \text { P-valor(F) } & 1,06 \mathrm{e}-67 \\ \text { Log da verossimilhança } & -7564,335 & \text { Critério de Akaike } & 15286,67 \\ \text { Critério de Schwarz } & 15652,70 & \text { Critério Hannan-Quinn } & 15427,62 \\ \text { rô } & 0,195596 & \text { Durbin-Watson } & 1,479694\end{array}$

Teste para diferenciar interceptos de grupos Hipótese nula: Os grupos têm um intercepto comum Estatística de teste: $\mathrm{F}(75,681)=8,54165$ com $\mathrm{p}$-valor $=\mathrm{P}(\mathrm{F}(75,681)>8,54165)=2,71717 \mathrm{e}-059$ 
Teste de Wald independente da distribuição para heteroscedasticidade Hipótese nula: as unidades têm a mesma variância de erro Estatística de teste assintótica: Qui-quadrado(76) = 9,86612e+032 com $\mathrm{p}$-valor $=0$

\section{Modelo 9: Efeitos-aleatórios (GLS), usando 760 observações Incluídas 76 unidades de corte transversal Comprimento da série temporal $=\mathbf{1 0}$ Variável dependente: INVEST}

$\begin{array}{lccccc} & \text { Coeficiente } & \text { Erro Padrão } & \text { razão-t } & \text { p-valor } & \\ \text { const } & 22230,8 & 1041,71 & 21,3406 & <0,00001 & * * * \\ \text { Dt } & 1369,23 & 666,352 & 2,0548 & 0,04024 & * * \\ \text { Cont } & 2313,23 & 1487,86 & 1,5547 & 0,12043 & \\ \text { Eco } & 737,231 & 1487,86 & 0,4955 & 0,62039 & \\ \text { Cont_Dt } & -4121,23 & 951,742 & -4,3302 & 0,00002 & * * * \\ \text { Eco_Dt } & 3310,77 & 951,742 & 3,4786 & 0,00053 & * * *\end{array}$

Média var. dependente

23785,53

D.P. var. dependente

7347,935

Soma resíd. quadrados

$3,81 \mathrm{e}+10$

E.P. da regressão

7107,897

Log da verossimilhança

$-7816,296$

Critério de Akaike

15644,59

Critério de Schwarz
15672,39
Critério Hannan-Quinn

'Por dentro' da variância $=2,88617 \mathrm{e}+007$

'Por entre' a variância $=2,5328 \mathrm{e}+007$

teta utilizado para quasi-desmediação $=0,662433$

Teste de Breusch-Pagan -

Hipótese nula: Variância do erro de unidade-específica $=0$

Estatística de teste assintótica: Qui-quadrado $(1)=624,944$

com $\mathrm{p}$-valor $=6,28643 \mathrm{e}-138$

Teste de Hausman -

Hipótese nula: As estimativas GLS são consistentes

Estatística de teste assintótica: Qui-quadrado(3) = 5,32877e-013

com $\mathrm{p}$-valor $=1$ 


\section{Modelo 10: MQO agrupado, usando 760 observações Incluídas 76 unidades de corte transversal Comprimento da série temporal $=\mathbf{1 0}$ Variável dependente: $E S F O R C$ Erros padrão de Beck-Katz}

$\begin{array}{lccccl} & \text { Coeficiente } & \text { Erro Padrão } & \text { razão-t } & p \text {-valor } & \\ \text { Const } & -0,549567 & 0,291117 & -1,8878 & 0,05944 & * \\ \text { Dt } & -0,206212 & 0,411702 & -0,5009 & 0,61660 & \\ \text { Cont } & 1,33948 & 0,109637 & 12,2174 & <0,00001 & * * * \\ \text { Eco } & 0,654668 & 0,163337 & 4,0081 & 0,00007 & * * * \\ \text { Cont_Dt } & -1,02466 & 0,15505 & -6,6086 & <0,00001 & * * * \\ \text { Eco_Dt } & 1,00462 & 0,230994 & 4,3491 & 0,00002 & * * *\end{array}$

Média var. dependente Soma resíd. quadrados R-quadrado $\mathrm{F}(5,754)$ Log da verossimilhança Critério de Schwarz Rô

$$
\begin{array}{r}
0,000000 \\
3402,483 \\
0,085778 \\
14,14899 \\
-1647,991 \\
3335,783 \\
0,564676
\end{array}
$$

D.P. var. dependente

2,214375

2,124283

0,079715

$3,00 \mathrm{e}-13$

3307,983

3318,688

0,790598

Teste de White para a heteroscedasticidade Hipótese nula: sem heteroscedasticidade Estatística de teste: $\mathrm{LM}=5,98235$

com $\mathrm{p}$-valor $=\mathrm{P}($ Qui-quadrado $(5)>5,98235)=0,30794$

$$
\begin{array}{r}
\text { Diagnósticos: assumindo um painel equilibrado com } 76 \text { cortes transversais } \\
\text { observados durante } 10 \text { períodos }
\end{array}
$$

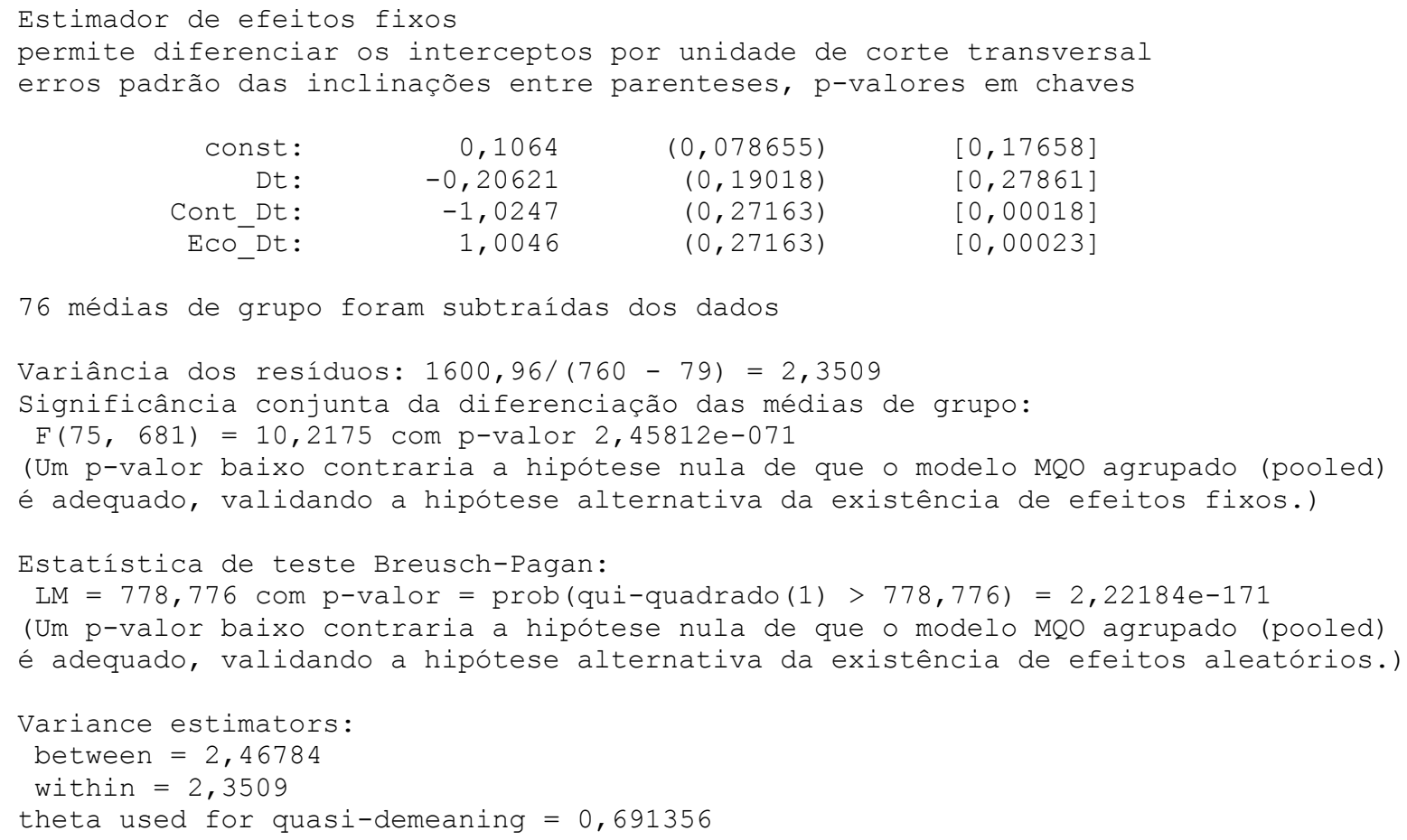

$\begin{array}{rrrr}\text { Const: } & 0,1064 & (0,078655) & {[0,17658]} \\ \text { Dt: } & -0,20621 & (0,19018) & {[0,27861]} \\ \text { Cont_Dt: } & -1,0247 & (0,27163) & {[0,00018]} \\ \text { Eco_Dt: } & 1,0046 & (0,27163) & {[0,00023]}\end{array}$

76 médias de grupo foram subtraídas dos dados 


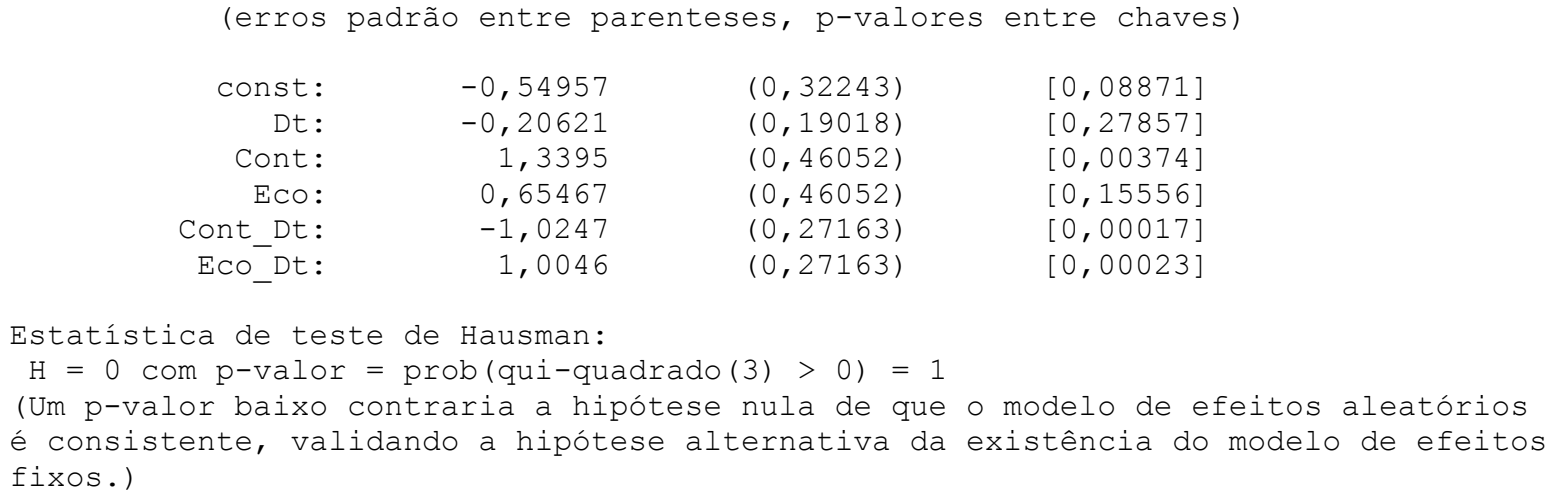

\section{Modelo 11: Efeitos-fixos, usando 760 observações Incluídas 76 unidades de corte transversal Comprimento da série temporal $=\mathbf{1 0}$ Variável dependente: $E S F O R C$ Erros padrão de Beck-Katz}

$\begin{array}{lccccc} & \text { Coeficiente } & \text { Erro Padrão } & \text { razão-t } & p \text {-valor } & \\ \text { Const } & 0,106402 & 0,281623 & 0,3778 & 0,70569 & \\ \text { Dt } & -0,206212 & 0,411702 & -0,5009 & 0,61662 & \\ \text { Cont_Dt } & -1,02466 & 0,15505 & -6,6086 & <0,00001 & * * * \\ \text { Eco_Dt } & 1,00462 & 0,230994 & 4,3491 & 0,00002 & * * *\end{array}$

$\begin{array}{lrlr}\text { Média var. dependente } & 0,000000 & \text { D.P. var. dependente } & 2,214375 \\ \text { Soma resíd. quadrados } & 1600,961 & \text { E.P. da regressão } & 1,533264 \\ \text { R-quadrado } & 0,569834 & \text { R-quadrado ajustado } & 0,520563 \\ \text { F(78, 681) } & 11,56549 & \text { P-valor(F) } & 2,65 \mathrm{e}-82 \\ \text { Log da verossimilhança } & -1361,509 & \text { Critério de Akaike } & 2881,018 \\ \text { Critério de Schwarz } & 3247,050 & \text { Critério Hannan-Quinn } & 3021,970 \\ \text { rô } & 0,085649 & \text { Durbin-Watson } & 1,680238\end{array}$

Teste para diferenciar interceptos de grupos Hipótese nula: Os grupos têm um intercepto comum Estatística de teste: $F(75,681)=10,2175$ com $\mathrm{p}$-valor $=\mathrm{P}(\mathrm{F}(75,681)>10,2175)=2,45812 \mathrm{e}-071$

Teste de Wald independente da distribuição para heteroscedasticidade Hipótese nula: as unidades têm a mesma variância de erro Estatística de teste assintótica: Qui-quadrado(76) = 1633,12 com $\mathrm{p}$-valor $=9,91964 \mathrm{e}-291$

\section{Modelo 12: Efeitos-aleatórios (GLS), usando 760 observações Incluídas 76 unidades de corte transversal Comprimento da série temporal $=\mathbf{1 0}$ Variável dependente: $E S F O R C$}

$\begin{array}{cccccc} & \text { Coeficiente } & \text { Erro Padrão } & \text { razão- } t & \text { p-valor } & \\ \text { const } & -0,549567 & 0,322426 & -1,7045 & 0,08871\end{array} *$




$\begin{array}{lccccc}\text { Dt } & -0,206212 & 0,190178 & -1,0843 & 0,27857 & \\ \text { Cont } & 1,33948 & 0,460517 & 2,9086 & 0,00374 & * * * \\ \text { Eco } & 0,654668 & 0,460517 & 1,4216 & 0,15556 & \\ \text { Cont_Dt } & -1,02466 & 0,271628 & -3,7723 & 0,00017 & * * * \\ \text { Eco_Dt } & 1,00462 & 0,271628 & 3,6985 & 0,00023 & * * *\end{array}$

Média var. dependente

0,000000

3402,483

$-1647,991$

Log da verossimilhança

Critério de Schwarz
D.P. var. dependente

E.P. da regressão

Critério de Akaike

Critério Hannan-Quinn
2,214375

2,122875

3307,983

3318,688

'Por dentro' da variância $=2,3509$

'Por entre' a variância $=2,46784$

teta utilizado para quasi-desmediação $=0,691356$

Teste de Breusch-Pagan -

Hipótese nula: Variância do erro de unidade-específica $=0$

Estatística de teste assintótica: Qui-quadrado(1) $=778,776$

com $\mathrm{p}$-valor $=2,22184 \mathrm{e}-171$

Teste de Hausman -

Hipótese nula: As estimativas GLS são consistentes

Estatística de teste assintótica: Qui-quadrado(3) $=0$

com $\mathrm{p}$-valor $=1$

\section{Modelo 13: MQO agrupado, usando 760 observações Incluídas 76 unidades de corte transversal Comprimento da série temporal $=\mathbf{1 0}$ Variável dependente: $D E S V$ Erros padrão de Beck-Katz}

$\begin{array}{lccccl} & \text { Coeficiente } & \text { Erro Padrão } & \text { razão- } t & p \text {-valor } & \\ \text { const } & -6895,93 & 1363,81 & -5,0564 & <0,00001 & * * * \\ \text { Dt } & -4752,22 & 1928,72 & -2,4639 & 0,01396 & * * \\ \text { Cont } & 4320,17 & 896,971 & 4,8164 & <0,00001 & * * * \\ \text { Eco } & 1180,18 & 1689,2 & 0,6987 & 0,48498 & \\ \text { Cont_Dt } & -8595,16 & 1268,51 & -6,7758 & <0,00001 & * * * \\ \text { Eco_Dt } & 4708,06 & 2388,89 & 1,9708 & 0,04911 & * *\end{array}$

$\begin{array}{lrlr}\text { Média var. dependente } & -8102,038 & \text { D.P. var. dependente } & 18250,80 \\ \text { Soma resíd. quadrados } & 2,38 \mathrm{e}+11 & \text { E.P. da regressão } & 17771,45 \\ \text { R-quadrado } & 0,058086 & \text { R-quadrado ajustado } & 0,051840 \\ \text { F(5, 754) } & 9,299480 & \text { P-valor(F) } & 1,32 \mathrm{e}-08 \\ \text { Log da verossimilhança } & -8512,246 & \text { Critério de Akaike } & 17036,49 \\ \text { Critério de Schwarz } & 17064,29 & \text { Critério Hannan-Quinn } & 17047,20 \\ \text { rô } & 0,407279 & \text { Durbin-Watson } & 1,136294\end{array}$

Teste de White para a heteroscedasticidade - 
Hipótese nula: sem heteroscedasticidade

Estatística de teste: $\mathrm{LM}=11,0394$

com $\mathrm{p}$-valor $=\mathrm{P}($ Qui-quadrado $(5)>11,0394)=0,0506038$

Diagnósticos: assumindo um painel equilibrado com 76 cortes transversais
observados durante 10 períodos

Estimador de efeitos fixos

permite diferenciar os interceptos por unidade de corte transversal

erros padrão das inclinações entre parenteses, p-valores em chaves

$\begin{array}{rrrr}\text { Const: } & -5086,6 & (761,47) & {[0,00000]} \\ \text { Dt: } & -4752,2 & (1841,1) & {[0,01006]} \\ \text { Cont_Dt: } & -8595,2 & (2629,7) & {[0,00114]} \\ \text { Eco_Dt: } & 4708,1 & (2629,7) & {[0,07384]}\end{array}$

76 médias de grupo foram subtraídas dos dados

Variância dos resíduos: 1,5005e+011/(760 - 79) = 2,20338e+008

Significância conjunta da diferenciação das médias de grupo:

$\mathrm{F}(75,681)=5,33006 \mathrm{com} \mathrm{p}-\mathrm{val}$ or $8,62147 \mathrm{e}-034$

(Um p-valor baixo contraria a hipótese nula de que o modelo MQo agrupado (pooled)

é adequado, validando a hipótese alternativa da existência de efeitos fixos.)

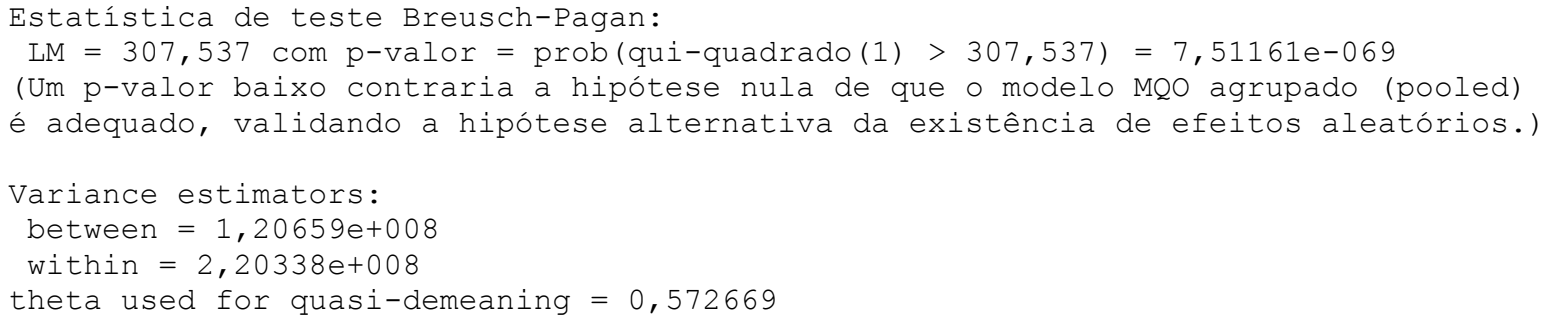

\section{Modelo 14: Efeitos-fixos, usando 760 observações \\ Incluídas 76 unidades de corte transversal \\ Comprimento da série temporal $=\mathbf{1 0}$ \\ Variável dependente: $D E S V$ \\ Erros padrão de Beck-Katz}

$\begin{array}{lccccl} & \text { Coeficiente } & \text { Erro Padrão } & \text { razão- } t & p \text {-valor } & \\ \text { const } & -5086,6 & 1156,76 & -4,3973 & 0,00001 & * * * \\ \text { Dt } & -4752,22 & 1928,72 & -2,4639 & 0,01399 & * *\end{array}$




$\begin{array}{lccccl}\text { Cont_Dt } & -8595,16 & 1268,51 & -6,7758 & <0,00001 & * * * \\ \text { Eco_Dt } & 4708,06 & 2388,89 & 1,9708 & 0,04915 & * *\end{array}$

Média var. dependente

$-8102,038$
$1,50 \mathrm{e}+11$
0,406485
5,979515
$-8336,742$
17197,52
0,002667

D.P. var. dependente

18250,80

Soma resíd. quadrados

E.P. da regressão

14843,80

R-quadrado

R-quadrado ajustado

0,338506

$\mathrm{F}(78,681)$

P-valor(F)

$3,07 \mathrm{e}-40$

Log da verossimilhança

Critério de Akaike

16831,48

Critério de Schwarz

Critério Hannan-Quinn

16972,44 rô

Durbin-Watson

1,803311

Teste para diferenciar interceptos de grupos -

Hipótese nula: Os grupos têm um intercepto comum

Estatística de teste: $F(75,681)=5,33006$

com $\mathrm{p}$-valor $=\mathrm{P}(\mathrm{F}(75,681)>5,33006)=8,62147 \mathrm{e}-034$

Teste de Wald independente da distribuição para heteroscedasticidade -

Hipótese nula: as unidades têm a mesma variância de erro

Estatística de teste assintótica: Qui-quadrado(76) = 2,35174e+019

com $\mathrm{p}$-valor $=0$

\section{Modelo 15: Efeitos-aleatórios (GLS), usando 760 observações \\ Incluídas 76 unidades de corte transversal \\ Comprimento da série temporal $=\mathbf{1 0}$ \\ Variável dependente: $D E S V$}

$\begin{array}{lccccl} & \text { Coeficiente } & \text { Erro Padrão } & \text { razão- } t & p \text {-valor } & \\ \text { const } & -6895,93 & 2342,69 & -2,9436 & 0,00334 & * * * \\ \text { Dt } & -4752,22 & 1841,15 & -2,5811 & 0,01004 & * * \\ \text { Cont } & 4320,17 & 3346,03 & 1,2911 & 0,19705 & \\ \text { Eco } & 1180,18 & 3346,03 & 0,3527 & 0,72440 & \\ \text { Cont_Dt } & -8595,16 & 2629,68 & -3,2685 & 0,00113 & * * * \\ \text { Eco_Dt } & 4708,06 & 2629,68 & 1,7904 & 0,07380 & *\end{array}$

Média var. dependente

$$
\begin{array}{r}
-8102,038 \\
2,38 \mathrm{e}+11 \\
-8512,246 \\
17064,29
\end{array}
$$

D.P. var. dependente

18250,80

Soma resíd. quadrados

E.P. da regressão

17759,68

Log da verossimilhança

Critério de Akaike

17036,49

Critério de Schwarz

Critério Hannan-Quinn

17047,20

'Por dentro' da variância $=2,20338 \mathrm{e}+008$

'Por entre' a variância $=1,20659 \mathrm{e}+008$

teta utilizado para quasi-desmediação $=0,572669$

Teste de Breusch-Pagan -

Hipótese nula: Variância do erro de unidade-específica $=0$

Estatística de teste assintótica: Qui-quadrado(1) = 307,537

com p-valor $=7,51161 \mathrm{e}-069$

Teste de Hausman - 
Hipótese nula: As estimativas GLS são consistentes

Estatística de teste assintótica: Qui-quadrado(3) = 1,39585e-013

com $\mathrm{p}$-valor $=1$

\section{Modelo 16: MQO agrupado, usando 760 observações Incluídas 76 unidades de corte transversal \\ Comprimento da série temporal $=\mathbf{1 0}$ \\ Variável dependente: SIMULA/TEMP Erros padrão de Beck-Katz}

$\begin{array}{lccccc} & \text { Coeficiente } & \text { Erro Padrão } & \text { razão-t } & p \text {-valor } & \\ \text { const } & 6,23353 & 0,525178 & 11,8694 & <0,00001 & * * * \\ \text { Dt } & -0,806676 & 0,742713 & -1,0861 & 0,27777 & \\ \text { Cont } & 1,38455 & 0,411107 & 3,3679 & 0,00080 & * * * \\ \text { Eco } & -0,064859 & 0,525511 & -0,1234 & 0,90181 & \\ \text { Cont_Dt } & -0,627111 & 0,581393 & -1,0786 & 0,28109 & \\ \text { Eco_Dt } & 2,38186 & 0,743184 & 3,2049 & 0,00141 & * * *\end{array}$

Média var. dependente

6,552906

D.P. var. dependente

4,759407

Soma resíd. quadrados

16660,18

E.P. da regressão

4,700610

0,030981

$\mathrm{F}(5,754)$

4,821355

Log da verossimilhança

$-2251,627$

Critério de Schwarz rô
0,024555

P-valor(F)

Critério de Akaike

0,000240

4515,255

Critério Hannan-Quinn

4525,960

Durbin-Watson
R-quadrado ajustado

Teste de White para a heteroscedasticidade -

Hipótese nula: sem heteroscedasticidade

Estatística de teste: $\mathrm{LM}=22,344$

com $\mathrm{p}$-valor $=\mathrm{P}(\mathrm{Qui}$-quadrado $(5)>22,344)=0,000450348$

Diagnósticos: assumindo um painel equilibrado com 76 cortes transversais observados durante 10 períodos

Estimador de efeitos fixos

permite diferenciar os interceptos por unidade de corte transversal

erros padrão das inclinações entre parenteses, p-valores em chaves

$\begin{array}{rrrr}\text { Const: } & 6,6676 & (0,19254) & {[0,00000]} \\ \text { Dt: } & -0,80668 & (0,46555) & {[0,08359]} \\ \text { Cont_Dt: } & -0,62711 & (0,66493) & {[0,34595]} \\ \text { Eco_Dt: } & 2,3819 & (0,66493) & {[0,00037]}\end{array}$

76 médias de grupo foram subtraídas dos dados

Variância dos resíduos: 9593,72/(760 - 79) = 14,0877

Significância conjunta da diferenciação das médias de grupo:

$\mathrm{F}(75,681)=6,68807 \mathrm{com}$ p-valor $5,87386 \mathrm{e}-045$

(Um p-valor baixo contraria a hipótese nula de que o modelo MQO agrupado (pooled)

é adequado, validando a hipótese alternativa da existência de efeitos fixos.) 


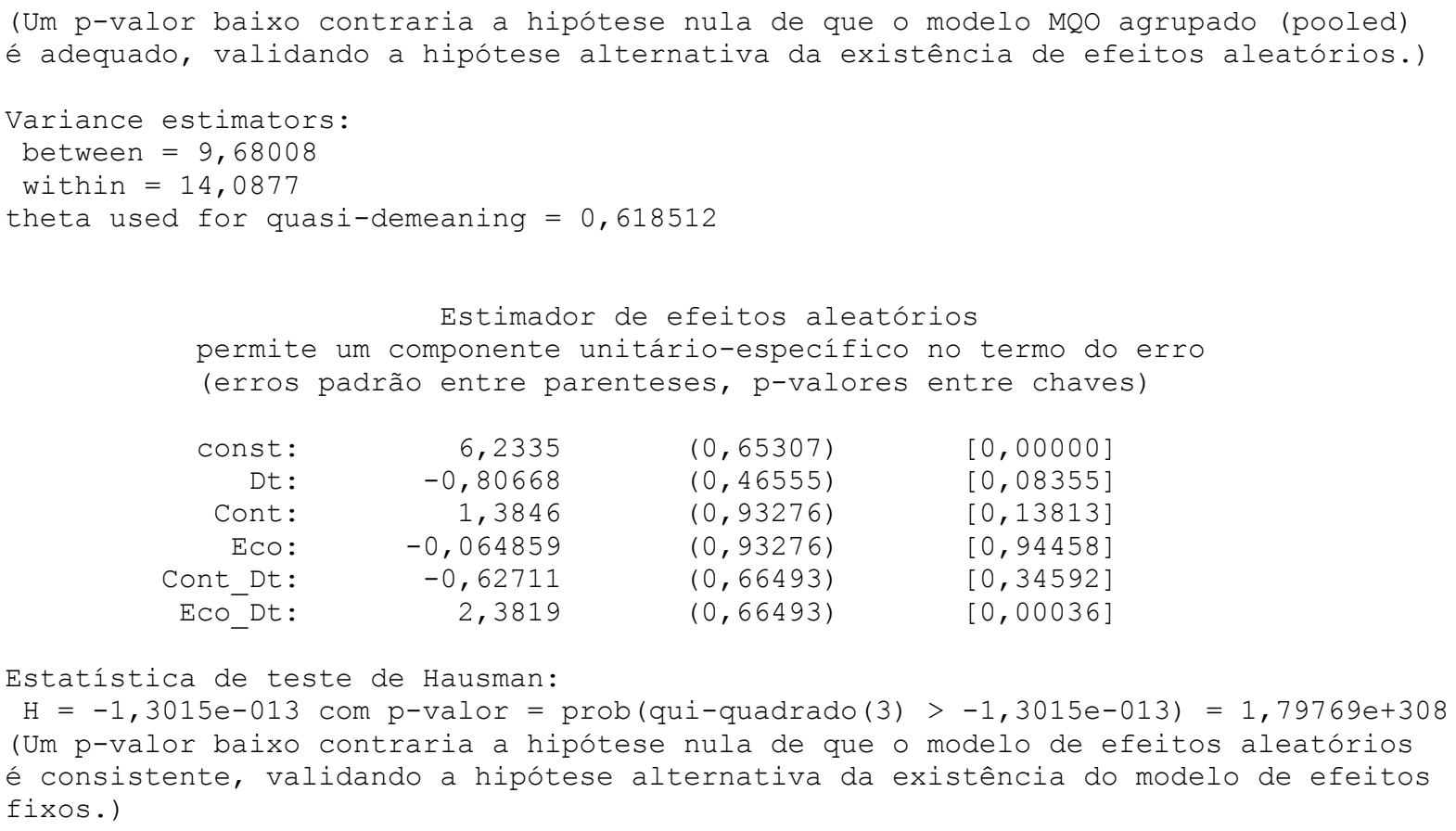

\section{Modelo 17: Efeitos-fixos, usando 760 observações Incluídas 76 unidades de corte transversal Comprimento da série temporal $=\mathbf{1 0}$ Variável dependente: SIMULA/TEMP Erros padrão de Beck-Katz}

$\begin{array}{lccccc} & \text { Coeficiente } & \text { Erro Padrão } & \text { razão- } t & p \text {-valor } & \\ \text { const } & 6,66763 & 0,435924 & 15,2954 & <0,00001 & * * * \\ \text { Dt } & -0,806676 & 0,742713 & -1,0861 & 0,27781 & \\ \text { Cont_Dt } & -0,627111 & 0,581393 & -1,0786 & 0,28113 & \\ \text { Eco_Dt } & 2,38186 & 0,743184 & 3,2049 & 0,00141 & * * *\end{array}$

$\begin{array}{lrlr}\text { Média var. dependente } & 6,552906 & \text { D.P. var. dependente } & 4,759407 \\ \text { Soma resíd. quadrados } & 9593,720 & \text { E.P. da regressão } & 3,753358 \\ \text { R-quadrado } & 0,441993 & \text { R-quadrado ajustado } & 0,378081 \\ \text { F(78, 681) } & 6,915580 & \text { P-valor(F) } & 5,44 \mathrm{e}-48 \\ \text { Log da verossimilhança } & -2041,901 & \text { Critério de Akaike } & 4241,801 \\ \text { Critério de Schwarz } & 4607,833 & \text { Critério Hannan-Quinn } & 4382,754 \\ \text { rô } & -0,047423 & \text { Durbin-Watson } & 1,827275\end{array}$

Teste para diferenciar interceptos de grupos Hipótese nula: Os grupos têm um intercepto comum Estatística de teste: $\mathrm{F}(75,681)=6,68807$ com $\mathrm{p}$-valor $=\mathrm{P}(\mathrm{F}(75,681)>6,68807)=5,87386 \mathrm{e}-045$

Teste de Wald independente da distribuição para heteroscedasticidade Hipótese nula: as unidades têm a mesma variância de erro Estatística de teste assintótica: Qui-quadrado(76) $=22857$ com $\mathrm{p}$-valor $=0$ 
Modelo 18: Efeitos-aleatórios (GLS), usando 760 observações

Incluídas 76 unidades de corte transversal

Comprimento da série temporal $=\mathbf{1 0}$

Variável dependente: SIMULA/TEMP

$\begin{array}{lccccl} & \text { Coeficiente } & \text { Erro Padrão } & \text { razão-t } & p \text {-valor } & \\ \text { const } & 6,23353 & 0,653065 & 9,5450 & <0,00001 & * * * \\ \text { Dt } & -0,806676 & 0,465547 & -1,7327 & 0,08355 & * \\ \text { Cont } & 1,38455 & 0,932764 & 1,4844 & 0,13813 & \\ \text { Eco } & -0,064859 & 0,932764 & -0,0695 & 0,94458 & \\ \text { Cont_Dt } & -0,627111 & 0,664934 & -0,9431 & 0,34592 & \\ \text { Eco_Dt } & 2,38186 & 0,664934 & 3,5821 & 0,00036 & * * *\end{array}$

Média var. dependente

6,552906

D.P. var. dependente

4,759407

Soma resíd. quadrados

16660,18

E.P. da regressão

4,697495

Log da verossimilhança

$-2251,627$

Critério de Akaike

4515,255

Critério de Schwarz

4543,055

Critério Hannan-Quinn

4525,960

'Por dentro' da variância $=14,0877$

'Por entre' a variância $=9,68008$

teta utilizado para quasi-desmediação $=0,618512$

Teste de Breusch-Pagan -

Hipótese nula: Variância do erro de unidade-específica $=0$

Estatística de teste assintótica: Qui-quadrado(1) $=443,65$

com $\mathrm{p}$-valor $=1,73824 \mathrm{e}-098$

Teste de Hausman -

Hipótese nula: As estimativas GLS são consistentes

Estatística de teste assintótica: Qui-quadrado(3) $=-1,3015 \mathrm{e}-013$

com $\mathrm{p}$-valor $=$ NA 


\section{APÊNDICE 7 - TESTE DE NORMALIDADE E HOMOGENEIDADE DE VARIÂNCIA DAS VARIÁVEIS DEPENDENTES}

\begin{tabular}{|c|c|c|c|c|c|c|}
\hline \multicolumn{7}{|c|}{ Teste de Normalitdade } \\
\hline \multirow{2}{*}{ VARIÁVEIS } & \multicolumn{3}{|c|}{ Kolmogorov-Smirnov } & \multicolumn{3}{|c|}{ Shapiro-Wilk } \\
\hline & Statistic & $\mathrm{df}$ & Sig. & Statistic & $\mathrm{df}$ & Sig. \\
\hline Desv & 0,33 & 510,00 & 0,00 & 0,49 & 510,00 & 0,00 \\
\hline Simula & 0,08 & 510,00 & 0,00 & 0,95 & 510,00 & 0,00 \\
\hline Temp & 0,17 & 510,00 & 0,00 & 0,92 & 510,00 & 0,00 \\
\hline Invest & 0,21 & 510,00 & 0,00 & 0,78 & 510,00 & 0,00 \\
\hline Esforc & 0,07 & 510,00 & 0,00 & 0,98 & 510,00 & 0,00 \\
\hline
\end{tabular}

Teste de Homogeneidadede Variância

\begin{tabular}{|l|r|r|}
\hline VARIÁVEIS & Levene Statistic & Sig. \\
\hline Desv & 5,29 & 0,02 \\
Simula & 0,02 & 0,89 \\
Temp & 0,03 & 0,86 \\
Invest & 1,50 & 0,22 \\
Esforc & 0,25 & 0,62 \\
Simula/Temp & 2,32 & 0,10 \\
\hline
\end{tabular}

